Portland State University

PDXScholar

Spring 7-22-2013

\title{
Arsenic Mobility and Compositional Variability in High-Silica Ash Flow Tuffs
}

Courtney Beth Young Savoie

Portland State University

Follow this and additional works at: https://pdxscholar.library.pdx.edu/open_access_etds

Part of the Geology Commons, and the Other Environmental Sciences Commons Let us know how access to this document benefits you.

\section{Recommended Citation}

Savoie, Courtney Beth Young, "Arsenic Mobility and Compositional Variability in High-Silica Ash Flow Tuffs" (2013). Dissertations and Theses. Paper 1012.

https://doi.org/10.15760/etd.1012

This Thesis is brought to you for free and open access. It has been accepted for inclusion in Dissertations and Theses by an authorized administrator of PDXScholar. Please contact us if we can make this document more accessible: pdxscholar@pdx.edu. 
Arsenic Mobility and Compositional Variability in High-Silica Ash Flow Tuffs

\section{by}

Courtney Beth Young Savoie

A thesis submitted in partial fulfillment of the requirements for the degree of

Master of Science

in

Geology

Thesis Committee:

Robert B. Perkins, Chair

Martin J. Streck

Carl Palmer

Portland State University

2013 


\section{$\underline{\text { ABSTRACT }}$}

Volcanic rocks typically have only low to moderate arsenic concentrations, nonethe-less, elevated levels of arsenic in ground waters have been associated with pyroclastic and volcaniclastic rocks and sediments in many parts of the world. The potential for arsenic leaching from these deposits is particularly problematic as they often comprise important water-bearing units in volcanic terrains. However, the role that chemical and mineralogical variations play in controlling the occurrence and mobility of arsenic from pyroclastic rocks is largely unexplored.

This study uses chemical and X-ray diffraction data to characterize and classify 49 samples of ash-flow tuffs, and 11 samples of tuffaceous sediments. The samples exhibit a range of devitrification and chemical weathering. Total and partial digestion, and water extractions of samples are used to determine the total, environmentally available, and readily leachable fractions of arsenic present in all tuff samples. Leaching experiments were also performed with buffered solutions to determine the influence of elevated $\mathrm{pH}$ levels on arsenic mobility.

The 49 tuff samples have a mean arsenic content of $7.5 \mathrm{mg} \mathrm{kg}^{-1}$, a geometric mean arsenic content of $4.8 \mathrm{mg} \mathrm{kg}^{-1}$, a median arsenic content of $5.2 \mathrm{mg} \mathrm{kg}^{-1}$, and a maximum arsenic concentration of $81 \mathrm{mg} \mathrm{kg}^{-1}$. The mean and median values are $2.8-$ 4.4x the average crustal abundance of $1.7 \mathrm{mg} \mathrm{kg}^{-1}$ (Wedepohl, 1995), and consistent with previously reported values for volcanic glasses and felsic volcanic rocks (Onishi and Sandell, 1955; Wedepohl, 1995), although the maximum arsenic content is higher than 
previously reported (e.g., Casentini et al., 2010; Fiantis et al., 2010; Nobel et al., 2004).

In addition, the arsenic concentrations of tuffs were found to be highly heterogenous, both between and within individual units, and in some cases, individual outcrops.

Results of whole rock and leachate analyses indicate that there is no significant difference in the total arsenic content of tuffs as a result of devitrification or weathering, but both devitrified and weathered tuffs contain higher levels of environmentally available arsenic than unweathered glassy tuffs. Glassy tuffs did not produce any readily leachable arsenic, while individual devitrified and weathered tuffs both generated aqueous concentrations that exceeded regulatory limits after 18 hours. Leaching of weathered tuffs produced higher levels of arsenic at high ( $\sim 9-11) \mathrm{pH}$ than in tests conducted at circum-neutral $\mathrm{pH}$. Devitrified and glassy tuffs showed no increase in leachable arsenic with increasing $\mathrm{pH}$.

The results of this study indicate that devitrification and weathering processes determine the host phases, degree of adsorption, and overall mobility of arsenic from ashflow tuffs. Tuffs that have undergone different types of alteration are likely to have different host phases of arsenic, and different mechanisms that mobilize arsenic into the environment. Potential host phases and mobility mechanisms are discussed, and a conceptual model of arsenic behavior in ash-flow tuffs is proposed. 


\section{ACKNOWLEDGMENTS}

Thank you to my advisor, Ben Perkins, for all of his patience, support, pep talks, ability to remain calm in the face of broken lab equipment, and for generally putting up with me during this whole process. I would also like to thank Martin Streck for sharing his expertise on ash-flow tuffs and where to find all the best samples. Thanks to Carl Palmer for his thoughtful comments and insights. I would also like to thank Marin Klinger, Megan Masterson, and Katie Davis for volunteering to help with sample preparation. Last, but not least, many thanks to all of my friends and family, who have been endlessly patient and encouraging during this process, and whose love and support I couldn't have done this without. Funding for this research was provided by the Geological Society of America. 


\section{TABLE OF CONTENTS}

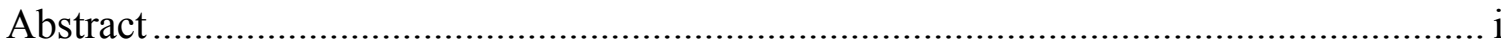

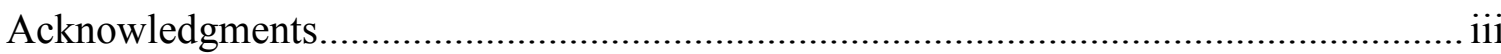

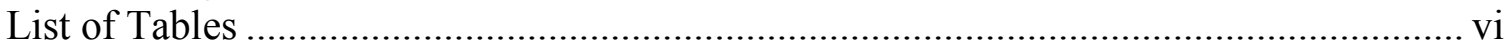

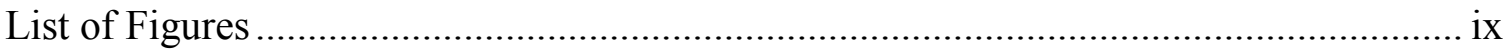

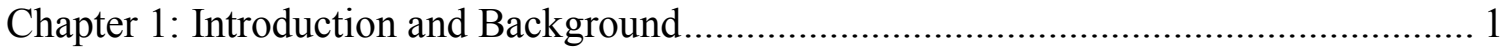

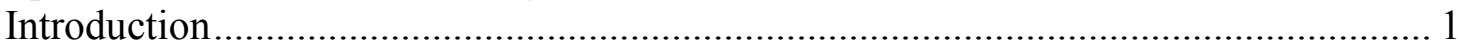

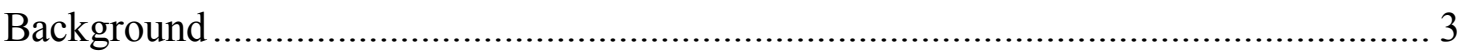

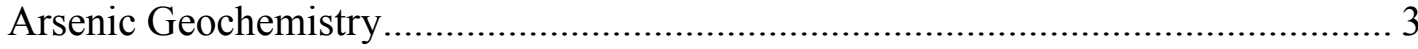

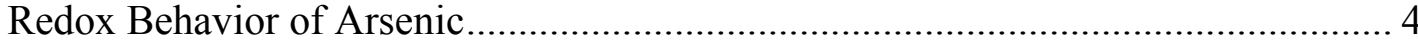

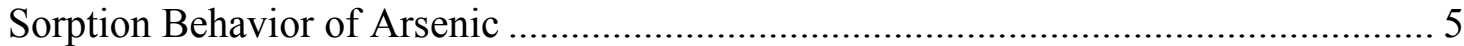

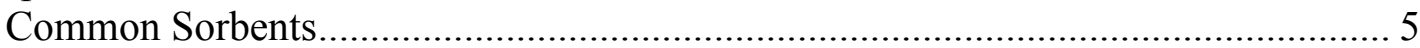

Reducing Groundwater Systems .................................................................. 8

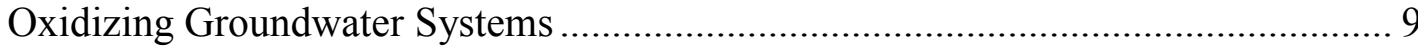

Chemical and Mineralogical Variations in Ash-Flow Tuffs................................. 9

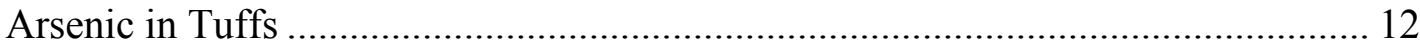

Chapter 2: Arsenic Occurrence in Ash-Flow Tuffs and Associated Sediments ............... 17

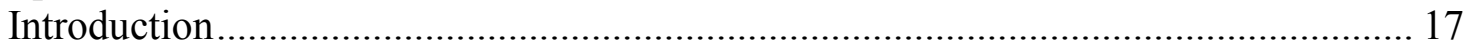

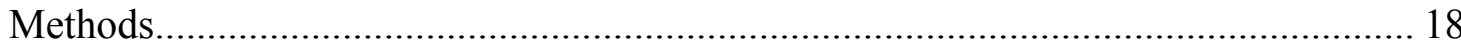

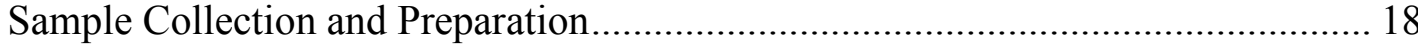

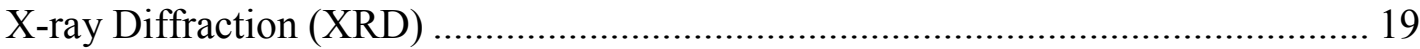

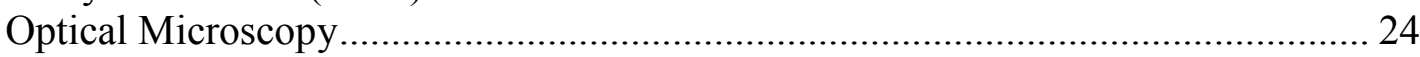

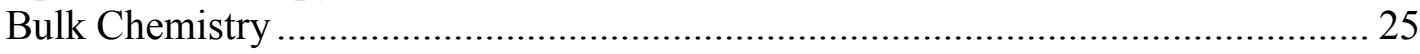

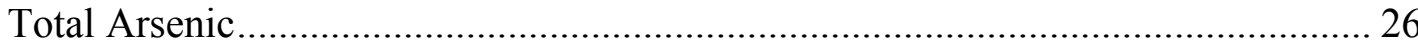

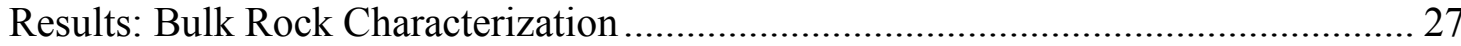

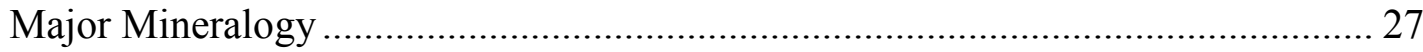

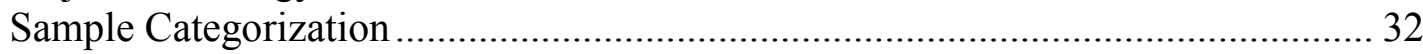

Results: Bulk Rock Chemistries ........................................................................ 34

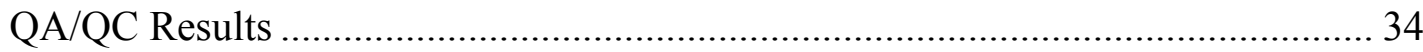

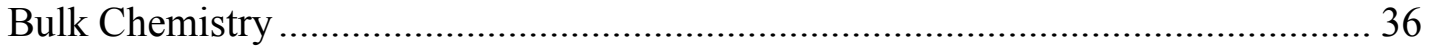

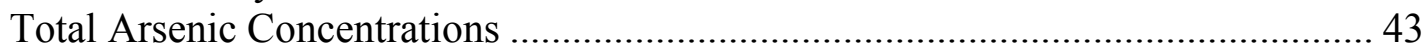

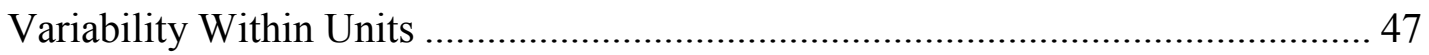

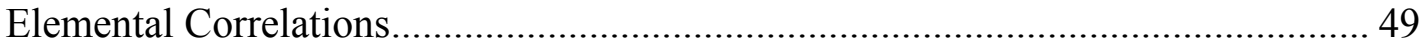

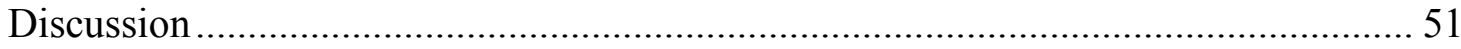

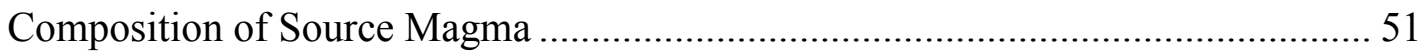

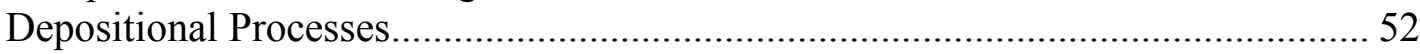

Post-Depositional Alteration Processes .......................................................... 53

Chapter 3: Arsenic Mobility In Ash-Flow Tuffs and Associated Sediments .................. 56

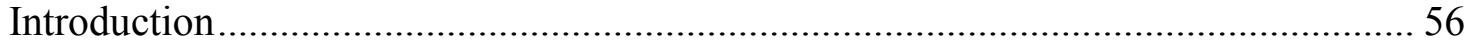

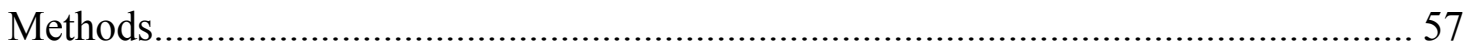

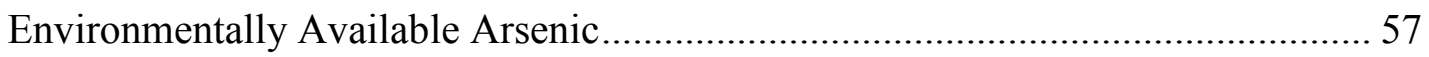

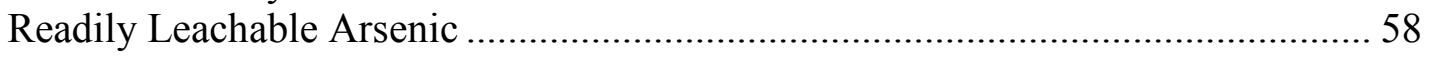




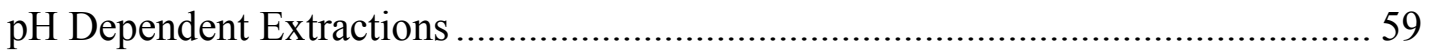

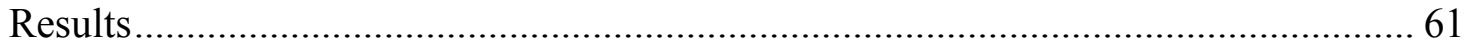

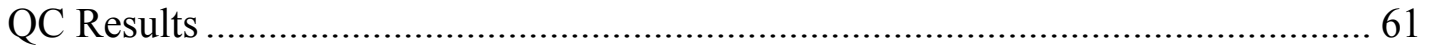

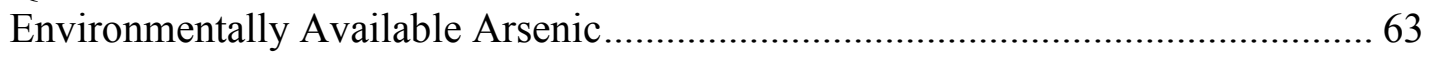

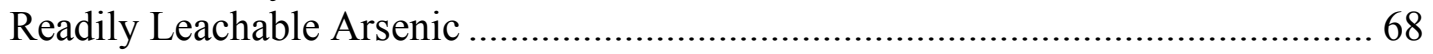

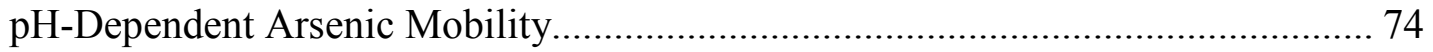

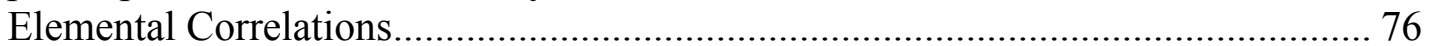

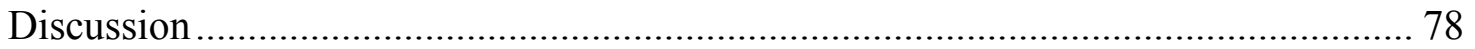

Potential Host Phases of Arsenic ..................................................................... 78

Potential Mechanisms of Arsenic Mobilization..................................................... 82

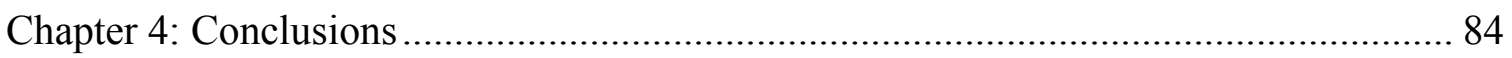

Conclusions and Conceptual Model .................................................................. 84

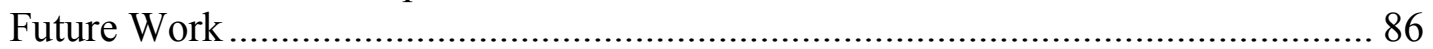

Works Cited .................................................................................................... 88

Appendix A: Analytical Operating Conditions and Quality Control............................ 92

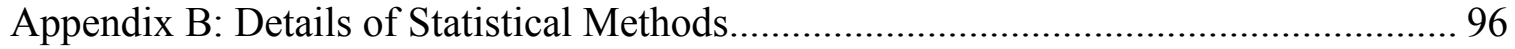

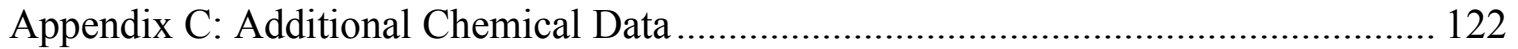




\section{LIST OF TABLES}

Table 1. Total and environmentally available arsenic concentrations of select tuff samples used in preliminary As leaching study. Available arsenic refers to arsenic present in phases other than glasses and silicate mineral phases such as feldspars and quartz. Note: total As concentrations from previous INAA analysis. Errors $=1 \sigma$ from replicate analysis.

Table 2. Locations and ages of samples used in this study. 20

Table 3. Major mineralogy and categorization of tuff samples, based on semi-quantitative XRD results, optical microscopy, and examination of hand samples. Percentages of amorphous material (glass) was not included in semi-quantitative XRD results, and was instead estimated solely from examination of XRD patterns, thin sections, hand samples.

Table 4. Recoveries for certified reference materials analyzed via ICP-OES. Arsenic recoveries ranged from $82.7 \%$ to $94.6 \%$. S had recovery percentages within $\pm 5 \%$, but other elements were more variable.

Table 5. Relative percent differences for duplicate samples analyzed via EPA Method 3052 .

Table 6. Recoveries from Method Blank and check standards analyzed via ICP-OES. Check standard QC1 had a concentration of $100 \mathrm{ug} / \mathrm{L}$ for all elements except $\mathrm{Sb}$ and Sn, and check standard QC2 had a concentration of $50 \mathrm{ug} / \mathrm{L}$ for all elements except $\mathrm{Sb}$ and $\mathrm{Sn}$

Table 7. Relative percent differences for sample DT3, analyzed at the WSU Geoanalytical Lab (WSU) and Activation Laboratories (AL). Major elements are reported in weight percent, and trace elements are reported in $\mathrm{mg} / \mathrm{kg}$.

Table 8. Major element chemistry for tuff and tuffaceous sediment samples. All values were obtained via XRF, and reported in weight percent.

Table 9. Selected trace element concentrations $\left(\mathrm{mg} \mathrm{kg}^{-1}\right)$ for tuff and tuffaceous sediment samples. Full trace element results can be found in Appendix C. For samples analyzed at Activation Laboratories the elements $\mathrm{Cu}, \mathrm{Mo}, \mathrm{Pb}, \mathrm{Ni}, \mathrm{Zn}, \mathrm{S}, \mathrm{Li}, \mathrm{Be}, \mathrm{Sr}$, and $\mathrm{V}$ were obtained via ICP-MS, and the elements $\mathrm{As}, \mathrm{Ba}, \mathrm{Cr}, \mathrm{Rb}$, and $\mathrm{Sb}$ were obtained via INAA. For samples analyzed at WSU the elements $\mathrm{Ba}, \mathrm{Cr}, \mathrm{Cu}, \mathrm{Ni}, \mathrm{Pb}$, $\mathrm{Rb}, \mathrm{Sr}, \mathrm{V}$, and $\mathrm{Zn}$ were analyzed via XRF and the elements $\mathrm{As}, \mathrm{Be}$, and Mo were analyzed via ICP-OES at Portland State University. Blank entries indicate that values were not analyzed.

Table 10. Total arsenic contents of tuffs and tuffaceous sediments. Numbers in parentheses indicate values that include samples identified as outliers 
Table 11. Test statistics (W) and p-values for Shapiro-Wilk tests of normality.

Table 12. Test statistics, number of samples, and p-values for Brown-Forsythe tests of equal variances.

Table 13. Test statistic (U), number of samples, and p-values for Man-Whitney-Wilcoxon tests of equality performed on sample categories.

Table 14. Statistically significant $(\mathrm{p}<0.05)$ elemental correlations with arsenic. Italicized items showed a negative correlation with arsenic, while un-italicized items showed a positive correlation.

Table 15. Buffer solutions used to control $\mathrm{pH}$ levels in $\mathrm{pH}$ specific leaching experiments.

Table 16. Relative percent differences for duplicate samples analyzed via EPA Method 3051a.

Table 17. Relative percent differences for water extractions analyzed in duplicate. 63

Table 18. Environmentally available fraction of arsenic present in ash-flow tuffs and tuffaceous sediments. Numbers in parentheses indicate values that include samples identified as outliers.

Table 19. Test statistics (W) and p-values for Shapiro-Wilk tests of normality. 64

Table 20. Test statistics, number of samples, and p-values for Brown-Forsythe tests of equal variances.

Table 21. Test statistic (U), number of samples, and p-values for Man-Whitney-Wilcoxon tests of equality performed on sample categories.

Table 22. Readily leachable fraction of arsenic present in ash-flow tuffs and tuffaceous sediments. Values in parentheses indicate values that include samples below the MDL of $102 \mu \mathrm{g} / \mathrm{kg}$.

Table 23. Test statistics (W) and p-values for Shapiro-Wilk tests of normality.

Table 24. Test statistics (F), numerator and denominator degrees of freedom, and $\mathrm{p}$ values for $\mathrm{F}$ tests of eqaulity of variances.

Table 25. Test statistic ( $\mathrm{t}$ ), number of samples, and p-values for two sample students ttests of equality performed on sample categories.

Table 26. Aqueous arsenic concentrations produced by water leaching experiments. Descriptive statistical values only include samples that exceeded method detection limits. 
Table 27. Statistically significant $(p<0.05)$ elemental correlations with arsenic. Italicized elements showed a negative correlation with arsenic, while un-italicized elements

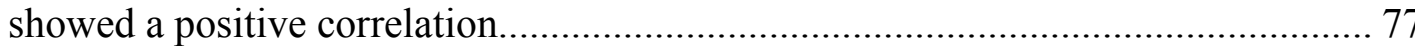




\section{LIST OF FIGURES}

Figure 1. Eh-pH diagram for aqueous arsenic species at $25^{\circ} \mathrm{C}$ and 1 bar pressure, from (Smedley and Kinniburgh, 2002).......................................................................... 3

Figure 2. Adsorption of arsenate and arsenite onto A) amorphous iron oxide and B) goethite as a function of $\mathrm{pH}$. Arsenic concentrations range from $100 \mu \mathrm{M}(\boldsymbol{\square})$ to 10 $\mu \mathrm{M}(\mathrm{O})$. From Dixit \& Hering (2003)................................................................ 7

Figure 3. Conceptual model of cooling ash-flow unit showing zonation and vertical porosity variation (Istok et al., 1994).

Figure 4. Arsenic K-edge XANES spectra of selected tuff samples from preliminary As leaching study. The less altered tuff contained primarily As(III) while the highly altered tuff contained primarily $\operatorname{As}(\mathrm{V})$.

Figure 5. XRD analysis of six tuff samples used in preliminary As leaching study displaying increasing degrees of low-temperature alteration. More altered tuffs contain a larger number of mineral phases, which increases the number of potential host phases of arsenic in altered tuffs relative to unweathered glassy samples........ 16

Figure 6. Sample PG2, under plane light at 5x magnification, displaying axilotic texture produced during devitrification, where minerals crystallized perpendicular to the boundaries of glass shards.

Figure 7. Sample PG1 under plane light at 5x magnification, displaying both axiolitic texture and alteration to green and brown clay minerals.

Figure 8. XRD patterns for unweathered glassy (RST9) and devitrified samples (RST13). Glass content of samples was estimated based upon the deviation of background levels from a straight line between approximately 10 and $40^{\circ} 2 \theta$, coupled with visual examination of hand samples and thin sections.

Figure 9. Arsenic as a function of alumina/alkali ratios of tuff samples. The majority of the samples have ratios $>1$, and there is no correlation between alumina/alkali ratios and arsenic concentrations.

Figure 10. Log transformed distributions of total arsenic concentrations for samples divided by category. A: without outlying values. B: with outlying values. Yellow squares indicate mean values.

Figure 11. Ranges of arsenic found in individual geologic units. DC $=$ Dinner Creek Tuff, DT $=$ Dale Tuff, DVC $=$ Devine Canyon Tuff, FD = Tuff of Foster Dam, LG = Tuff of Leslie Gulch, MK = Tuff of Mohawk, PG = Picture Gorge Tuff, RST = Rattlesnake Tuff, SR = Tuff of Smith Rock. 
Figure 12. Stratigraphy and corresponding arsenic concentrations for two sections of individual tuff units. The type section of the Rattlesnake tuff shows higher arsenic levels upsection in the less porous sections of the unit. The Dinner Creek section shows arsenic concentrations ranging from $<0.5 \mathrm{mg} \mathrm{kg}^{-1}$ (non-detect value plotted as $0 \mathrm{mg} \mathrm{kg}^{-1}$ ) to $6.8 \mathrm{mg} \mathrm{kg}^{-1}$, with no apparent relationship between arsenic concentration and position within the section. Error bars are based on INAA recovery percents from certified reference materials from Activation Laboratories, Ltd.

Figure 13. Log transformed Arsenic and FeO concentrations in tuffs and tuffaceous sediments. Although statistically significant positive correlations were found between arsenic and $\mathrm{FeO}$, there is not a strong linear relationship between the elements

Figure 14. Environmentally available fraction of arsenic present in tuffs and tuffaceous sediments. Yellow squares indicate mean values. In unweathered glassy tuffs significantly less of the total arsenic is present in the environmentally available fraction than is found in devitrified or weathered tuffs, or tuffaceous sediments. ... 66

Figure 15. Environmentally available fraction of arsenic present in devitrified and glassy tuffs, by degree of weathering. Yellow squares indicate mean values. Weathering produces substantial differences in the environmentally available fraction of arsenic in glassy tuffs, but the difference between weathered and unweathered devitrified tuffs is not significant.

Figure 16. Environmentally available arsenic as a function of total arsenic concentrations. There is a direct relationship between total and available arsenic in all categories except glassy tuffs.

Figure 17. Readily leachable arsenic contents of ash-flow tuffs and tuffaceous sediments. Yellow boxes represent mean values. Tuffaceous sediments contained significantly more readily leachable arsenic than all categories of tuffs. Devitrified and weathered tuffs showed a greater range of readily leachable arsenic values than unweathered glassy tuffs.

Figure 18. Readily leachable arsenic as a function of total arsenic present in samples. There is no correlation between the total amount of arsenic present in tuffs and sediments and the amount present in the readily leachable fraction.

Figure 19. Aqueous arsenic concentrations produced by water leaching experiments. Weathered and devitrified tuffs and tuffaceous sediments all produced aqueous arsenic concentrations exceeding regulatory limits.

Figure 20. Arsenic concentrations from leaching experiments with uncontrolled $\mathrm{pH}$ compared with concentrations produced at $\mathrm{pH} 9$ and 11. In weathered tuffs arsenic concentrations increased slightly from the circum-neutral conditions of the 
uncontrolled leachate experiments to $\mathrm{pH} 9$, while arsenic concentrations decreased slightly between circum-neutral conditions and $\mathrm{pH} 9$.................................... 76

Figure 21. Linear relationship between readily leachable arsenic and iron in weathered

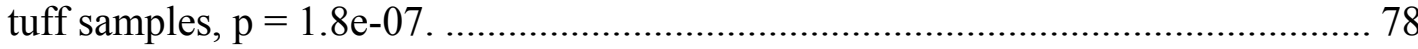

Figure 22. Conceptual model of arsenic behavior in ash-flow tuffs............................. 85 


\section{CHAPTER 1: INTRODUCTION AND BACKGROUND}

\section{INTRODUCTION}

The occurrence of groundwater containing elevated arsenic concentrations has emerged as a major health concern throughout the world. Arsenic is known to cause cancer of the skin, bladder, and lungs, damage to the circulatory and nervous systems, hypertension, and diabetes (Brown and Ross, 2002; Ng et al., 2003). Arsenic levels exceeding the World Health Organization Maximum Contaminant Level (MCL) of 50 $\mu \mathrm{g} / \mathrm{L}$ occur in many locations worldwide including Bangladesh, India, Cambodia, Argentina, the United States, Hungary, and China, among others, and is likely to occur in additional regions where reliable data regarding drinking water is currently unavailable (Amini et al., 2008). Within the United States, where approximately half the population depends on groundwater sources for drinking water, arsenic concentrations exceeding the Environmental Protection Agency MCL of $10 \mu \mathrm{g} / \mathrm{L}$ are found in $5-11 \%$ of groundwater sourced drinking water systems (Ryker, 2003).

Elevated arsenic concentrations in drinking water supplies in several locations within the United States, Argentina, Greece, Turkey, Chile and Italy have been associated with volcanic rocks and ash-flow tuffs (Casentini et al., 2010; Johannesson and Tang, 2009; Welch et al., 2000). Proximity to volcanic rocks has been found to be statistically predictive of arsenic contamination of water supplies (Amini et al., 2008). Felsic tuffs have been identified as primary hydrologic units in $~ 25 \%$ of the regions in the United States known to contain high groundwater arsenic levels and in at least one case, dissolution of volcanic glass has been identified as the primary geochemical source of 
arsenic in groundwater (Johannesson and Tang, 2009; Welch et al., 2000). Several studies have identified volcanic tuffs or tuffaceous sediments as the source of groundwater arsenic in the southern Willamette Valley of Oregon (Goldblatt et al., 1963; Hinkle and Polette, 1999; Nadakavukaren et al., 1984; Whanger et al., 1977).

Despite the widespread association of elevated groundwater arsenic levels with ash-flow tuffs, the mechanisms of arsenic release and the role that compositional variations play in the mobility of arsenic is largely unexplored in the literature. Tuffs vary considerably in composition and can experience both high- and low-temperature alteration, the degree of which can vary considerably, even within a single unit. The goal of my study is to quantify the degree to which chemical composition, devitrification, and low-temperature alteration control the mobility of arsenic and other trace elements from high-silica $\left(>70 \% \mathrm{SiO}_{2}\right)$ ash-flow tuffs under varying environmental conditions. Developing a better understanding of arsenic-mineral associations in tuffs and identifying the characteristics and conditions that promote high dissolved arsenic concentrations will improve the predictive modeling of arsenic behavior in volcanic terrain and aid in the identification of aquifers that are likely to yield high arsenic groundwaters. 


\section{BACKGROUND}

\section{Arsenic Geochemistry}

Arsenic in groundwater exists primarily as As(III) or As(V). The arsenic species present is dependent of the $\mathrm{pH}$ and redox conditions of the specific water systems in question (Figure 1).

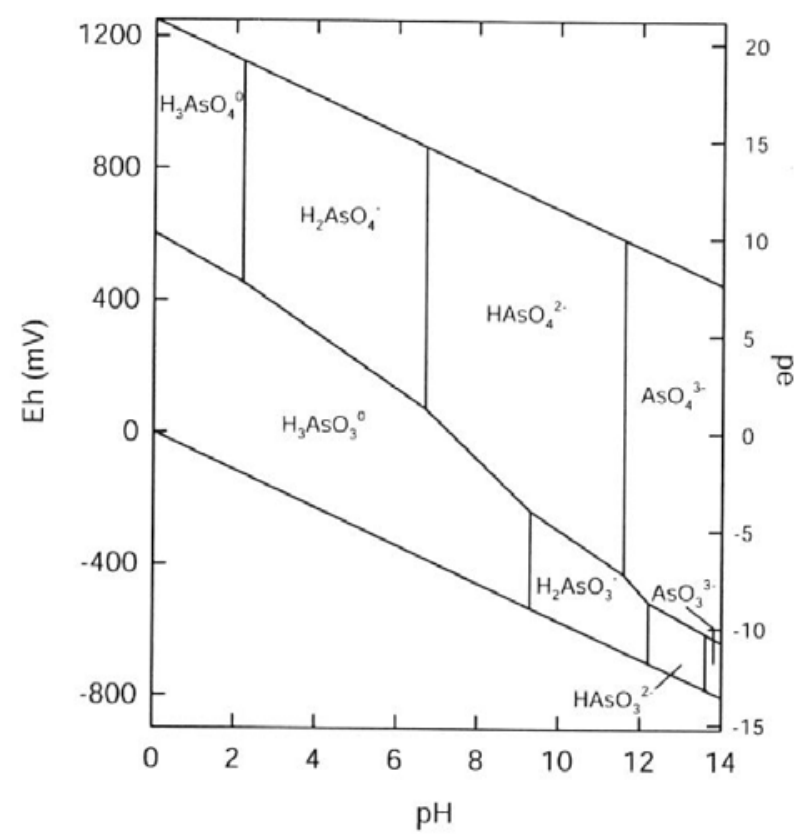

Figure 1. Eh-pH diagram for aqueous arsenic species at $25^{\circ} \mathrm{C}$ and 1 bar pressure, from (Smedley and Kinniburgh, 2002).

Under circum-neutral $\mathrm{pH}$, arsenate occurs primarily as $\mathrm{HAsO}_{4}^{-2}$ or $\mathrm{H}_{2} \mathrm{AsO}_{4}{ }^{-}$and is the dominant form of arsenic in oxidizing environments, while arsenite occurs predominantly as $\mathrm{H}_{3} \mathrm{AsO}_{3}{ }^{0}$ and is the dominant form under reducing conditions. Both oxidation states are commonly found in natural water systems (Cullen and Reimer, 1989; Welch et al., 
2000). The occurrence of arsenate as an oxyanion contributes to its mobility at $\mathrm{pH}$ values typically found in groundwaters. Most toxic trace metals occur as cations which have limited mobility at circumneutral $\mathrm{pH}$ due to the tendency of cations to become more strongly sorbed as $\mathrm{pH}$ increases (Smedley and Kinniburgh, 2002). In contrast, toxic trace elements that occur as oxyanions become less strongly sorbed as $\mathrm{pH}$ increases.

\section{Redox Behavior of Arsenic}

The speciation of arsenic is controlled by redox conditions and plays a major role in arsenic mobility mechanisms. As(III) is thermodynamically unstable in aerobic conditions, but the oxidation process proceeds slowly, with a half life of one to three years, unless mediated by microbial action (Rhine et al., 2008; Stollenwerk, 2003). The rate of oxidation under atmospheric conditions has also been observed to increase at $\mathrm{pH}>$ 9 (Manning and Goldberg, 1997). In contrast, the reduction of $\mathrm{As}(\mathrm{V})$ to $\mathrm{As}(\mathrm{III})$ proceeds rapidly under both biotic and abiotic conditions (Stollenwerk, 2003).

Redox conditions also influence the mobility of arsenic by affecting arsenic bearing minerals, and major sorbents of arsenic. Arsenic is frequently hosted in sulfide minerals, and Fe-oxides and oxyhydroxides are a major sorbent of arsenic. Reduction of $\mathrm{Fe}(\mathrm{III})$ present primarily as oxides and oxyhydroxides to $\mathrm{Fe}(\mathrm{II})$ present primarily as free cations, and oxidation of sulfide minerals are both processes associated with arsenic contamination of groundwater systems. Fe(III) reduction occurs after the reduction of $\mathrm{O}_{2}$, $\mathrm{NO}_{3}{ }^{-}$, and $\mathrm{MnO}_{2}$, at an Eh close to $0 \mathrm{mV}$, and before the reduction of $\mathrm{As}(\mathrm{V})$ and $\mathrm{SO}_{4}{ }^{2-}$ (Langmuir, 1997; Smedley and Kinniburgh, 2002). 


\section{SORPTION BEHAVIOR OF ARSENIC}

Sorption and coprecipitation processes are the primary mechanisms controlling the mobility of dissolved arsenic in natural waters (Dixit and Hering, 2003; Welch et al., 2000). Adsorption processes are controlled by aquifer mineralogy, arsenic concentrations and speciation, $\mathrm{pH}$, and concentrations of competing anions (Stollenwerk, 2003). Adsorption of arsenic is positively correlated with the Fe- and Al-oxide and clay content of aquifer solids, and these minerals act as the primary sorbents of arsenic, although solid organic matter and carbonate minerals may act as sorbents as well (Goldberg, 2002;

Stollenwerk, 2003).

\section{Common Sorbents}

Iron, aluminum, and manganese oxides are the most prevalent sorbents for arsenic in aquifer sediments, occurring both as discrete particles and as coatings on other mineral surfaces (Stollenwerk, 2003; Welch et al., 2000). Iron oxides and oxyhydroxides are the most abundant sorbent in aquifer solids, and occur in varying compositions and degrees of crystallinity including hydrous ferric oxides (HFO), goethite, and magnetite (Dixit and Hering, 2003; Jang and Dempsey, 2008). Poorly crystalline oxyhydroxides that form by precipitation of $\mathrm{Fe}(\mathrm{III})$ from solution have the highest sorption capacity due to the decrease in surface area and surface complexation sites as the degree of crystallinity increases (Stollenwerk, 2003). Aluminum oxides and oxyhydroxides are structurally similar to Fe minerals and display similar sorption capacity and behavior for arsenic but are generally less abundant in aquifer solids (Stollenwerk, 2003) . 
Clay minerals are another potential sorbent of arsenic. Kaolinite, illite, chlorite, and halloysite have all been observed to sorb both As(III) and As(V) (Stollenwerk, 2003). Overall clay minerals have negative surface charges, but surface metal cations at the edges of particles, most commonly aluminum, have the capacity to form surface complexes with arsenic (Davis and Kent, 1990). The dependence of arsenic sorption on Al-OH sites at clay mineral edges results in some similar responses of clay minerals and aluminum oxides to geochemical parameters including pH (Stollenwerk, 2003). One major area where clay minerals differ from each other and aluminum oxide minerals is in the concentration of sorption sites. Kaolinite has been observed to adsorb greater amounts of arsenic than equal amounts of illite and montmorillonite with larger surface areas, indicating that the number of sorption sites of a specific clay mineral plays a larger role than surface area (Manning and Goldberg, 1996).

\section{$\mathrm{pH}$ Dependence}

For all potential adsorbents the sorption of arsenic is $\mathrm{pH}$ dependent. For Fe oxide minerals, sorption of $\mathrm{As}(\mathrm{V})$ is highest at low $\mathrm{pH}$ and begins declining near $\mathrm{pH} 4$ while sorption of $\mathrm{As}(\mathrm{III})$ increases to a maximum at circum-neutral $\mathrm{pH}$ conditions ( $\mathrm{pH} 5$ to 9), decreasing under alkaline conditions (Figure 2) (Dixit and Hering, 2003). Both aluminum oxides and clay minerals display similar sorption patterns with respect to $\mathrm{pH}$, with $\mathrm{As}(\mathrm{V})$ declining with increasing $\mathrm{pH}$ and $\mathrm{As}(\mathrm{III})$ reaching a maximum at circum-neutral $\mathrm{pH}$ (Goldberg, 2002). When both $\mathrm{As}(\mathrm{III})$ and $\mathrm{As}(\mathrm{V})$ are present in a system, the sorption behavior of $\mathrm{As}(\mathrm{V})$ is largely unchanged, while $\mathrm{As}(\mathrm{III})$ increases until it reaches a maximum at $\mathrm{pH} 10$ for Fe-oxides, and then rapidly decreases (Jang and Dempsey, 2008). 

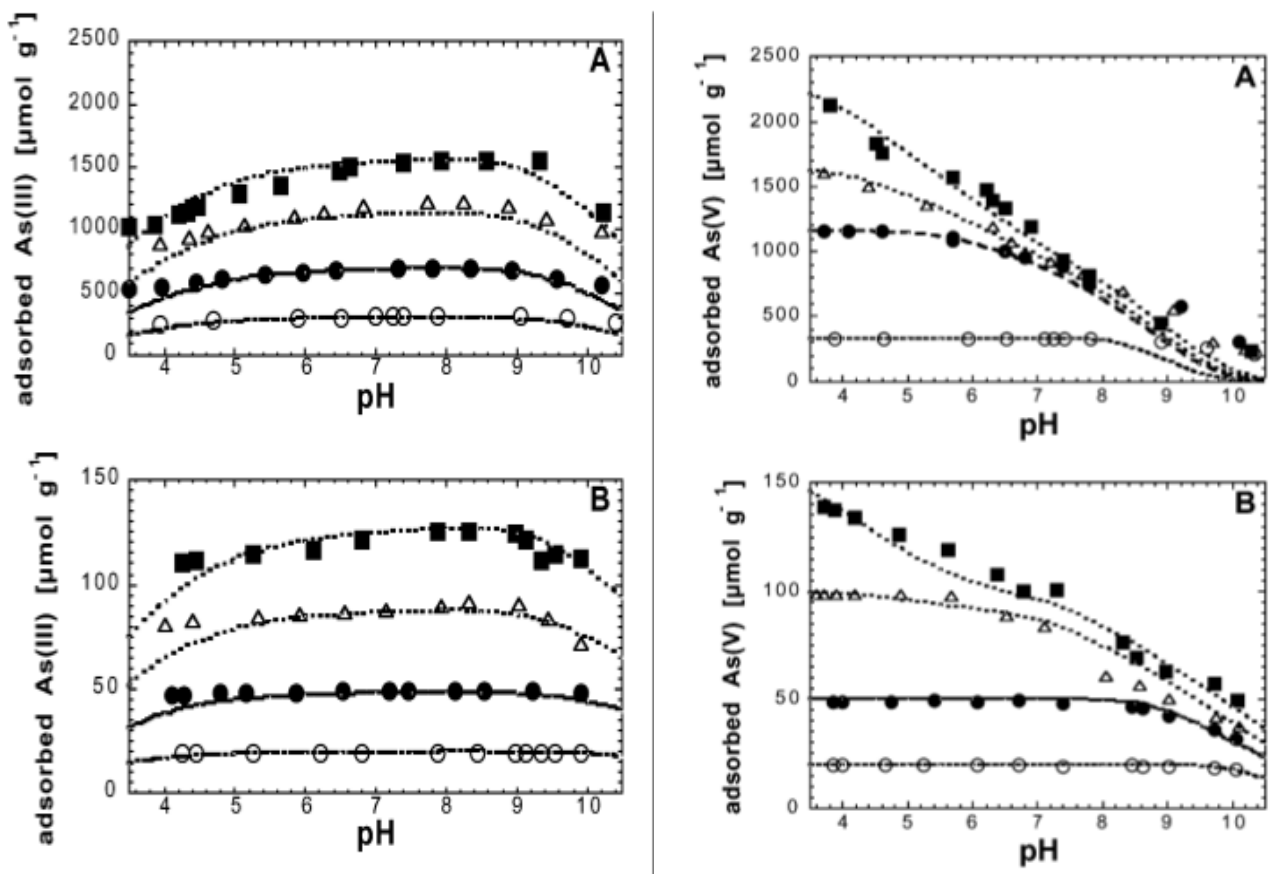

Figure 2. Adsorption of arsenate and arsenite onto A) amorphous iron oxide and B) goethite as a function of pH. Arsenic concentrations range from $100 \mu \mathrm{M}(\mathbf{\square})$ to $10 \mu \mathrm{M}(\mathrm{O})$. From Dixit \& Hering (2003).

\section{Competing Anions}

Competing anions, chiefly phosphate, can decrease the adsorption of arsenic. The influence of phosphate on arsenic sorption is well documented, and elevated arsenic concentrations are correlated with high phosphate concentrations in a number of locations throughout the world (Dixit and Hering, 2003; Welch et al., 2000). Phosphate will decrease the adsorption of both $\mathrm{As}(\mathrm{V})$ and As(III), but a higher degree of similarity between $\mathrm{P}(\mathrm{V})$ and $\mathrm{As}(\mathrm{V})$ results in more effective competition with $\mathrm{As}(\mathrm{V})$ (Stollenwerk, 2003). Competition with phosphate will decrease the adsorption of As(V) over the full $\mathrm{pH}$ range, while phosphate primarily decreases the adsorption of $\mathrm{As}(\mathrm{III})$ at $\mathrm{pH}<9$ (Jain and Loeppert, 2000). 
Silicic acid is a less effective competitor than phosphate, but is known to compete with arsenic for sorption sites at $\mathrm{pH}$ values greater than 8 (Dixit and Hering, 2003; Stollenwerk, 2003). Dissolved organic matter (DOC) may also compete with arsenic for sorption sites. In sufficient quantities, DOC, chiefly humic and fulvic acids, may cause oxyhydroxides to which arsenic is adsorbed to dissolve. However, high DOC concentrations tend to occur in reduced waters so these effects likely would impact only adsorbed As(III) (Ravenscroft et al., 2009).

\section{Reducing Groundwater Systems}

Arsenic contamination of reducing groundwater systems is known to occur in Bangladesh, Taiwan, Vietnam, and Hungary and Romania (Ravenscroft et al., 2009; Smedley and Kinniburgh, 2002). In all of these locations the contaminated aquifers are composed of Quaternary sedimentary deposits containing high proportions of organic matter, with waters characterized by high $\mathrm{Fe}, \mathrm{Mn}$, and $\mathrm{NH}_{4}$ concentrations (Smedley and Kinniburgh, 2002). The primary geochemical trigger for arsenic mobility in these reducing environments is reductive dissolution of Fe-oxides that act as a sink for arsenic. $\mathrm{As} \mathrm{Fe}^{3+}$ that comprises the oxides and oxyhydroxides is reduced to $\mathrm{Fe}^{2+}$ both crystalline and amorphous forms of $\mathrm{Fe}$ oxide minerals dissolve, releasing any adsorbed or coprecipitated arsenic (Ravenscroft et al., 2009; Welch et al., 2000). During the process of dissolution arsenic may be released and immediately readsorbed to the residual oxide surfaces, preventing arsenic contamination until all or most of the Fe-oxides are reduced (Ravenscroft et al., 2009). In environments with exceptionally high organic matter concentrations, such as Bangladesh, elevated phosphate concentrations are found as well, 
which may contribute to the mobilization of arsenic adsorbed to clays or aluminum oxides.

\section{Oxidizing Groundwater Systems}

Arsenic contamination of oxidizing groundwater systems is known to occur in Italy, Argentina, Chile, Mexico, and the Southwestern United States (Casentini et al., 2010; Smedley and Kinniburgh, 2002; Welch et al., 2000). These environments are frequently, but not always, arid, and the groundwater systems are characterized by high $\mathrm{pH}$, and often high salinity and elevated F or B concentrations (Smedley and Kinniburgh, 2002). The geology of these aquifers is more variable than contaminated aquifers with reducing groundwater systems, and include volcanic rocks and sediments as well as alluvial sediments (Smedley and Kinniburgh, 2002). In oxidizing environments the primary geochemical trigger for mobilizing arsenic is alkali desorption, which describes the tendency of $\mathrm{As}(\mathrm{V})$ to desorb as $\mathrm{pH}$ increases in alkaline oxic waters (Ravenscroft et al., 2009). The occurrence of alkali desorption in arid environments and the presence of high salinity in many waters contaminated by alkali desorption indicates that it may operate in conjunction with evaporative concentration of arsenic in some environments, with evaporation increasing the concentrations of arsenic and the alkalinity of these waters.

\section{Chemical and Mineralogical Variations in Ash-Flow Tuffs}

Although elevated arsenic levels in groundwaters have often been associated with ash-flow tuffs, there has been little investigation in the role that variations in tuffs may 
play in either the occurrence or mobility of arsenic from these units. Compositional variations in high-silica ash-flow tuffs can be divided into three primary categories: chemical variations in the source material, high-temperature alteration that occurs immediately after deposition, and low temperature alteration to zeolites and clays. Unaltered ash-flow tuffs display the same range of compositional variation found in highsilica igneous rocks, but for the purposes of this project the primary variation investigated will be the $\mathrm{Al} /\left(\mathrm{Na}_{2} \mathrm{O}+\mathrm{K}_{2} \mathrm{O}\right)$ ratio. Peralkaline (e.g. low $\left.\mathrm{Al} /\left(\mathrm{Na}_{2} \mathrm{O}+\mathrm{K}_{2} \mathrm{O}\right)\right)$ ash-flow tuffs have been observed to weather at higher rates than tuffs with higher $\mathrm{Al} /\left(\mathrm{Na}_{2} \mathrm{O}+\mathrm{K}_{2} \mathrm{O}\right)$ ratios and equal $\mathrm{SiO}_{2}$ concentrations (Streck, M., personal communication). Both alkali and aluminum content are likely to play a role in weathering and arsenic mobility, since aluminum is necessary for the formation of low temperature alteration products, and the release of alkalis will influence the $\mathrm{pH}$ of groundwaters in peralkaline tuff units.

High-temperature alteration processes that occur immediately after deposition of an ash-flow tuff include devitrification and vapor phase alteration. Devitrification occurs during slow cooling within the interior of thick tuffs deposited at high temperatures, resulting in the glassy ash and pumice particles crystallizing into fine-grained feldspars, primarily sanidine, and other silica minerals including cristobalite, quartz and tridymite (Ross and Smith, 1980; Vaniman, 2006). Vapor-phase alteration is distinguished from devitrification in that it occurs primarily in pore spaces rather than within individual glass particles and will often result in larger crystals (Ross and Smith, 1980). Vapor-phase alteration produces the same primary minerals as devitrification, but can also include a wide variety of minor minerals that can incorporate elements expelled from glass 
particles during devitrification (Vaniman, 2006). High temperature alteration processes typically occur in the interior of individual cooling units, and produce distinct zonation within the body of the tuff (Figure 3). Element mobility during high-temperature alteration of peralkaline silicic lavas occurs during crystallization and is attributed to both expulsion of the vapor phase and groundwater leaching (Weaver et al., 1990). Na, F, Cl, Cs, Y, and rare earth elements (REE) have been observed to be depleted during crystallization (Weaver et al., 1990).

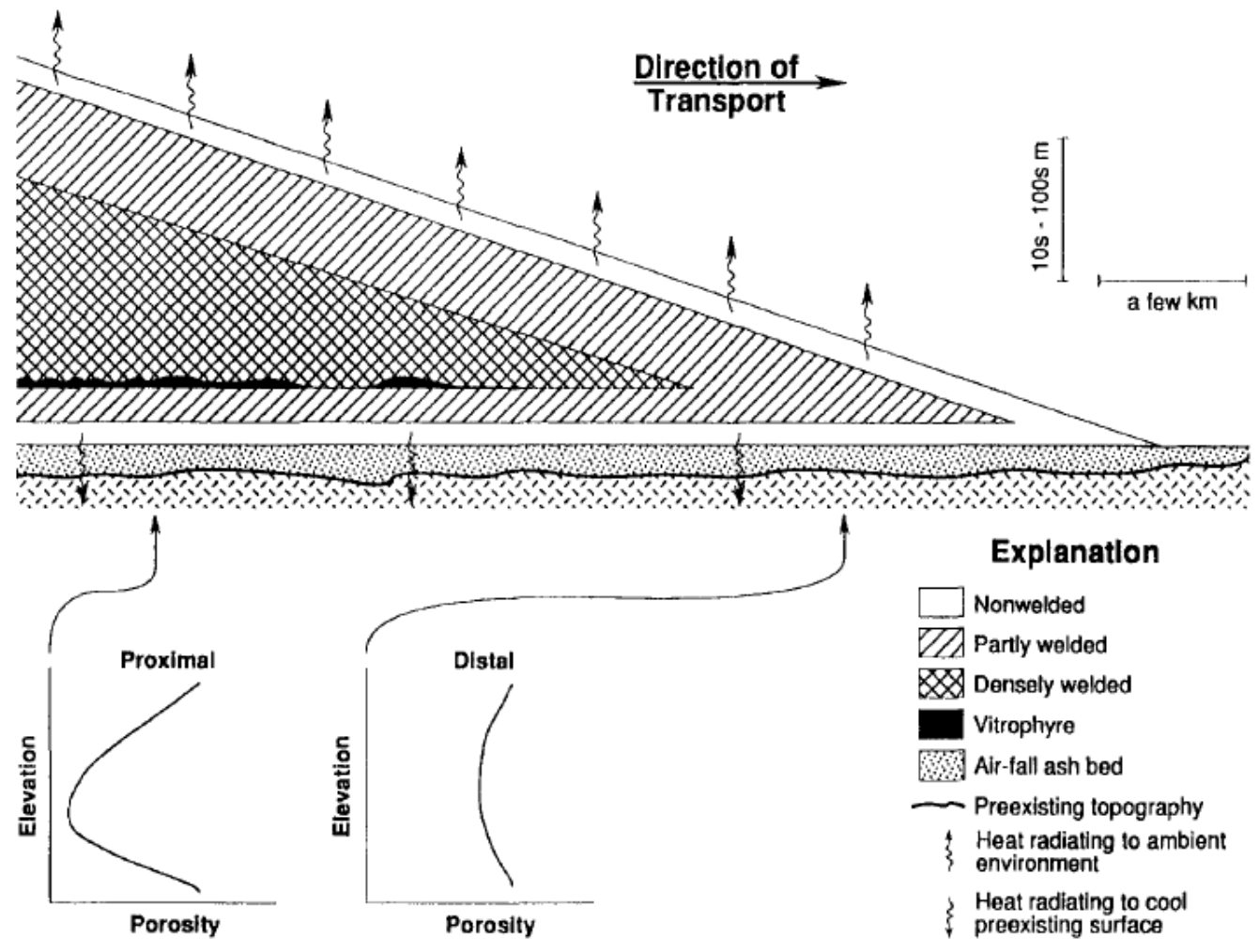

Figure 3. Conceptual model of cooling ash-flow unit showing zonation and vertical porosity variation (Istok et al., 1994). 
Low-temperature alteration processes occur over longer time periods than high temperature alteration. As ash-flow tuffs are exposed to low-temperature waters, the unstable volcanic glasses are altered first to clay minerals, often smectites (Vaniman, 2006). As alteration progresses the relative abundance of illites and chlorites increases (Fisher and Schmincke, 1984). At high pH and ionic strength large quantities of zeolites are also formed during low temperature alteration of tuffs (Vaniman, 2006). Clinoptilolite is the most common zeolite produced outside of saline lake environments, but mordenite, chabazite and phillipsite are also common and the specific minerals formed will be influenced by the $\mathrm{Si} / \mathrm{Al}$ ratio of the tuff (Vaniman, 2006). During low-temperature alteration, elements can be depleted by groundwater leaching or enriched by structural incorporation in minerals, ion exchange, and adsorption (Zielinski, 1982).

\section{Arsenic in Tuffs}

Surprisingly little information is available regarding the range of arsenic concentrations in volcanic glass. The most oft-cited source, even today, is Onishi and Sandell (1955), who report an average arsenic concentration of $5.9 \mathrm{mg} / \mathrm{kg}$ based on 12 volcanic glass samples. Nicolli et al. (1989) found arsenic concentrations ranged between 6.8 and $10.4 \mathrm{mg} / \mathrm{kg}$ with a geometric mean of $8.7 \mathrm{mg} / \mathrm{kg}$ in 10 samples of volcanic glass isolated from volcanically derived loess. These mean values are approximately four times the average crustal abundance of $1.7 \mathrm{mg} / \mathrm{kg}$ (Wedepohl, 1995). There are some indications that arsenic concentrations increase with silica content in volcanic rocks, although it is unclear if this holds true for volcanic glasses (Onishi and Sandell, 1955). The upper limit of arsenic in volcanic glass appears be $\sim 20 \mathrm{mg} / \mathrm{kg}$ (Casentini et al., 2010; 
Fiantis et al., 2010), although Noble at al. (2004) reported arsenic concentrations of up to $65 \mathrm{mg} / \mathrm{kg}$ in glassy calc-alkalic volcanic rocks from Peru.

The concentrations of arsenic in ash-flow tuffs is relatively modest in comparison to shales, which often have mean arsenic contents in excess of $10 \mathrm{mg} / \mathrm{kg}$ (Onishi and Sandell, 1955), but which are not typically sources of groundwater arsenic. Thus, the association of tuffs with elevated groundwater arsenic levels must be due to one or more processes that allow for mobilization, not simply elevated arsenic concentrations. Possible mechanisms include: 1) the relatively rapid dissolution of reactive glasses (Nadakavukaren et al., 1984; Nicolli et al., 1989); 2) dissolution of other readily soluble arsenic-bearing phases, possibly vapor phase alteration products or lithic fragments; 3) alkali desorption wherein weathering of volcanic glass causes an increase in solution $\mathrm{pH}$ which promotes release of arsenic from mineral surfaces (Smedley and Kinniburgh, 2002); and or 4) the dissolution of minerals containing competing anions that promote desorption of arsenic via anion exchange (Casentini et al., 2010). 
Arsenic K-edge XANES Spectra of Natural Tuff Samples

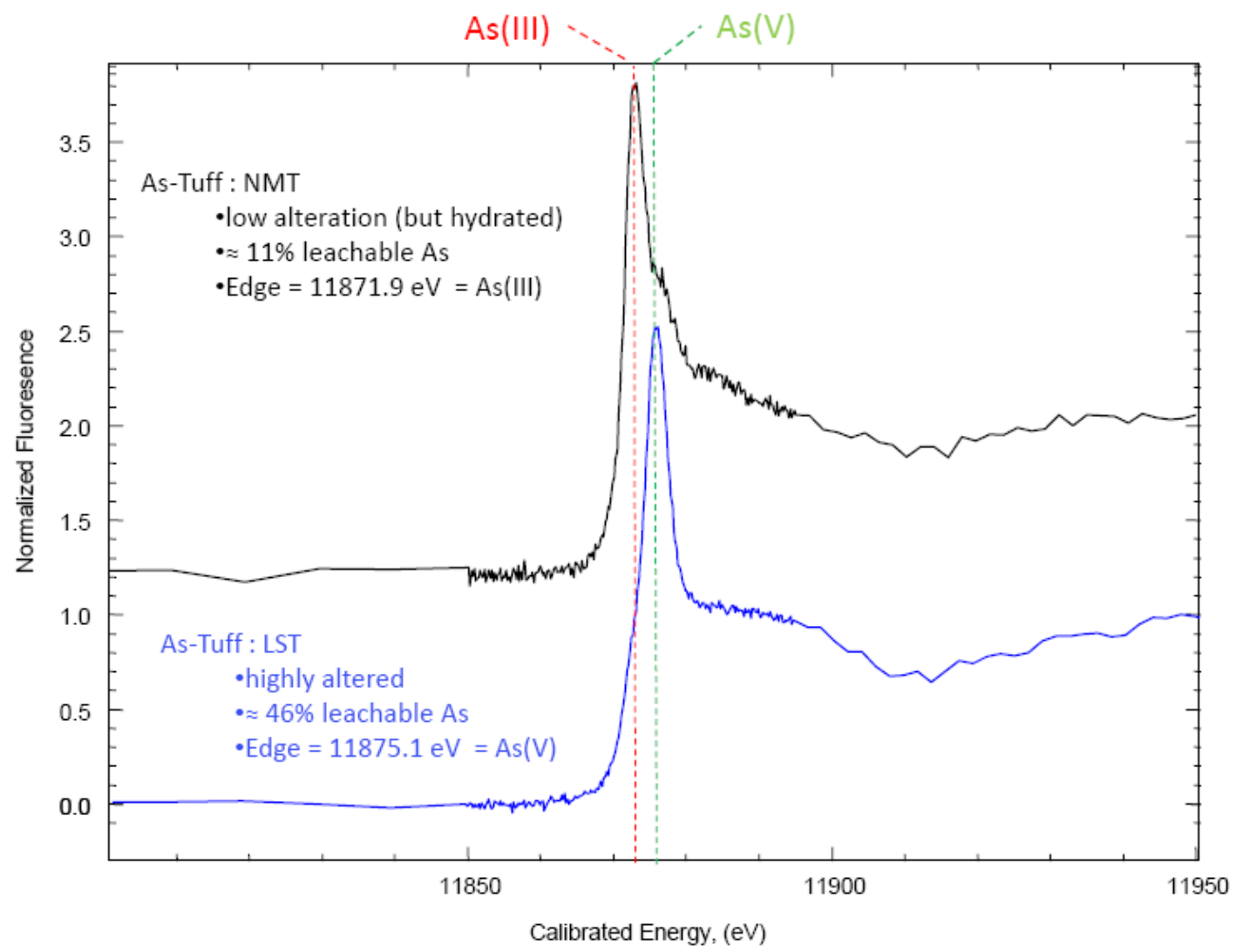

Collected Jan 2011 @ SSRL BL 11-2 by A. Foster for R. B. Perkins

Figure 4. Arsenic K-edge XANES spectra of selected tuff samples from preliminary As leaching study. The less altered tuff contained primarily As(III) while the highly altered tuff contained primarily As(V).

Preliminary data suggest that arsenic in unaltered glassy tuffs is present predominantly as As(III) while arsenic in altered tuffs is predominantly As(V) (Figure 4). Results of a preliminary arsenic leaching study suggest that arsenic is more easily leached from altered tuffs that unaltered tuffs (Table 1, Figure 5). Altered tuffs present far more complications in terms of identifying the residence of oxidized arsenic because a variety of new hosts are possible, including secondary silica, secondary iron/manganese oxides 
or aluminum hydroxides, and various clays and zeolites. The host phase plays an important role in terms of sorption characteristics and stability under varying conditions.

Table 1. Total and environmentally available arsenic concentrations of select tuff samples used in preliminary As leaching study. Available arsenic refers to arsenic present in phases other than glasses and silicate mineral phases such as feldspars and quartz. Note: total As concentrations from previous INAA analysis. Errors $=1 \tau$ from replicate analysis.

\begin{tabular}{lcccc}
\hline \hline & $\begin{array}{c}\text { Total As } \\
\left(\boldsymbol{\mu g ~ g ~}^{-1}\right)\end{array}$ & $\begin{array}{c}\text { "Available" As } \\
\left(\boldsymbol{\mu g ~ g ~}^{-1}\right)\end{array}$ & Available/Total & Degree of Alteration \\
\hline Little Butte & $\sim 4 ?$ & $2.18 \pm 0.07$ & 0.55 & Highly Altered \\
LST & $\sim 4 ?$ & $1.85 \pm 0.03$ & 0.46 & Highly Altered \\
San Luis (NM) & $1.9 \pm 0.5$ & $0.64 \pm 0.04$ & 0.34 & Intermediate \\
San Luis (RC) & $2.3 \pm 0.4$ & $0.39 \pm 0.03$ & 0.17 & Intermediate \\
NMT & $4.2 \pm 0.3$ & $0.48 \pm 0.01$ & 0.11 & Hydrated Glass \\
RST & $4.1 \pm 0.4$ & $0.26 \pm 0.03$ & 0.06 & Fresh Glass \\
\hline
\end{tabular}




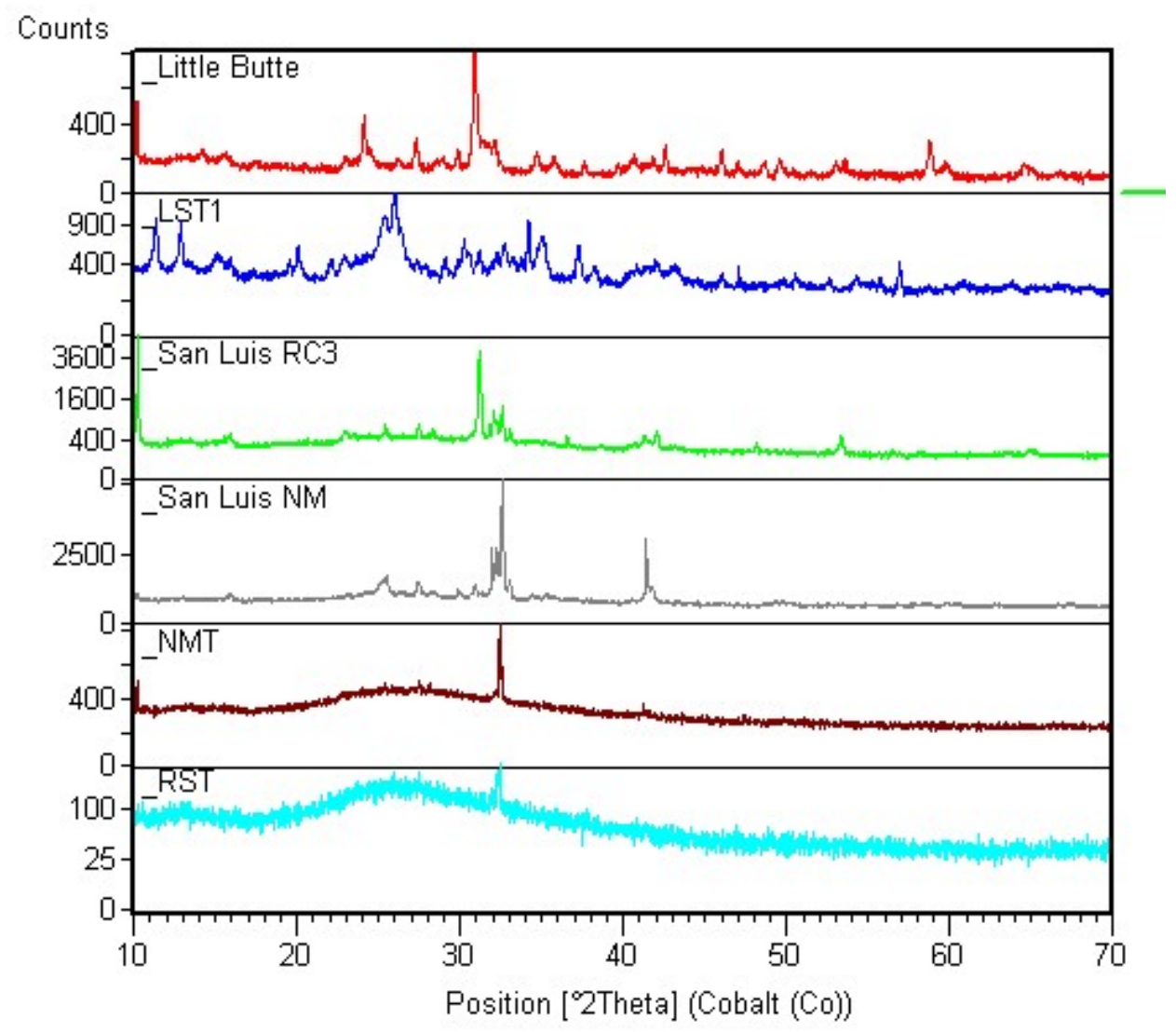

Figure 5. XRD analysis of six tuff samples used in preliminary As leaching study displaying increasing degrees of low-temperature alteration. More altered tuffs contain a larger number of mineral phases, which increases the number of potential host phases of arsenic in altered tuffs relative to unweathered glassy samples. 
CHAPTER 2: ARSENIC OCCURRENCE IN ASH-FLOW TUFFS AND ASSOCIATED $\underline{\text { SEDIMENTS }}$

INTRODUCTION

Despite the widespread association between ash-flow tuffs and arsenic contamination, surprisingly little is known about arsenic occurrence in these units. Previously reported values for mean arsenic concentrations are based on only 10-12 samples of volcanic glasses, and there has been little effort to identify arsenic host phases or to correlate arsenic with other elements in these rocks (Onishi and Sandell, 1955; Nicolli et al., 1989). Ash-flow tuffs are complex geologic units that can display multiple types and degrees of alteration, but most research involving arsenic and tuffs focuses on glassy tuffs, and does not consider devitrification and weathering.

In this study, 49 tuff samples spanning a range of chemical and mineralogical compositions, as well as 11 samples of tuffaceous sediments were used to investigate the behavior of arsenic in ash-flow tuffs. Specific objectives of the study are 1) to better quantify the levels of arsenic found in tuffs, 2) to determine if bulk chemical composition, particularly alumina-alkali ratios, influence levels of arsenic found in tuffs, and 3) to determine if devitrification and weathering influence arsenic concentrations in tuffs. 


\section{METHODS}

\section{Sample Collection and Preparation}

For this study, 42 hand samples of tuffs and tuffaceous sediments were collected from various locations throughout Oregon. Eight samples were collected from the Southern Willamette Valley, and 23 samples were collected from Central and Eastern Oregon. As both tuffs and tuffaceous sediments have been suggested as sources of groundwater arsenic, 11 samples of tuffaceous sediments were collected from Eastern Oregon. Wherever possible, samples displaying different alteration states were obtained from the same unit, and in some cases the same location. Full sections of unweathered samples were collected from single outcrops for two units, the Dinner Creek Tuff and the Rattlesnake Tuff. An additional 18 samples obtained from the existing collection of Dr. Martin Streck collection were also analyzed. Sample locations can be found in Table 2.

To prepare samples for analysis, visibly altered exteriors were chipped away with a rock hammer, and approximately fist-sized or smaller chunks of sample were fed through a Braun jaw-crusher until the largest pieces were between $\sim 2 \mathrm{~cm}$ and $\sim 5 \mathrm{~mm}$. Early samples were hand split, and one quarter of the sample was then run through a disc grinder, until the largest pieces were $\sim 5 \mathrm{~mm}$. For later samples this step was eliminated in favor of using a finer setting on the crusher to achieve a smaller grain size. $(\sim 5 \mathrm{~mm})$. In

all cases, the equipment was thoroughly cleaned between samples.

Crushed samples were hand split and $\sim 5-15 \mathrm{~g}$ portions were sent to either the Washington State University Geoanalytical Lab, in Pullman, WA, or Activation 
Laboratories Ltd., in Ontario, Canada for bulk chemical analysis. The remainder of each crushed sample was split up to four times using a small (Jones-type) riffle splitter, and split portions $(\sim 5-10 \mathrm{~g})$ ground to a fine powder using a Fisher alumina ceramic mortar grinder. Samples were ground for $20-30$ minutes. If grains larger than $\sim 0.5 \mathrm{~mm}$ remained after 30 minutes, grinding was finished by hand with a ceramic mortar and pestle.

\section{X-ray Diffraction (XRD)}

To characterize the mineralogy of the tuffs samples were analyzed using a Phillips (now PANalytical) Theta-Theta PW3040 X-ray diffractometer equipped with a standard scintillation counter and copper anode X-ray lamp. Samples were further ground by hand using an agate mortar and pestle until they passed through a $65 \mu \mathrm{m}$ sieve. A random powder mount was prepared using a side-pack aluminum sample holder. Diffraction patterns were obtained in continuous mode using a step size of 0.020 degrees two theta ( 20 ) and scan step times of 1.00 second from 5 to $75^{\circ} 2 \theta$. 


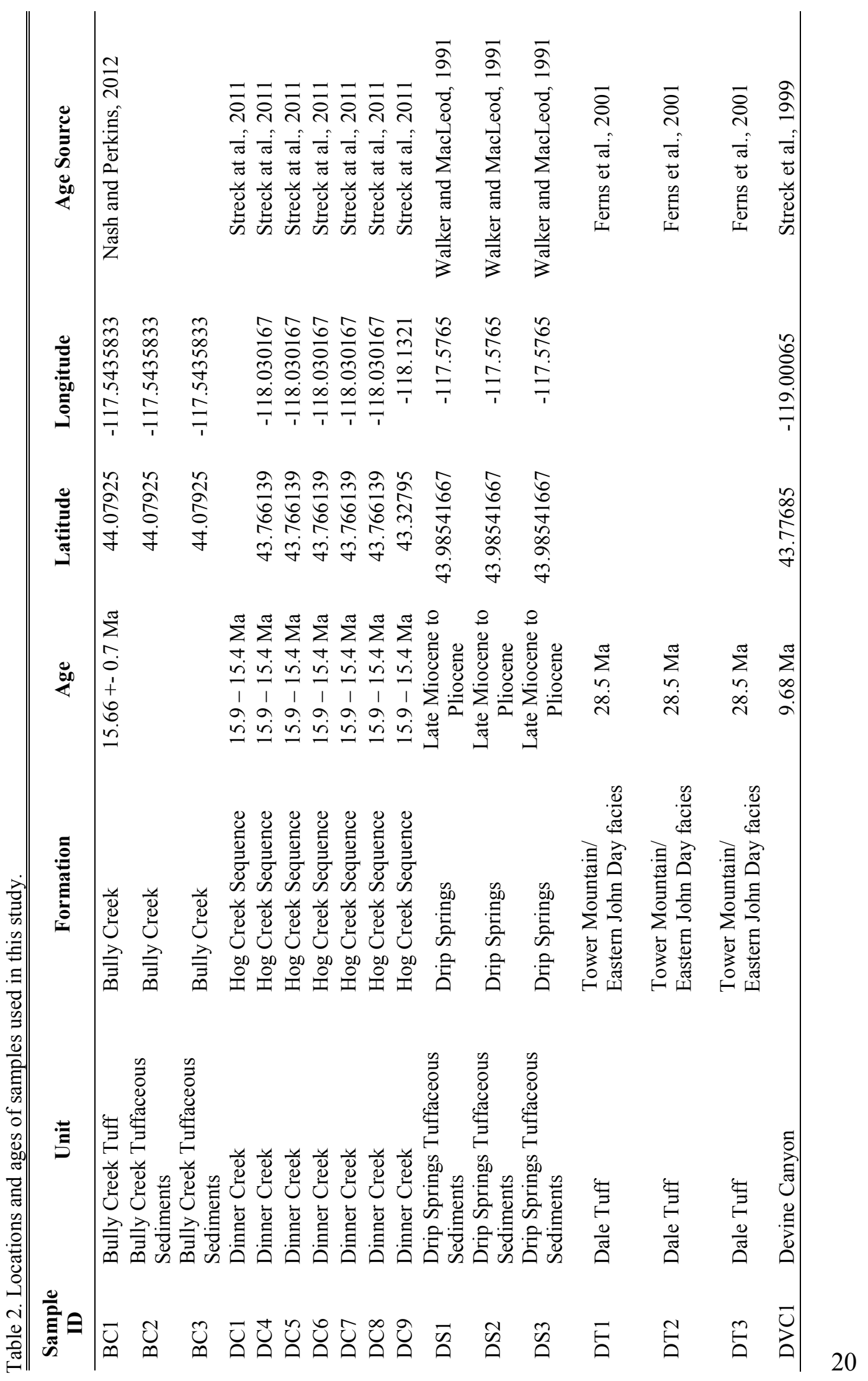




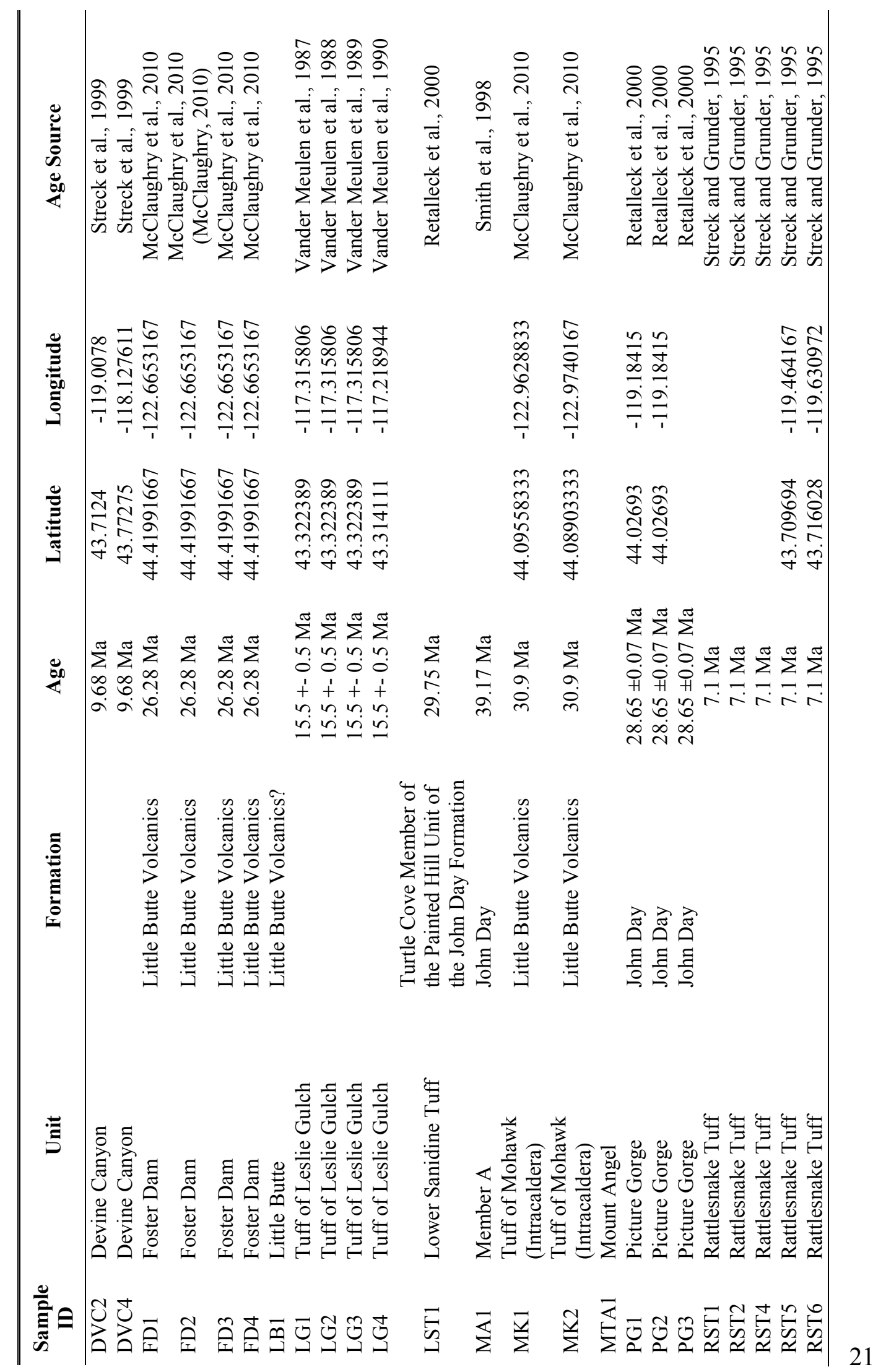




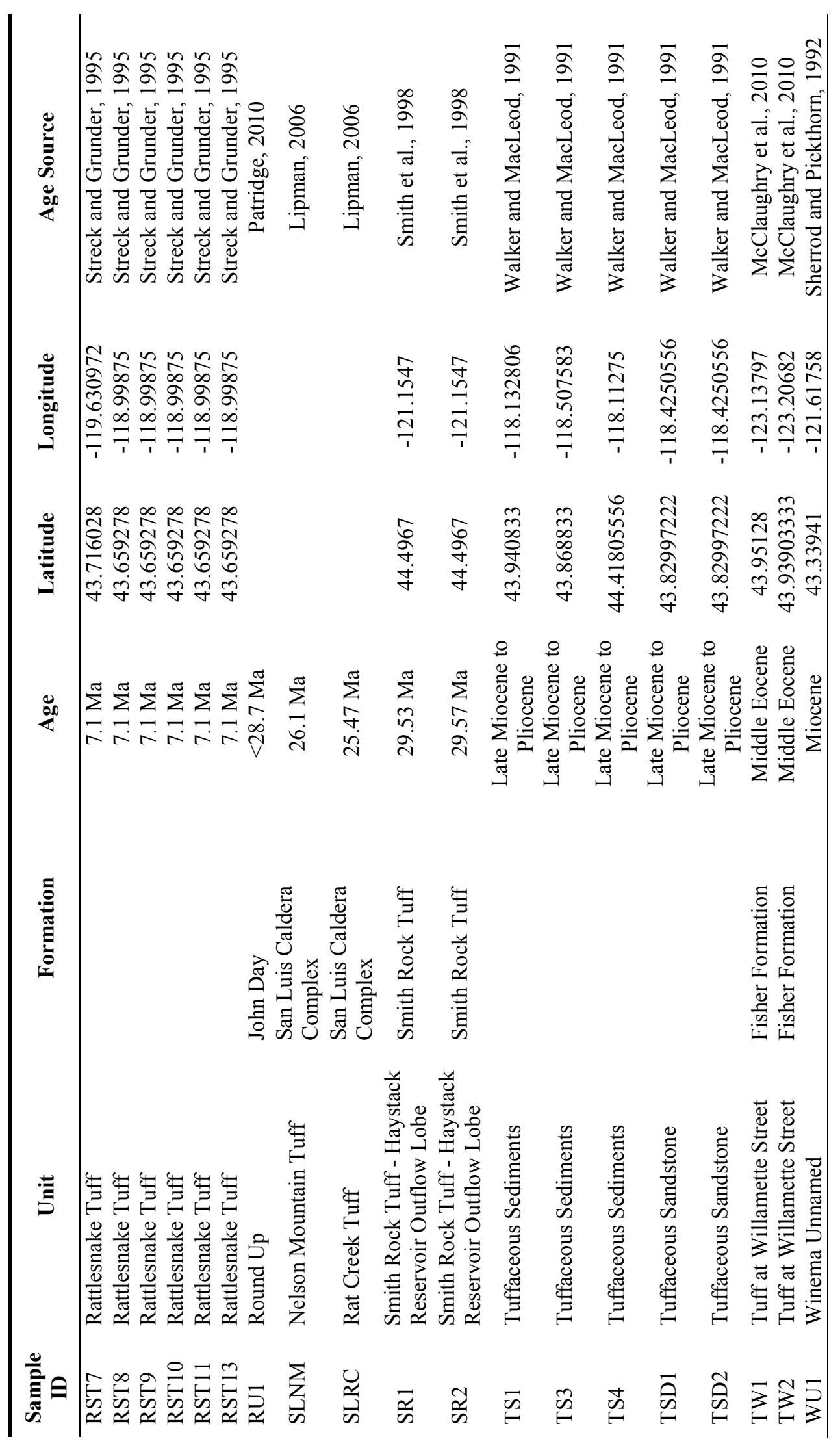


Diffraction patterns were analyzed using PANalytical X'Pert Highscore Plus software package, to obtain semi-quantitative mineral compositions. When possible AutoQuan software was used to perform non-standardized Reitveld analysis and obtain more accurate semi-quantitative compositional percentages. In some cases the software database was missing one or more of the mineral phases present in the samples, and Reitveld analysis was not performed. Amorphous phases were not included in these results, and the proportion of amorphous phases (glass) was estimated based on deviations in the background of XRD patterns from a straight line, particularly between approximately 10 and $40^{\circ} 2 \theta$, where the presence of amorphous phases produces a wide curved deviation of the background pattern from a straight line.

The XRD used produces wide low-intensity peaks at approximately $4-5^{\circ} 2 \theta$ and $8-9^{\circ} 2 \theta$ that are consistently present in XRD patterns. These peaks were determined to be instrument artifacts, possibly due to misaligned slits and peaks at these positions were excluded from analysis unless significantly larger than that measured on a blank holder. 


\section{Optical Microscopy}

Thin sections of selected samples were examined in order to confirm the XRD results and identify any potential minor mineral phases that were not identified in the XRD patterns. In addition, particular textures were considered to be indicative of different alteration processes (

Figure 6).

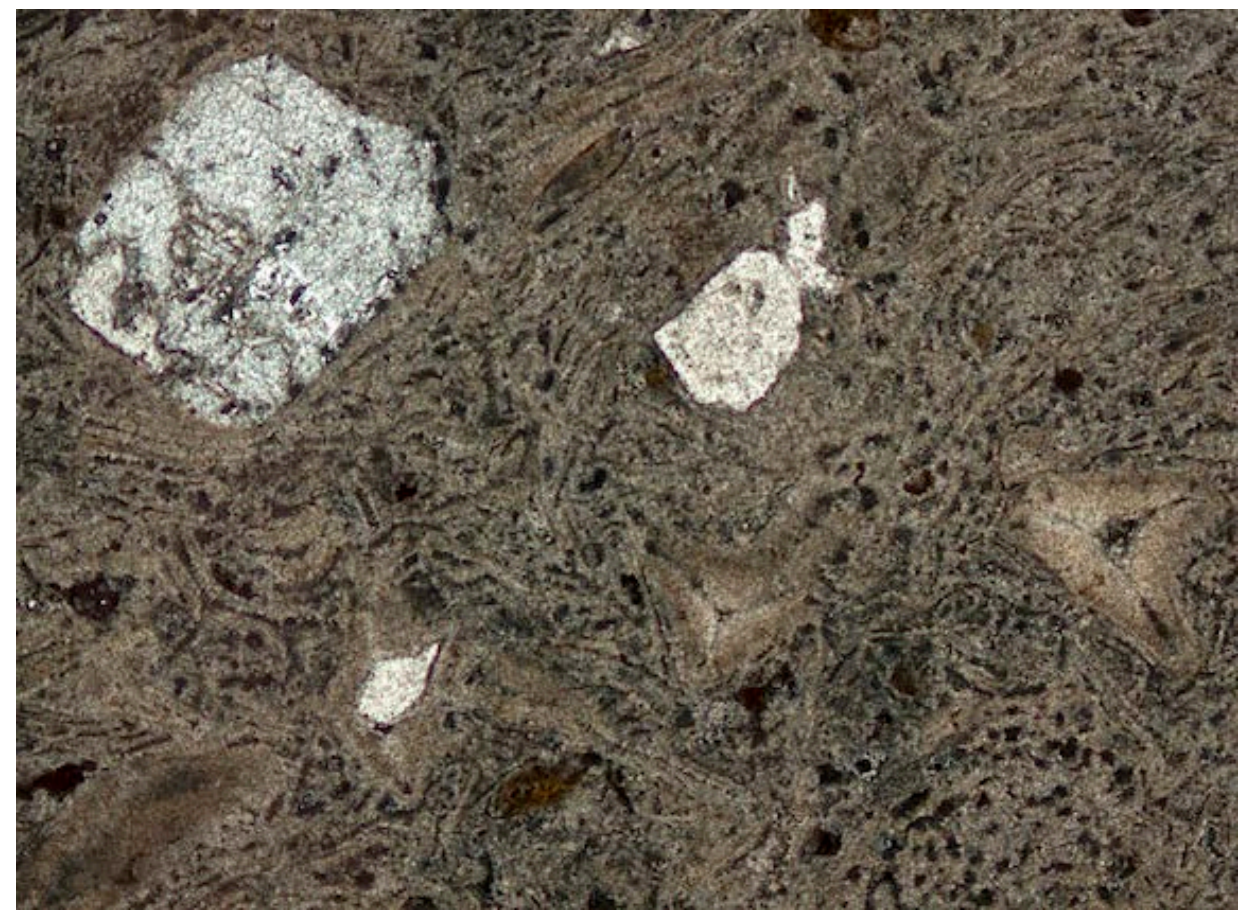

Figure 6. Sample PG2, under plane light at 5x magnification, displaying axilotic texture produced during devitrification, where minerals crystallized perpendicular to the boundaries of glass shards. 


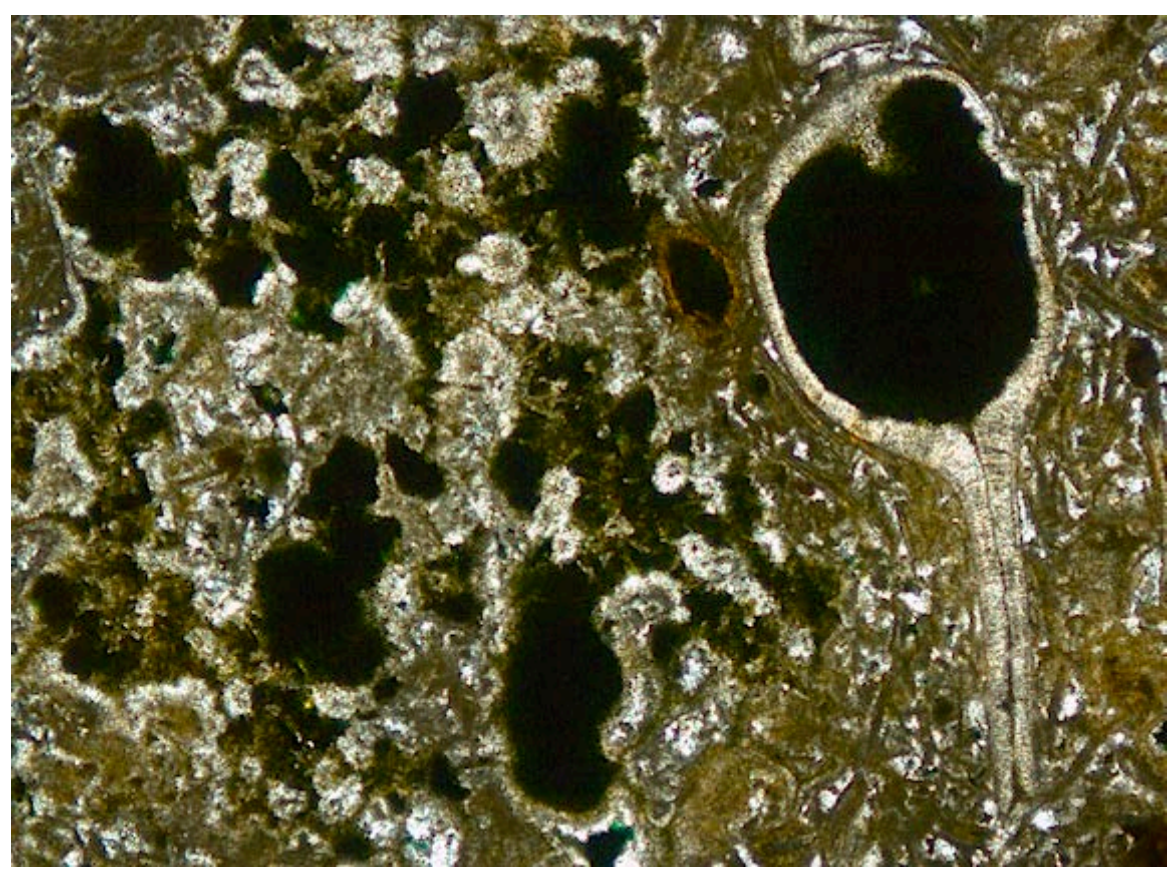

Figure 7. Sample PG1 under plane light at 5x magnification, displaying both axiolitic texture and alteration to green and brown clay minerals.

\section{Bulk Chemistry}

Crushed samples were hand split, and $\sim 5-10 \mathrm{~g}$ portions were sent to either the Washington State University Geoanalytical Lab, in Pullman, WA, or Activation Laboratories Ltd., in Ontario, Canada for bulk chemical analysis. At both labs, values for major elements were obtained via X-ray fluorescence (XRF). For samples sent to WSU, selected trace elements (Ni, $\mathrm{Cr}, \mathrm{V}, \mathrm{Ba}, \mathrm{Rb}, \mathrm{Sr}, \mathrm{Ga}, \mathrm{Cu}, \mathrm{Zn}, \mathrm{Pb}, \mathrm{La}, \mathrm{Ce}, \mathrm{Th}$, and $\mathrm{Nd}$ ) were obtained via XRF. For samples sent to Activation Laboratories trace elements were determined via ICP-MS (Cu, Cd, Mo, Pb, Ni, Zn, S, Be, Li, Sr, V, Y) or Instrumental Neutron Activation Analysis (INAA) (As, Ba, Co, Cr, Cs, Eu, Rb, Sb, Sc, Se, Th, La, Ce, $\mathrm{Nd}, \mathrm{Sm}, \mathrm{Sn}, \mathrm{Yb}, \mathrm{Lu})$. 


\section{Total Arsenic}

For samples where arsenic values were not obtained via INAA at Activation Laboratories, samples were digested following US EPA Method 3052 (US Environmental Protection Agency, 1996b). Sample aliquots were weighed to $0.250 \pm$ $0.001 \mathrm{~g}$ and placed in Teflon vessels that had been cleaned with concentrated nitric acid and repeatedly rinsed with deionized water $(18.2 \mathrm{M} \Omega \mathrm{cm})$. Subsequently, $1.5 \mathrm{~mL}$ tracemetal grade $\mathrm{HF}, 4.5 \mathrm{~mL}$ trace-metal grade $\mathrm{HNO}_{3}{ }^{-}$, and $1 \mathrm{~mL}$ trace-metal grade $\mathrm{HCl}$ were added to the vessels. Samples were digested using a Milestone Ethos EZ microwave digester for 40 minutes reaching a final temperature of $240^{\circ} \mathrm{C}$ for 20 minutes. Method blanks and certified reference materials (JR1 from the Japanese Geological Survey, and SRM 1633a from the National Bureau of Standards) were run every 20 samples, and duplicate digests were carried out on three samples. After digestion samples were poured into $50 \mathrm{~mL}$ plastic centrifuge tubes. Vessels were rinsed three times with $18.2 \mathrm{M} \Omega \mathrm{cm}$ distilled water, and the water was added to the samples. Centrifuge tubes were filled with water to $25 \mathrm{~mL}$.

Samples were further diluted to a total of $50.0 \mathrm{~mL}$ in test tubes (1:1 dilution) and analyzed using an Agilent 700 Series ICP-OES with an inert sample introduction system (a V-groove nebulizer with Sturman-Masters spray chamber and alumina injector). Detailed operating conditions for the analysis are listed in Appendix A. 


\section{RESULTS: BULK ROCK CHARACTERIZATION}

\section{Major Mineralogy}

The major mineralogy of all samples was determined based of the results of XRD analysis in concert with examination of thin sections and hand samples. The percentage of glass present in all samples was estimated based upon deviations in background levels of the XRD patterns from a straight line, particularly between approximately 10 and 40 ${ }^{\circ} 2 \theta$ (Figure 8), coupled with examination of thin sections and hand samples to confirm the XRD results.
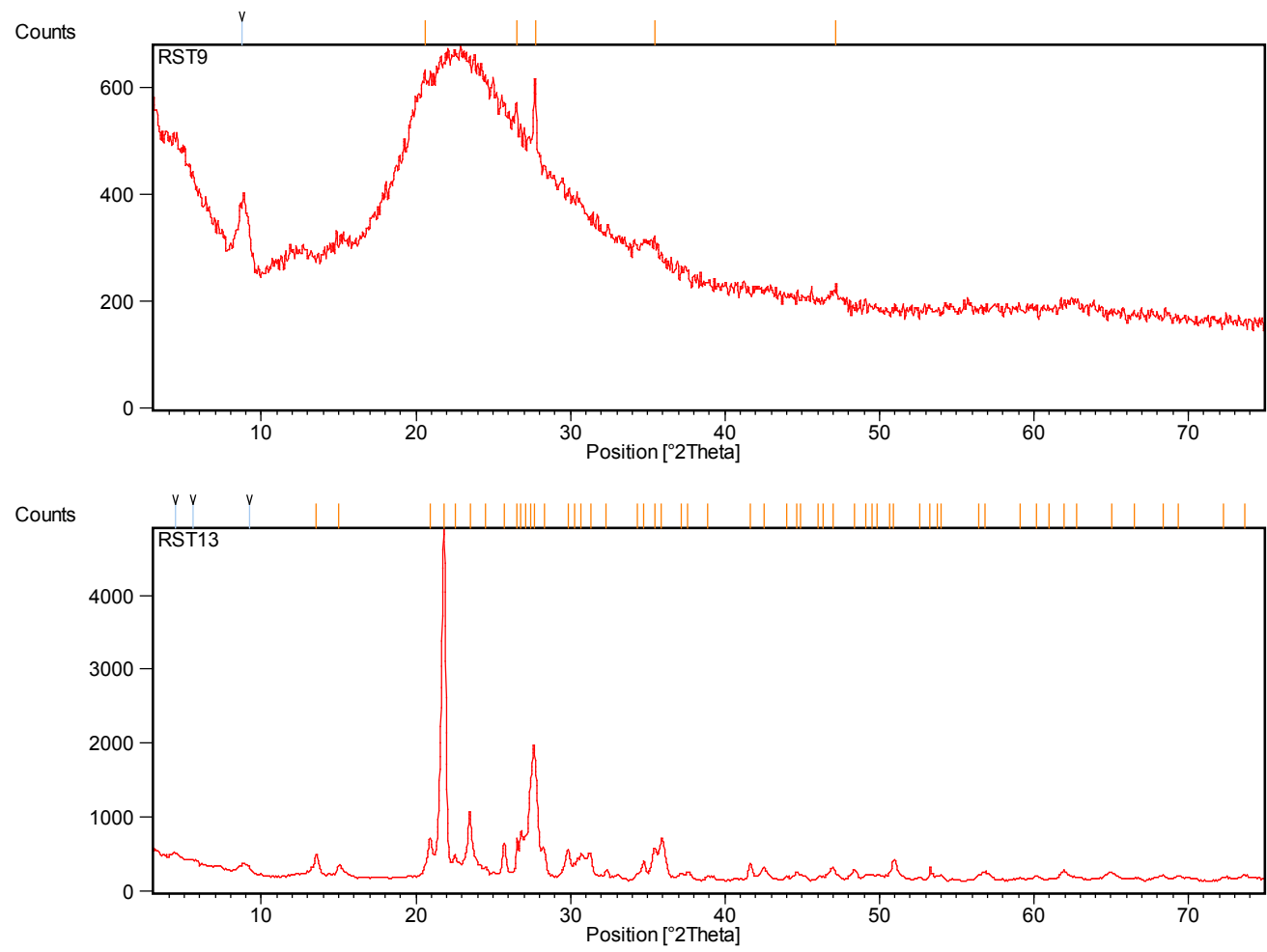

Figure 8. XRD patterns for unweathered glassy (RST9) and devitrified samples (RST13). Glass content of samples was estimated based upon the deviation of background levels from a straight line between approximately 10 and $40^{\circ} 2 \theta$, coupled with visual examination of hand samples and thin sections. 
The majority of minerals identified in XRD patterns fell into four categories; feldspars, low pressure silica polymorphs, zeolites, and clay minerals (Table 3). Sanidine was the most common feldspar identified followed by albite, but anorthoclase, microcline, and labradorite were all identified in at least one sample. In many cases multiple feldspars were acceptable matches to the XRD patterns, and especially in devitrified samples with very small crystals, the specific alkali feldspar present could not be identified in thin section. In these cases, the feldspar that best matched the XRD pattern was selected.

Quartz, cristobalite, and tridymite were all identified in multiple samples, and many samples contained more than one silica phase. Quartz can occur as a phenocryst in glassy samples, while cristobalite and tridymite occur exclusively as devitrification products. The presence of multiple silica polymorphs in a single sample may indicate either devitrification of a glassy rock that contains quartz phenocrysts, or multiple phases forming as the temperature decreases during the devitrification process.

Clays and zeolites are both common alteration products found in weathered tuffs. The most common clays identified in XRD patterns were smectites, particularly saponite and montmorillonite. Illite, kaolinite, and sepiolite were also identified in multiple samples. The clay mineral tosudite, a 1:1 interstratified chlorite-smectite mineral known to be a product of alteration of tuffs and tuffaceous sediments (Shimoda, 1969), was identified in a number of tuffaceous sediment samples. The zeolite minerals most commonly identified were heulandite, mordenite, and clinoptilolite. 
Table 3. Major mineralogy and categorization of tuff samples, based on semi-quantitative XRD results, optical microscopy, and examination of hand samples. Percentages of amorphous material (glass) was not included in semi-quantitative XRD results, and was instead estimated solely from examination of XRD patterns, thin sections, hand samples

\begin{tabular}{|c|c|c|c|c|c|}
\hline $\begin{array}{l}\text { Sample } \\
\text { ID }\end{array}$ & $\begin{array}{c}\text { Primary Minerals / } \\
\text { Glass }(>\mathbf{3 0} \%)\end{array}$ & $\begin{array}{c}\text { Secondary } \\
\text { Minerals (30\% - } \\
10 \%)\end{array}$ & $\begin{array}{c}\text { Minor Minerals } \\
(<\mathbf{1 0} \%)\end{array}$ & $\begin{array}{c}\text { Devitrification } \\
\text { Classification }\end{array}$ & $\begin{array}{c}\text { Weathering } \\
\text { Classification }\end{array}$ \\
\hline $\mathrm{BC} 1$ & $\begin{array}{l}\text { Saponite } \\
\text { Anorthoclase }\end{array}$ & & & Glassy & Weathered \\
\hline $\mathrm{BC} 2$ & Cristobalite & $\begin{array}{l}\text { Tridymite } \\
\text { Kaolinite }\end{array}$ & Sanidine & Sediment & Sediment \\
\hline $\mathrm{BC} 3$ & Montmorillonite & Sanidine & Quartz & Sediment & Sediment \\
\hline DC1 & $\begin{array}{l}\text { Glass } \\
\text { Anorthoclase }\end{array}$ & $\begin{array}{l}\text { Quartz } \\
\text { Montmorillonite }\end{array}$ & Sepiolite & Glassy & Unweathered \\
\hline DC4 & Glass & Labradorite & & Glassy & Unweathered \\
\hline DC5 & $\begin{array}{l}\text { Cristobalite } \\
\text { Sanidine } \\
\text { Albite }\end{array}$ & & & Devitrified & Unweathered \\
\hline DC6 & $\begin{array}{l}\text { Cristobalite } \\
\text { Sanidine }\end{array}$ & Albite & Tridymite & Devitrified & Unweathered \\
\hline DC7 & Cristobalite & $\begin{array}{l}\text { Sanidine } \\
\text { Albite }\end{array}$ & Tridymite & Devitrified & Unweathered \\
\hline DC8 & $\begin{array}{l}\text { Glass } \\
\text { Saponite } \\
\text { Labradorite }\end{array}$ & & & Glassy & Weathered \\
\hline DC9 & $\begin{array}{l}\text { Sanidine } \\
\text { Tridymite }\end{array}$ & & Albite & Devitrified & Unweathered \\
\hline DS1 & Saponite & Albite & $\begin{array}{l}\text { Tridymite } \\
\text { Cristobalite } \\
\text { Quartz }\end{array}$ & Sediment & Sediment \\
\hline DS2 & Tosudite & $\begin{array}{l}\text { Kaolinite } \\
\text { Tridymite } \\
\text { Cristobalite }\end{array}$ & $\begin{array}{l}\text { Calcite } \\
\text { Quartz }\end{array}$ & Sediment & Sediment \\
\hline DS3 & $\begin{array}{l}\text { Tridymite } \\
\text { Cristobalite }\end{array}$ & & Kaolinite & Sediment & Sediment \\
\hline DT1 & Albite & $\begin{array}{l}\text { Cristobalite } \\
\text { Glass }\end{array}$ & & Glassy & Unweathered \\
\hline DT2 & $\begin{array}{l}\text { Glass } \\
\text { Albite }\end{array}$ & & Illite & Glassy & Unweathered \\
\hline DT3 & $\begin{array}{l}\text { Sanidine } \\
\text { Cristobalite }\end{array}$ & & $\begin{array}{l}\text { Pigeonite } \\
\text { Quartz } \\
\text { Cordierite }\end{array}$ & Devitrified & Unweathered \\
\hline DVC1 & Sanidine & $\begin{array}{l}\text { Cristobalite } \\
\text { Quartz }\end{array}$ & & Devitrified & Unweathered \\
\hline DVC2 & Sanidine & $\begin{array}{l}\text { Quartz } \\
\text { Saponite }\end{array}$ & Cristobalite & Devitrified & Weathered \\
\hline DVC4 & Glass & $\begin{array}{l}\text { Albite } \\
\text { Quartz }\end{array}$ & & Glassy & Unweathered \\
\hline FD1 & Heulandite & $\begin{array}{l}\text { Quartz } \\
\text { Mordenite }\end{array}$ & Montmorillonite & Glassy & Weathered \\
\hline
\end{tabular}




\begin{tabular}{|c|c|c|c|c|c|}
\hline $\begin{array}{l}\text { Sample } \\
\text { ID }\end{array}$ & $\begin{array}{l}\text { Primary Minerals / } \\
\text { Glass }(>\mathbf{3 0} \%)\end{array}$ & $\begin{array}{c}\text { Secondary } \\
\text { Minerals (30\% - } \\
10 \%)\end{array}$ & $\begin{array}{c}\text { Minor Minerals } \\
(<\mathbf{1 0 \%})\end{array}$ & $\begin{array}{l}\text { Devitrification } \\
\text { Classification }\end{array}$ & $\begin{array}{c}\text { Weathering } \\
\text { Classification }\end{array}$ \\
\hline FD2 & Heulandite & $\begin{array}{l}\text { Mordenite } \\
\text { Quartz }\end{array}$ & Montmorillonite & Glassy & Weathered \\
\hline FD3 & Heulandite & $\begin{array}{l}\text { Mordenite } \\
\text { Quartz }\end{array}$ & Montmorillonite & Glassy & Weathered \\
\hline FD4 & Heulandite & $\begin{array}{l}\text { Mordenite } \\
\text { Quartz }\end{array}$ & & Glassy & Weathered \\
\hline LB1 & Illite & $\begin{array}{l}\text { Quartz } \\
\text { Sanidine }\end{array}$ & $\begin{array}{l}\text { Kaolinite } \\
\text { Zeolite ZSM-11 }\end{array}$ & Glassy & Weathered \\
\hline LG1 & $\begin{array}{l}\text { Heulandite } \\
\text { Mordenite }\end{array}$ & & Quartz & Glassy & Weathered \\
\hline LG2 & Sanidine & Quartz & $\begin{array}{l}\text { Cristobalite } \\
\text { Pyrite }\end{array}$ & Devitrified & Weathered \\
\hline LG3 & $\begin{array}{l}\text { Quartz } \\
\text { Microcline }\end{array}$ & & $\begin{array}{l}\text { Palygorskite } \\
\text { Cristobalite }\end{array}$ & Devitrified & Weathered \\
\hline LG4 & Quartz & Albite & Calcite & Devitrified & Weathered \\
\hline LST1 & $\begin{array}{l}\text { Clinoptilolite } \\
\text { Montomorillonite }\end{array}$ & $\begin{array}{l}\text { Albite } \\
\text { Glass }\end{array}$ & Calcite & Glassy & Weathered \\
\hline MA1 & $\begin{array}{l}\text { Saponite } \\
\text { Sanidine }\end{array}$ & $\begin{array}{l}\text { Cristobalite } \\
\text { Illite }\end{array}$ & & Devitrified & Weathered \\
\hline MK1 & Albite & $\begin{array}{l}\text { Quartz } \\
\text { Montmorillonite }\end{array}$ & & Devitrified & Unweathered \\
\hline MK2 & $\begin{array}{l}\text { Albite } \\
\text { Quartz }\end{array}$ & & Montmorillonite & Devitrified & Unweathered \\
\hline MTA1 & $\begin{array}{l}\text { Glass } \\
\text { Anorthoclase }\end{array}$ & & Illite & Glassy & Weathered \\
\hline PG1 & Quartz & $\begin{array}{l}\text { Sanidine } \\
\text { Illite } \\
\text { Cristobalite }\end{array}$ & & Devitrified & Weathered \\
\hline PG2 & $\begin{array}{l}\text { Cristobalite } \\
\text { Sanidine }\end{array}$ & Albite & & Devitrified & Unweathered \\
\hline PG3 & Glass & & $\begin{array}{l}\text { Sanidine } \\
\text { Saponite }\end{array}$ & Glassy & Unweathered \\
\hline RST1 & Glass & & $\begin{array}{l}\text { Montmorillonite } \\
\text { Quartz }\end{array}$ & Glassy & Unweathered \\
\hline RST3 & Glass & & & Glassy & Unweathered \\
\hline RST4 & $\begin{array}{l}\text { Sanidine } \\
\text { Cristobalite }\end{array}$ & & Biotite & Devitrified & Unweathered \\
\hline RST5 & Sanidine & $\begin{array}{l}\text { Tridymite } \\
\text { Quartz } \\
\text { Cristobalite } \\
\text { Albite }\end{array}$ & & Devitrified & Unweathered \\
\hline RST6 & Glass & $\begin{array}{l}\text { Sanidine } \\
\text { Quartz }\end{array}$ & & Glassy & Unweathered \\
\hline RST7 & $\begin{array}{l}\text { Sanidine } \\
\text { Cristobalite }\end{array}$ & & & Devitrified & Unweathered \\
\hline
\end{tabular}




\begin{tabular}{|c|c|c|c|c|c|}
\hline $\begin{array}{l}\text { Sample } \\
\text { ID }\end{array}$ & $\begin{array}{c}\text { Primary Minerals / } \\
\text { Glass }(>\mathbf{3 0 \%})\end{array}$ & $\begin{array}{c}\text { Secondary } \\
\text { Minerals (30\% - } \\
10 \%)\end{array}$ & 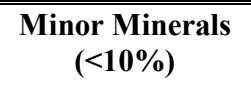 & $\begin{array}{c}\text { Devitrification } \\
\text { Classification }\end{array}$ & $\begin{array}{c}\text { Weathering } \\
\text { Classification }\end{array}$ \\
\hline RST8 & Glass & & $\begin{array}{l}\text { Sanidine } \\
\text { Quartz }\end{array}$ & Glassy & Unweathered \\
\hline RST9 & Glass & & $\begin{array}{l}\text { Albite } \\
\text { Quartz }\end{array}$ & Glassy & Unweathered \\
\hline RST10 & Glass & & $\begin{array}{l}\text { Albite } \\
\text { Quartz }\end{array}$ & Glassy & Unweathered \\
\hline RST11 & $\begin{array}{l}\text { Sanidine } \\
\text { Tridymite }\end{array}$ & Cristobalite & Helvite & Devitrified & Unweathered \\
\hline RST13 & $\begin{array}{l}\text { Sanidine } \\
\text { Cristobalite }\end{array}$ & & & Devitrified & Unweathered \\
\hline RU1 & $\begin{array}{l}\text { Clinoptilolite } \\
\text { Montmorillonite }\end{array}$ & Glass & Quartz & Glassy & Weathered \\
\hline SLNM & $\begin{array}{l}\text { Albite } \\
\text { Montmorillonite }\end{array}$ & & $\begin{array}{l}\text { Illite } \\
\text { Cristobalite } \\
\text { Quartz }\end{array}$ & Devitrified & Weathered \\
\hline SLRC & Illite & $\begin{array}{l}\text { Saponite } \\
\text { Glass }\end{array}$ & $\begin{array}{l}\text { Anorthite } \\
\text { Albite }\end{array}$ & Glassy & Weathered \\
\hline SR1 & Clinoptilolite & $\begin{array}{l}\text { Quartz } \\
\text { Albite } \\
\text { Mordenite }\end{array}$ & & Glassy & Weathered \\
\hline SR2 & Quartz & $\begin{array}{l}\text { Albite } \\
\text { Orthoclase }\end{array}$ & & Devitrified & Unweathered \\
\hline TS1 & Tosudite & Sanidine & $\begin{array}{l}\text { Cristobalite } \\
\text { Quartz }\end{array}$ & Sediment & Sediment \\
\hline TS3 & Tosudite & & Cristobalite & Sediment & Sediment \\
\hline TS4 & $\begin{array}{l}\text { Tosudite } \\
\text { Montmorillonite }\end{array}$ & & & Sediment & Sediment \\
\hline TSD1 & $\begin{array}{l}\text { Anorthite } \\
\text { Tosudite }\end{array}$ & & & Sediment & Sediment \\
\hline TSD2 & $\begin{array}{l}\text { Albite } \\
\text { Tosudite }\end{array}$ & & Quartz & Sediment & Sediment \\
\hline TW1 & Albite & Quartz & $\begin{array}{l}\text { Cristobalite } \\
\text { Illite } \\
\text { Montmorillonite }\end{array}$ & Devitrified & Unweathered \\
\hline TW2 & Heulandite & $\begin{array}{l}\text { Albite } \\
\text { Stilbite }\end{array}$ & $\begin{array}{l}\text { Illite } \\
\text { Chlorite } \\
\text { Quartz }\end{array}$ & Sediment & Sediment \\
\hline WU1 & Anorthoclase & $\begin{array}{l}\text { Cristobalite } \\
\text { Quartz }\end{array}$ & & Devitrified & Unweathered \\
\hline
\end{tabular}




\section{Sample Categorization}

Major mineralogy and bulk chemical analysis were used to categorize each sample. Each sample was placed into a category for two different compositional variables: degree of devitrification (devitrified or glassy), and degree of weathering (unweathered or weathered) (Table 3).

Samples were categorized as devitrified or glassy based on XRD results and optical microscopy. Samples containing glass were categorized as glassy, while samples lacking glass and containing cristobalite, tridymite, or quartz were categorized as devitrified. For highly weathered samples containing neither glass nor cristobalite, alteration products were used to distinguish between the categories. Both clays and zeolites are common alteration products found in tuffs, with zeolites forming specifically from the alteration of glass (Vaniman, 2006). Samples containing both clays and zeolites were categorized as originally glassy, and samples containing clays but lacking zeolites were categorized as originally devitrified. Although weathered samples were given a categorization of either glassy or devitrified, they were mineralogically distinct enough that they were excluded from the Devitrified and Glassy categories for the purposes of data analysis, and all subsequent references to those categories include only unweathered samples.

The degree of weathering was determined using the semi-quantitative XRD results, and was based on the proportion of alteration products (clays + zeolites) in each sample. When compared to observation of both hand samples and thin sections the 
proportions of clays and zeolites determined via AutoQuan software appeared to greatly exceed the actual amount of alteration products present, and the categories defined reflect that. Therefore, samples for which the estimated content of clays + zeolites was $\leq 30 \%$ were categorized as "Unweathered" while samples with estimated clay + zeolite contents $\geq 31 \%$ were categorized as "Weathered." A few exceptions to these categories were made, particularly for highly glassy rocks. Since the amount of glass present was not included in the semi-quantitative XRD results, samples composed primarily of glass produced results that contained very high percentages $(>90 \%)$ of clays, despite the rocks themselves obviously not being clay-rich. In these cases, the weathering categorization was determined primarily based on observation of hand samples, and thin sections if available.

Categorizations were compared to major element chemistry, particularly Loss on Ignition (LOI) values (Table 8). Samples classified as Unweathered that contained LOI values higher than $5 \%$ were re-examined, since high LOI values are a potential indicator of the presence of hydrated alteration products. Two samples with semi-quantitative clay percentages near the classification limit of $30 \%$ were reclassified as Weathered based on LOI values exceeding $5 \%$. 


\section{RESULTS: BULK ROCK CHEMISTRIES}

\section{QA/QC Results}

\section{For samples digested via EPA Method 3052 and analyzed via ICP-OES}

recoveries of As from certified reference standards ranged from $82.7 \%$ to $94.6 \%$, but were inconsistent for a number of other trace elements (Table 4).

Table 4. Recoveries for certified reference materials analyzed via ICP-OES. Arsenic recoveries ranged from $82.7 \%$ to $94.6 \%$. S had recovery percentages within $\pm 5 \%$, but other elements were more variable.

\begin{tabular}{lcccccc}
\hline \hline & \multicolumn{3}{c}{ JR-1 } & \multicolumn{3}{c}{ SRM 1633a } \\
\hline \multirow{2}{*}{ Element } & $\begin{array}{c}\text { Measured } \\
\text { Value } \\
(\mathrm{ppm})\end{array}$ & $\begin{array}{c}\text { Certified } \\
\text { Value } \\
(\mathrm{ppm})\end{array}$ & $\begin{array}{c}\text { Recovery } \\
\%\end{array}$ & $\begin{array}{c}\text { Measured } \\
\text { Value } \\
(\mathrm{ppm})\end{array}$ & $\begin{array}{c}\text { Certified } \\
\text { Value } \\
(\mathrm{ppm})\end{array}$ & $\begin{array}{c}\text { Recovery } \\
\%\end{array}$ \\
\hline $\mathrm{As}$ & 13.48 & 16.30 & 82.7 & 137.13 & 145.00 & 94.6 \\
$\mathrm{Be}^{*}$ & 2.64 & 3.34 & 78.9 & 11.72 & 12.00 & 97.7 \\
$\mathrm{Mo}^{*}$ & 2.57 & 3.25 & 79.1 & 24.93 & 29.00 & 86.0 \\
$\mathrm{Sb}$ & 1.64 & 1.19 & 138.2 & 11.42 & 6.80 & 167.9 \\
$\mathrm{Sm}$ & $<0.70$ & 6.03 & $<11$ & $<0.70$ & $\mathrm{NA}$ & \\
\hline
\end{tabular}

* Values for SRM 1633a are not certified values.

Three samples were prepared and analyzed in duplicate. Relative percent differences (RPDs) between arsenic concentrations in the duplicate samples ranged from 1.4 to $12 \%$ (Table 5$)$.

Table 5. Relative percent differences for duplicate samples analyzed via EPA Method 3052.

\begin{tabular}{lccccccccc}
\hline \hline Element & $\begin{array}{c}\text { MA1a } \\
(\mu \mathrm{g} / \mathrm{L})\end{array}$ & $\begin{array}{c}\text { MA1b } \\
(\mu \mathrm{g} / \mathrm{L})\end{array}$ & $\begin{array}{c}\text { RPD } \\
(\%)\end{array}$ & $\begin{array}{c}\text { RST4a } \\
(\mu \mathrm{g} / \mathrm{L})\end{array}$ & $\begin{array}{c}\text { RST4b } \\
(\mu \mathrm{g} / \mathrm{L})\end{array}$ & $\begin{array}{c}\text { RPD } \\
(\%)\end{array}$ & $\begin{array}{c}\text { MK2a } \\
(\mu \mathrm{g} / \mathrm{L})\end{array}$ & $\begin{array}{c}\text { MK2b } \\
(\mu \mathrm{g} / \mathrm{L})\end{array}$ & $\begin{array}{c}\text { RPD } \\
(\%)\end{array}$ \\
\hline $\mathrm{As}$ & 41.69 & 36.99 & 11.95 & 19.70 & 18.19 & 7.96 & 46.17 & 45.53 & 1.38 \\
$\mathrm{Be}$ & 13.67 & 14.05 & -2.74 & 12.58 & 12.28 & 2.42 & 6.04 & 6.02 & 0.25 \\
$\mathrm{Mo}$ & 3.83 & 3.31 & 14.41 & 6.84 & 6.93 & -1.32 & 1.98 & 2.58 & -26.03 \\
$\mathrm{Sm}$ & 19.96 & 15.74 & 23.59 & 18.38 & 18.29 & 0.50 & ND & ND & NA \\
\hline
\end{tabular}


Check standards were run during ICP-OES analysis as a check on instrumental accuracy. All elements reported produced values that were within $\pm 5 \%$ of the standard value (Table 6).

Table 6. Recoveries from Method Blank and check standards analyzed via ICP-OES. Check standard QC1 had a concentration of $100 \mathrm{ug} / \mathrm{L}$ for all elements except $\mathrm{Sb}$ and Sn, and check standard QC2 had a concentration of $50 \mathrm{ug} / \mathrm{L}$ for all elements except $\mathrm{Sb}$ and $\mathrm{Sn}$.

\begin{tabular}{lccccccc}
\hline \hline Element & $\begin{array}{c}\text { QC Blank1 } \\
(\mu \mathrm{g} / \mathrm{L})\end{array}$ & $\begin{array}{c}\text { QC1a } \\
(\mu \mathrm{g} / \mathrm{L})\end{array}$ & $\begin{array}{c}\text { QC2a } \\
(\mu \mathrm{g} / \mathrm{L})\end{array}$ & $\begin{array}{c}\text { QC Blank2 } \\
(\mu \mathrm{g} / \mathrm{L})\end{array}$ & $\begin{array}{c}\text { QC1b } \\
(\mu \mathrm{g} / \mathrm{L})\end{array}$ & $\begin{array}{c}\text { QC2b } \\
(\mu \mathrm{g} / \mathrm{L})\end{array}$ & $\begin{array}{c}\text { Method Blank } \\
(\mu \mathrm{g} / \mathrm{L})\end{array}$ \\
\hline $\mathrm{As}$ & $\mathrm{ND}$ & 103.3 & 49.6 & $\mathrm{ND}$ & 103.9 & 50.2 & $\mathrm{ND}$ \\
$\mathrm{Be}$ & $\mathrm{ND}$ & 98.6 & 48.6 & $\mathrm{ND}$ & 95.4 & 47.1 & $\mathrm{ND}$ \\
$\mathrm{Mo}$ & $\mathrm{ND}$ & 92.5 & 46.9 & $\mathrm{ND}$ & 91.0 & 45.1 & $\mathrm{ND}$ \\
$\mathrm{Sm}$ & $\mathrm{ND}$ & 100.6 & 54.7 & $\mathrm{ND}$ & 95.8 & 49.6 & $\mathrm{ND}$ \\
\hline
\end{tabular}

One sample, DT3, was analyzed at both the WSU Geoanalytical Lab and Activation Laboratories. The RPDs for the two analyses reached a maximum of $35 \%$ for major elements $\left(\mathrm{P}_{2} \mathrm{O}_{5}\right)$, and $106 \%$ for trace elements $(\mathrm{Cu})$ (Table 7). 
Table 7. Relative percent differences for sample DT3, analyzed at the WSU Geoanalytical Lab (WSU) and Activation Laboratories (AL). Major elements are reported in weight percent, and trace elements are reported in $\mathrm{mg} / \mathrm{kg}$.

\begin{tabular}{|c|c|c|c|}
\hline Element & DT3 WSU & DT3 AL & RPD \\
\hline $\mathrm{SiO} 2$ & 75.00 & 75.21 & -0.28 \\
\hline $\mathrm{A} 12 \mathrm{O} 3$ & 12.19 & 12.45 & -2.11 \\
\hline $\mathrm{FeO}$ & 1.13 & 1.25 & -10.26 \\
\hline $\mathrm{MnO}$ & 0.010 & 0.011 & -9.52 \\
\hline $\mathrm{MgO}$ & 0.29 & 0.35 & -18.75 \\
\hline $\mathrm{CaO}$ & 0.46 & 0.49 & -6.32 \\
\hline $\mathrm{Na} 2 \mathrm{O}$ & 2.97 & 3.04 & -2.33 \\
\hline $\mathrm{K} 2 \mathrm{O}$ & 4.61 & 4.62 & -0.22 \\
\hline $\mathrm{TiO} 2$ & 0.07 & 0.08 & -10.53 \\
\hline $\mathrm{P} 2 \mathrm{O} 5$ & 0.014 & 0.02 & -35.29 \\
\hline $\mathrm{Ni}^{1}$ & 2 & 3.00 & -30.77 \\
\hline $\mathrm{Cr}^{2}$ & 2.80 & $<2$ & NA \\
\hline $\mathrm{V}^{1}$ & 6.00 & 5.00 & 18.18 \\
\hline $\mathrm{Ba}^{2}$ & 602.80 & 460.00 & 26.87 \\
\hline $\mathrm{Rb}^{2}$ & 103.90 & 95.00 & 8.95 \\
\hline $\mathrm{Sr}^{1}$ & 31.40 & 35.00 & -10.84 \\
\hline $\mathrm{Y}^{1}$ & 18.50 & 16.00 & 14.49 \\
\hline $\mathrm{Cu}^{1}$ & 3.70 & 12.00 & -105.73 \\
\hline $\mathrm{Zn}^{1}$ & 23.20 & 31.00 & -28.78 \\
\hline $\mathrm{Pb}^{1}$ & 16.30 & 14.00 & 15.18 \\
\hline $\mathrm{La}^{2}$ & 33.00 & 32.90 & 0.30 \\
\hline $\mathrm{Ce}^{2}$ & 57.20 & 55.00 & 3.92 \\
\hline $\mathrm{Th}^{2}$ & 11.20 & 8.30 & 29.74 \\
\hline $\mathrm{Nd}^{2}$ & 20.20 & 22.00 & -8.53 \\
\hline
\end{tabular}

${ }^{1}$ Analyzed via ICP-MS at Activation Laboratories, and XRF at WSU.

${ }^{2}$ Analyzed via INAA at Activation Laboratories and XRF at WSU.

Bulk Chemistry

Major element chemistry for all samples is provided in Table 8 . Among tuff samples, $\mathrm{SiO}_{2}$ values ranged from a low of $52.8 \%$ in a weathered sample to a high of $81.8 \%$ in a devitrified sample. Total weight percents including Loss on Ignition (LOI) values ranged from a low of $97.7 \%$ to a high of $100.2 \%$. 


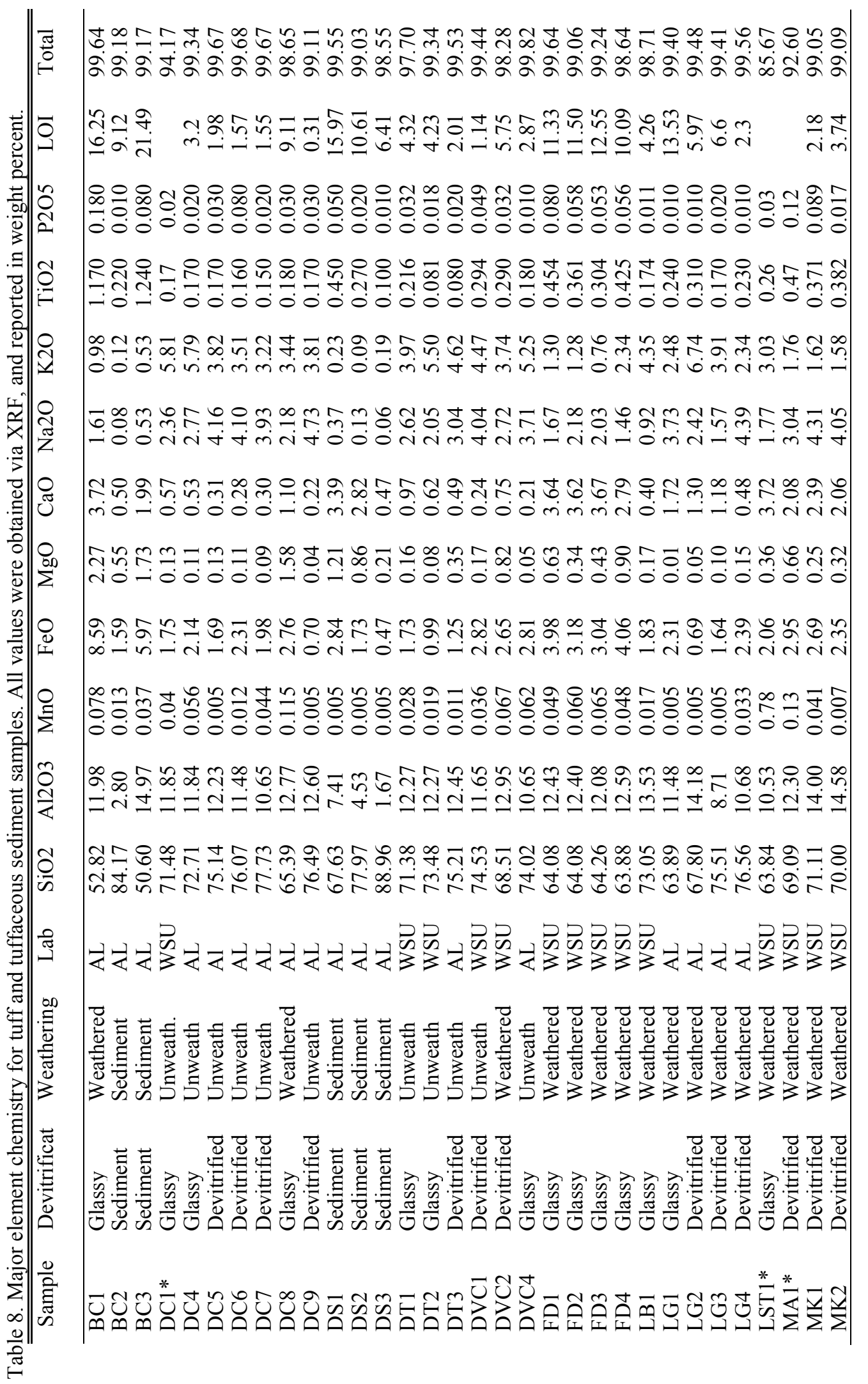




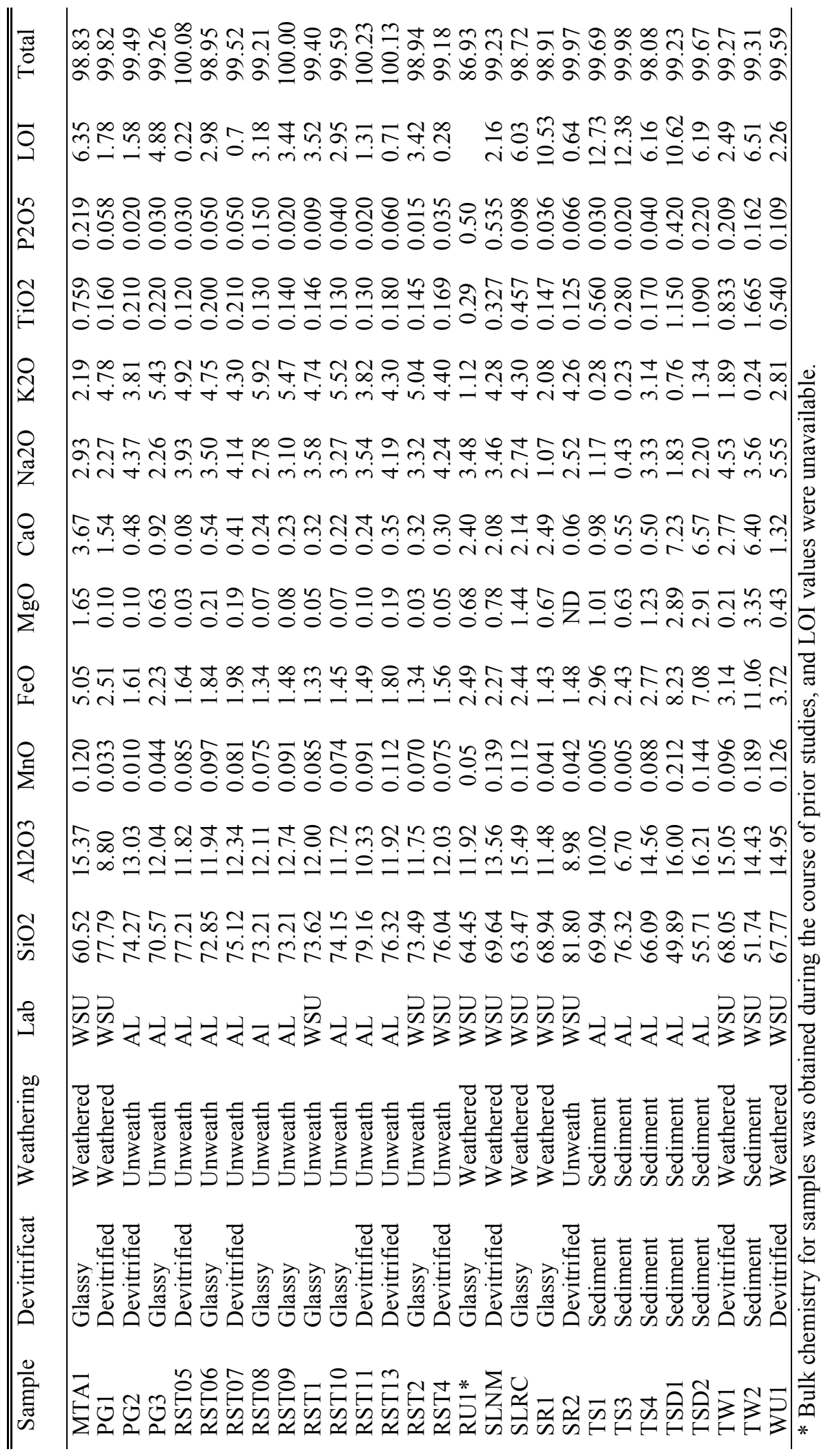


The majority of samples had alumina/alkali ratios $>1$, which is likely a result of loss of alkalis during alteration, rather than being representative of original magmatic composition. There was no correlation between alumina/alkali ratios and arsenic in any category of ash-flow tuffs (Figure 9).

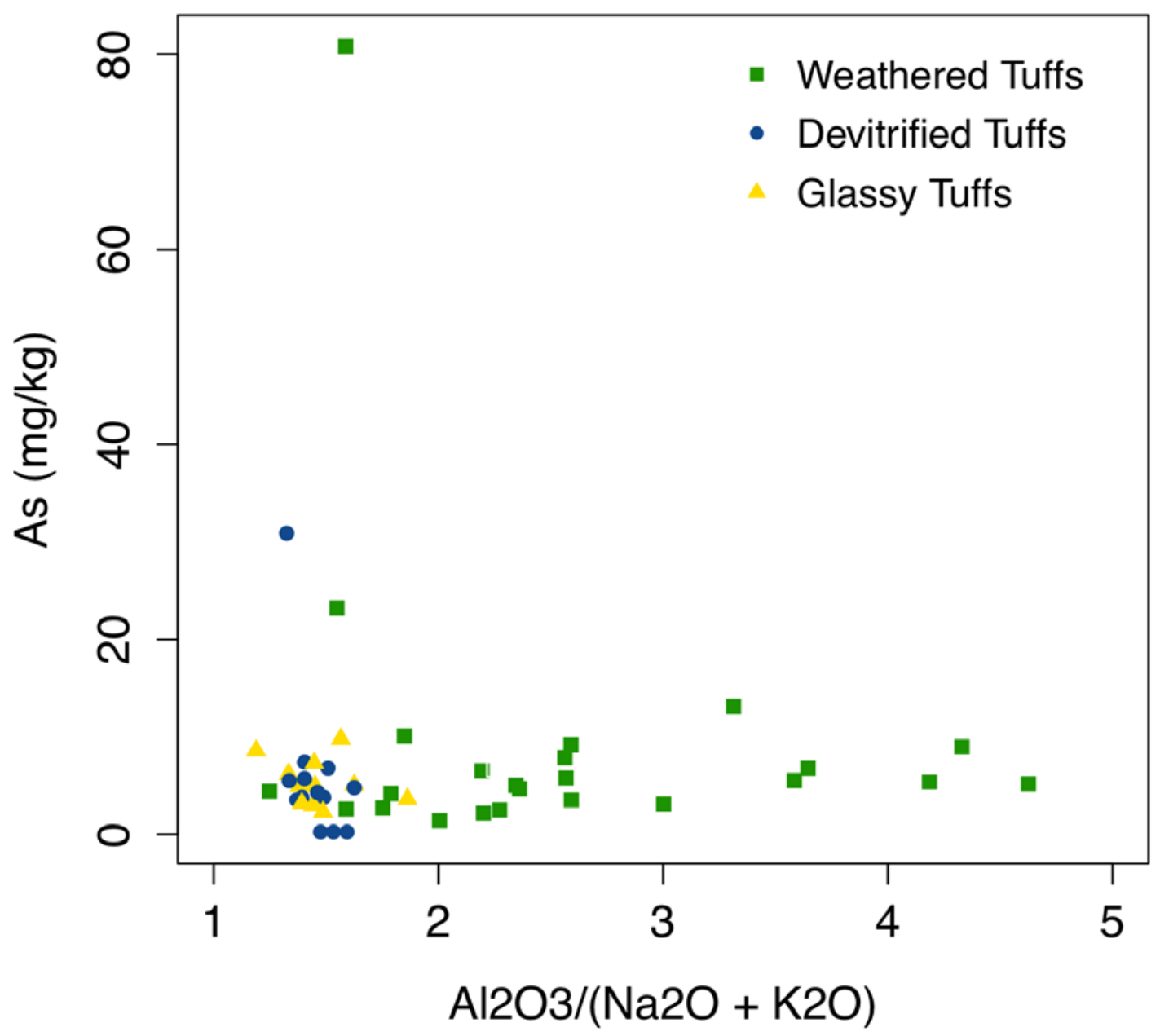

Figure 9. Arsenic as a function of alumina/alkali ratios of tuff samples. The majority of the samples have ratios $>1$, and there is no correlation between alumina/alkali ratios and arsenic concentrations. 
Trace element concentrations of tuff and tuffaceous sediment samples are located in Table 9. For samples analyzed via INAA at Activation Laboratories, five samples produced arsenic levels below the MDL of $0.5 \mathrm{mg} \mathrm{kg}^{-1}$. For samples analyzed via ICPOES, only one sample was below the MDL of $1.2 \mathrm{mg} \mathrm{kg}^{-1}$. 


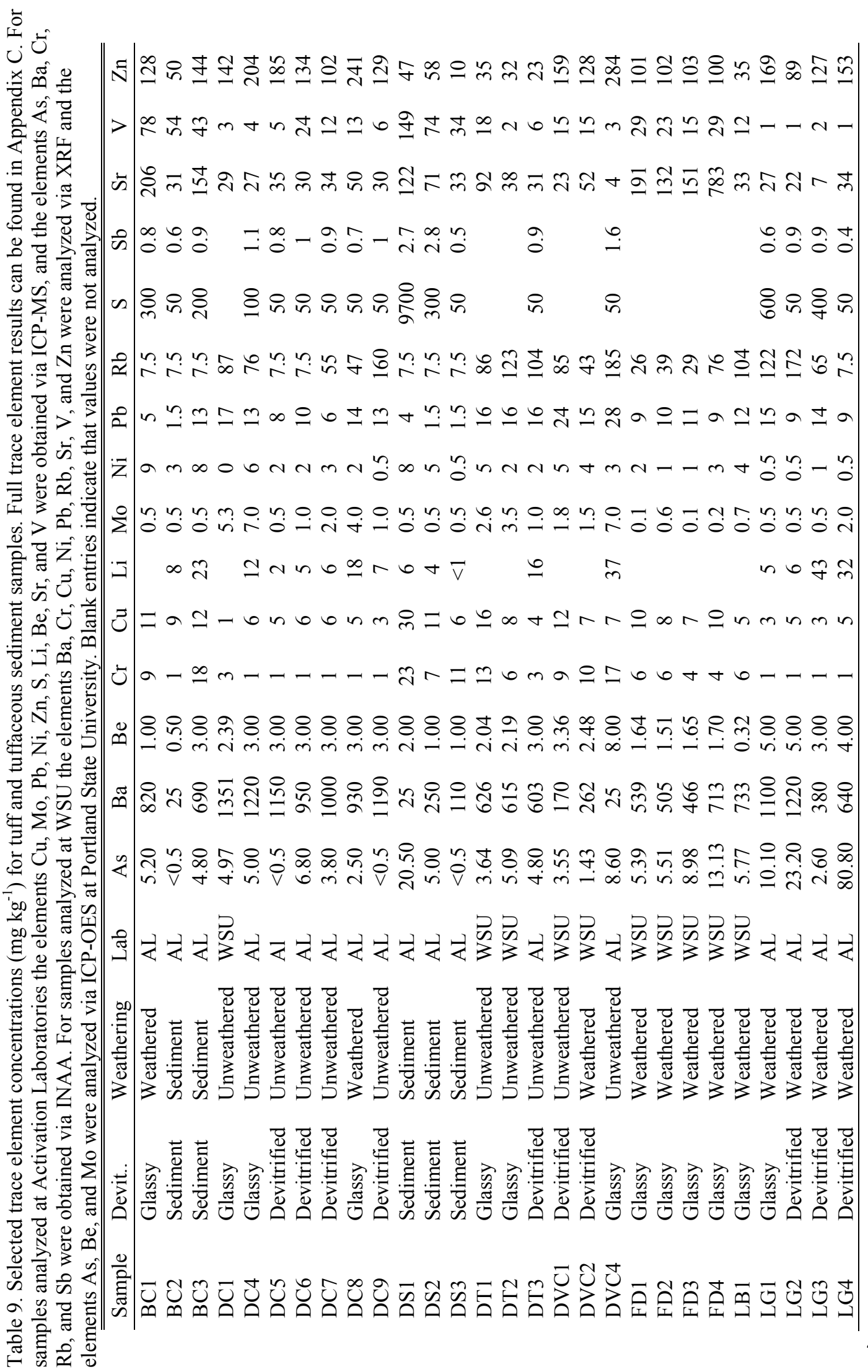


Total Arsenic Concentrations

The 49 tuff samples have a mean arsenic content of $7.5 \mathrm{mg} \mathrm{kg}^{-1}$, a geometric mean arsenic content of $4.8 \mathrm{mg} \mathrm{kg}^{-1}$, a median arsenic content of $5.2 \mathrm{mg} \mathrm{kg}^{-1}$, and a maximum arsenic content of $81 \mathrm{mg} \mathrm{kg}^{-1}$ (Table 10). The mean and median values are 2.8 $-4.4 \mathrm{x}$ the average crustal abundance of arsenic of $1.7 \mathrm{mg} \mathrm{kg}^{-1}$ (Wedepohl, 1995), and consistent with previously reported mean values for both felsic volcanic rocks $(3.5 \mathrm{mg}$ $\mathrm{kg}^{-1}$ ) and volcanic glasses (5.9 $\mathrm{mg} \mathrm{kg}^{-1}$ ) (Onishi and Sandell, 1955; Wedepohl, 1995).

Table 10. Total arsenic contents of tuffs and tuffaceous sediments. Numbers in parentheses indicate values that include samples identified as outliers.

\begin{tabular}{cccccc}
\hline \hline & $\begin{array}{c}\text { Mean } \\
(\mathrm{mg} / \mathrm{kg})\end{array}$ & $\begin{array}{c}\text { Geometric } \\
\text { Mean } \\
(\mathrm{mg} / \mathrm{kg})\end{array}$ & $\begin{array}{c}\text { Median } \\
(\mathrm{mg} / \mathrm{kg})\end{array}$ & $\begin{array}{c}\text { Standard } \\
\text { Deviation } \\
(\mathrm{mg} / \mathrm{kg})\end{array}$ & $\begin{array}{c}\text { Median } \\
\text { Absolute } \\
\text { Deviation } \\
(\mathrm{mg} / \mathrm{kg})\end{array}$ \\
\hline All Tuffs $\mathrm{n}=45(49)$ & $5.2(7.5)$ & $4.2(4.8)$ & $5.0(5.2)$ & $3.4(11)$ & $2.5(2.8)$ \\
Weathered Tuffs $\mathrm{n}=18(20)$ & $6.0(10.0)$ & $5.2(6.2)$ & $6.0(5.6)$ & $3.3(16)$ & $3.2(3.8)$ \\
Unweathered Tuffs $\mathrm{n}=28(29)$ & $4.7(5.7)$ & $3.4(3.7)$ & $4.6(4.9)$ & $2.6(5.8)$ & $1.9(2.2)$ \\
Devitrified $\mathrm{n}=15(16)$ & $4.3(9.6)$ & $2.4(2.9)$ & $4.3(4.7)$ & $2.6(17)$ & $2.1(2.3)$ \\
Glassy $\mathrm{n}=13$ & 6.1 & 4.9 & 6.0 & 3.1 & 2.8 \\
Tuffaceous Sediments $\mathrm{n}=10(11)$ & $4.5(6.3)$ & $2.0(2.5)$ & $4.3(5.6)$ & $4.9(7.7)$ & $4.8(7.3)$ \\
\hline
\end{tabular}

Arsenic values were normalized to $100 \%$ on an anhydrous basis. Four samples (LG4, LG2, SR2, and DS1) were identified as outliers using Grubbs test for outliers. Arsenic concentrations in tuffs were positively skewed, and appeared to be lognormally distributed, so the data were log transformed, and Shapiro-Wilk tests of normality were performed on arsenic concentrations for tuffs, tuffaceous sediments, and the different categories of tuff samples. At a significance level of $\alpha=0.05$, unweathered tuffs, glassy tuffs, and tuffaceous sediments were still found to be non-normally distributed after log 
transformation and removal of outliers (Table 11). Details of statistical methods can be found in Appendix B.

Table 11. Test statistics (W) and p-values for Shapiro-Wilk tests of normality.

\begin{tabular}{rcc}
\hline \hline & W & p-Value \\
\hline All Tuffs $\mathrm{n}=45$ & 0.782 & $7.93 \mathrm{E}-07$ \\
Weathered Tuffs $\mathrm{n}=18$ & 0.985 & 0.974 \\
Unweathered Tuffs $\mathrm{n}=28$ & 0.711 & $1.41 \mathrm{E}-05$ \\
Devitrified $\mathrm{n}=16$ & 0.971 & 0.917 \\
Glassy $\mathrm{n}=13$ & 0.699 & 0.0008 \\
Tuffaceous Sediments $\mathrm{n}=10$ & 0.844 & 0.050 \\
\hline
\end{tabular}

Brown-Forsythe tests for equality of variances were performed on log

transformed arsenic concentrations for all groups of samples with outliers removed (Table 12). At a significance level of $\alpha=0.05$, the variance of all tuffs was found to be different than the variance of tuffaceous sediments. Both devitrified and glassy and weathered and unweathered tuffs were found to have statistically indistinguishable variances.

Table 12. Test statistics, number of samples, and p-values for Brown-Forsythe tests of equal variances.

\begin{tabular}{lcccc}
\hline \hline & Test Stat & $\mathrm{n} 1$ & $\mathrm{n} 2$ & $\mathrm{p}$-Value \\
\hline Tuffs v. Tuffaceous Sediments & 8.12 & 46 & 10 & 0.006 \\
Weathered v. Unweathered Tuffs & 0.800 & 18 & 28 & 0.380 \\
Devitrified v. Glassy & 2.30 & 15 & 13 & 0.143 \\
\hline
\end{tabular}

Non-parametric Mann-Whitney-Wilcoxon tests were performed on log transformed arsenic values, and the arsenic concentrations were not found to be significantly different between the different categories of samples (Table 13). 
Table 13. Test statistic (U), number of samples, and p-values for Man-Whitney-Wilcoxon tests of equality performed on sample categories.

\begin{tabular}{lcccc}
\hline \hline & $\mathrm{U}$ & $\mathrm{n} 1$ & $\mathrm{n} 2$ & $\mathrm{p}$-Value \\
\hline Tuffs v. Tuffaceous Sediments & 273 & 46 & 10 & 0.367 \\
Weathered v. Unweathered Tuffs & 213 & 18 & 28 & 0.270 \\
Devitrified v. Glassy & 59 & 15 & 13 & 0.478 \\
\hline
\end{tabular}

\begin{abstract}
Although the categories are not statistically distinguishable, devitrified and weathered samples contain a larger range of arsenic concentrations than glassy samples, and higher maximum arsenic concentrations (Figure 10). Although $10 \%$ of all samples have arsenic concentrations in excess of $10 \mathrm{mg} \mathrm{kg}^{-1}$ no fresh glassy samples contain arsenic at those levels.
\end{abstract}



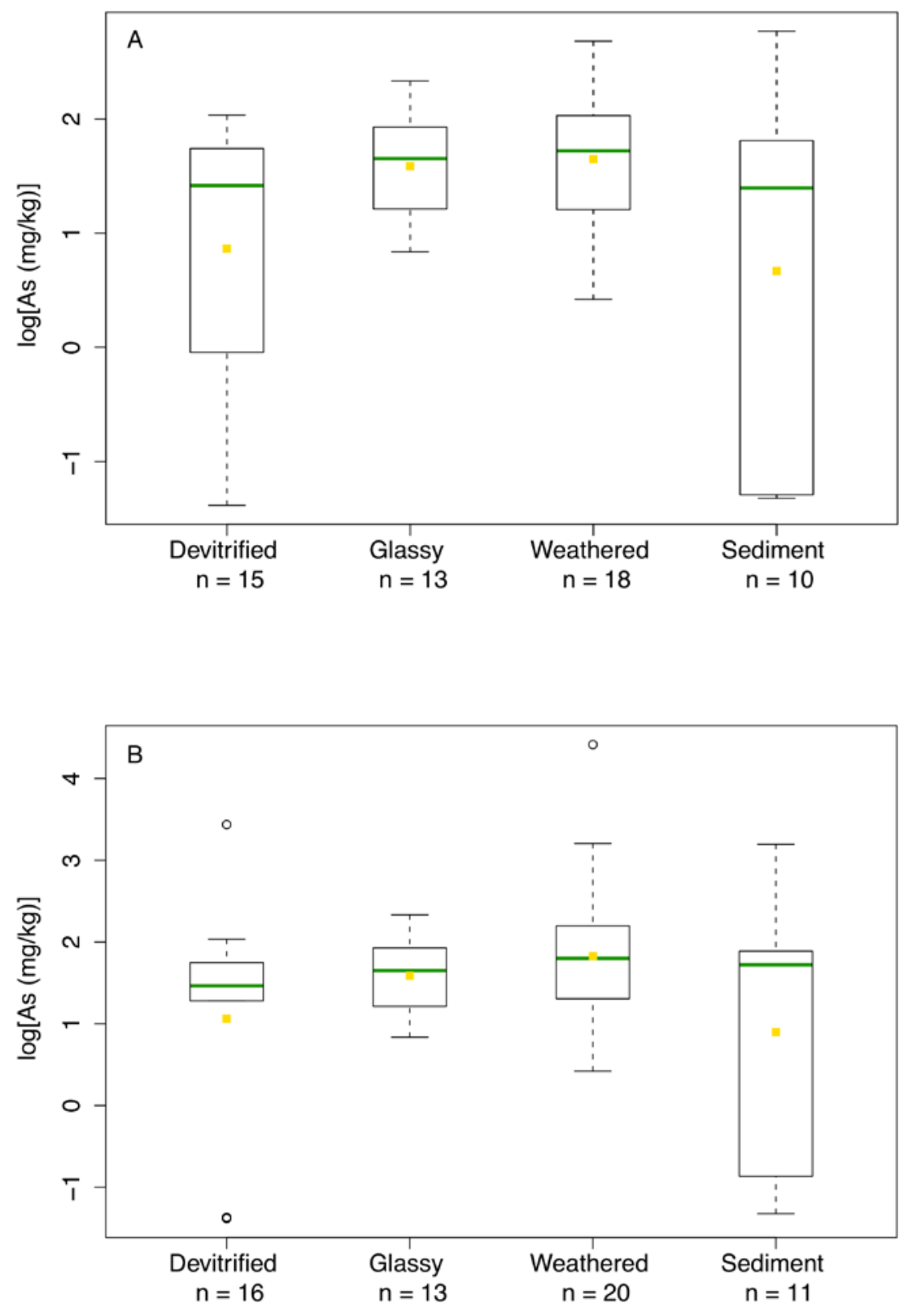

Figure 10. Log transformed distributions of total arsenic concentrations for samples divided by category. A: without outlying values. B: with outlying values. Yellow squares indicate mean values. 


\section{Variability Within Units}

Total arsenic concentrations can vary substantially within individual units (Figure 11). The most extreme example is the Tuff of Leslie Gulch, which has a maximum arsenic concentration or $81 \mathrm{mg} \mathrm{kg}^{-1}$, about 30 times greater than its minimum arsenic concentration of $2.6 \mathrm{mg} \mathrm{kg}^{-1}$.

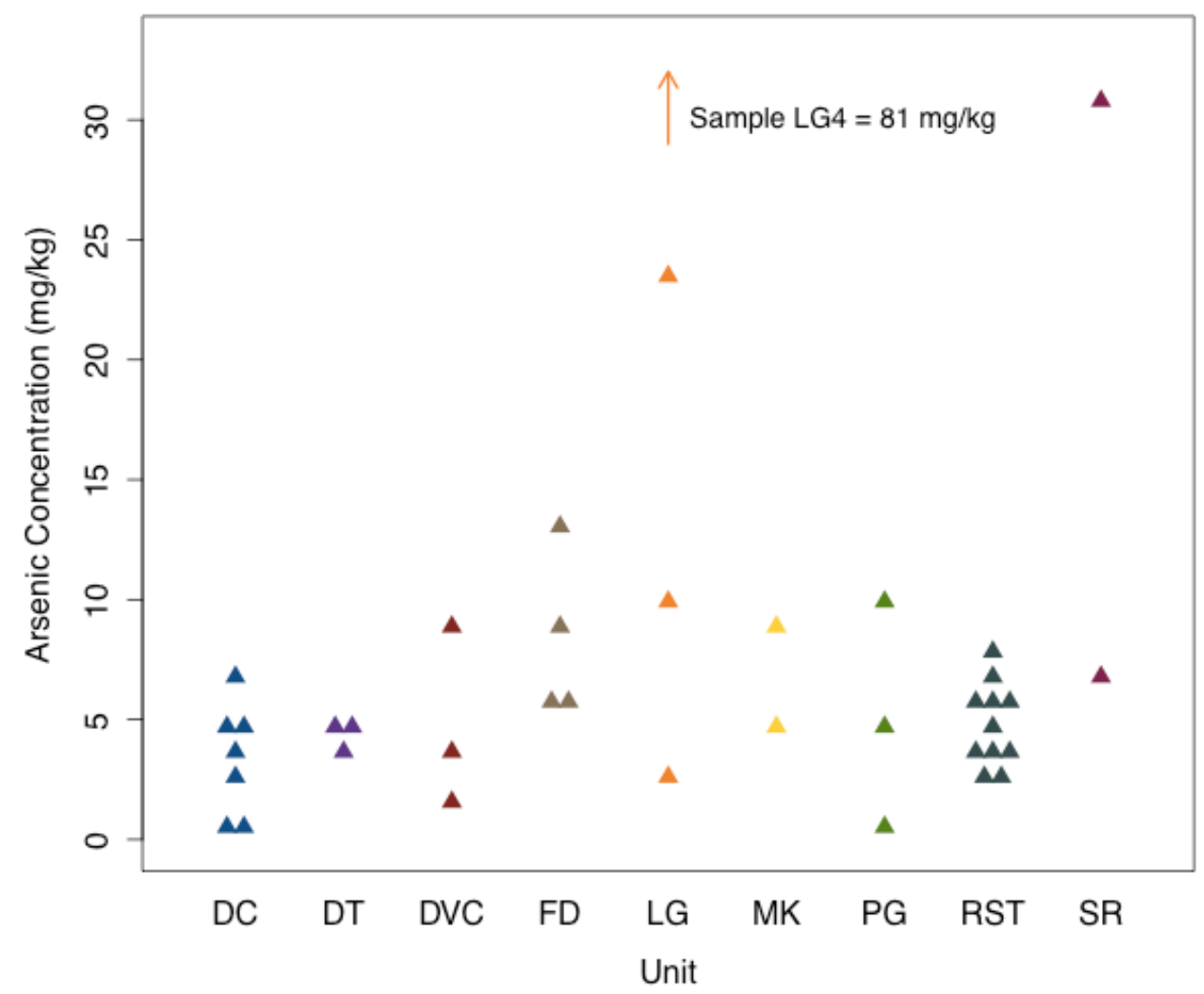

Figure 11. Ranges of arsenic found in individual geologic units. DC $=$ Dinner Creek Tuff, DT $=$ Dale Tuff, DVC $=$ Devine Canyon Tuff, FD = Tuff of Foster Dam, LG = Tuff of Leslie Gulch, MK = Tuff of Mohawk, PG = Picture Gorge Tuff, RST = Rattlesnake Tuff, SR = Tuff of Smith Rock. 
Arsenic concentrations varied within individual outcrops as well as individual

units. Complete sections from unwelded bases through devitrified tops were collected from single outcrops of the Rattlesnake Tuff and the Dinner Creek Tuff (Figure 12). Both sections contained ranges of arsenic concentrations $>5 \mathrm{mg} \mathrm{kg}^{-1}$.

Rattlesnake Tuff

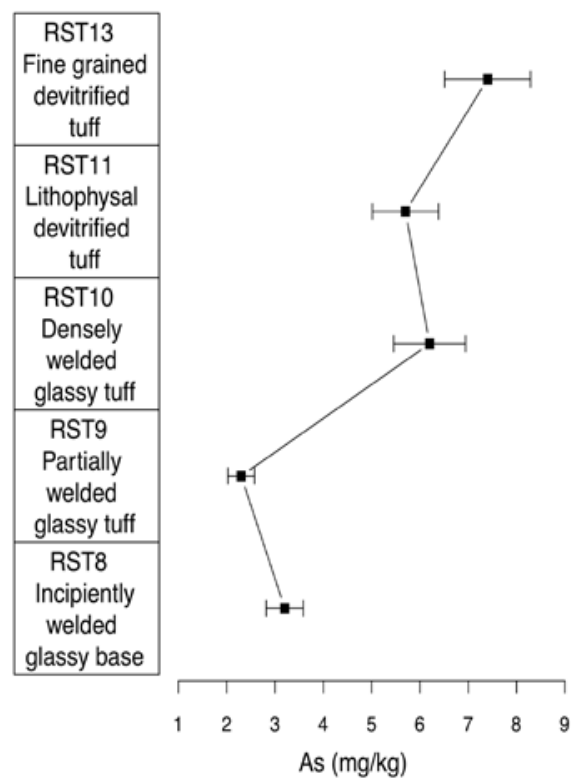

Dinner Creek Tuff

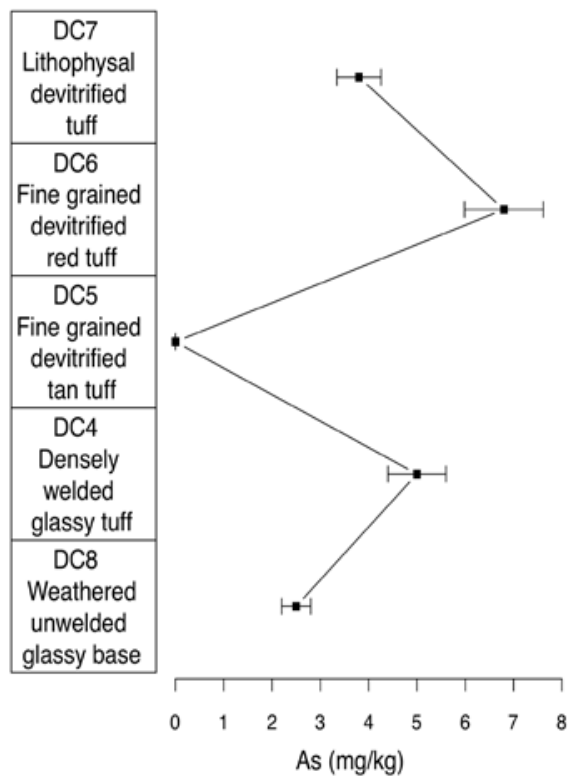

Figure 12. Stratigraphy and corresponding arsenic concentrations for two sections of individual tuff units. The type section of the Rattlesnake tuff shows higher arsenic levels upsection in the less porous sections of the unit. The Dinner Creek section shows arsenic concentrations ranging from $<0.5 \mathrm{mg} \mathrm{kg}^{-1}$ (non-detect value plotted as $0 \mathrm{mg} \mathrm{kg}^{-1}$ ) to $6.8 \mathrm{mg} \mathrm{kg}^{-1}$, with no apparent relationship between arsenic concentration and position within the section. Error bars are based on INAA recovery percents from certified reference materials from Activation Laboratories, Ltd.

In the Rattlesnake Tuff arsenic concentrations generally increased upsection, with lower arsenic levels in the incipiently and partially welded glassy samples at the base, and 
higher values in both the densely welded glassy sample and devitrified samples. In contrast, the Dinner Creek Tuff did not display any apparent relationship between arsenic concentration and vertical position within the section.

\section{Elemental Correlations}

Tests of correlation between arsenic and other elements were performed on log transformed data with outliers excluded using the non-parametric Spearman's rank correlation coefficient, which was chosen over Pearson's product moment correlation coefficient due to both the non-normal distribution of the data and the comparative robustness of Spearman's rank correlation coefficient when dealing with outliers. Details of statistical calculations can be found in Appendix B. Arsenic displayed statistically significant $(\mathrm{p}<0.05)$ correlations with a few of the elements in the samples used in this study (Table 14).

Table 14. Statistically significant $(p<0.05)$ elemental correlations with arsenic. Italicized items showed a negative correlation with arsenic, while un-italicized items showed a positive correlation.

\begin{tabular}{cl}
\hline \hline & \multicolumn{1}{c}{ Significant Correlations with Arsenic } \\
\hline All Tuffs $(\mathrm{df}=44)$ & $\mathrm{Al}_{2} \mathrm{O}_{3}, \mathrm{FeO}, \mathrm{Sb}$ \\
Weathered Tuffs $(\mathrm{df}=16)$ & $\mathrm{K}_{2} \mathrm{O}, \mathrm{Mo}$ \\
All Unweathered Tuffs $(\mathrm{df}=26)$ & $\mathrm{Al}_{2} \mathrm{O}_{3}, \mathrm{Cu}, \mathrm{FeO}, \mathrm{Sm}$ \\
Devitrified Tuffs $(\mathrm{df}=13)$ & $\mathrm{MnO}, \mathrm{Sm}$ \\
Glassy Tuffs $(\mathrm{df}=11)$ & $\mathrm{Cr}, \mathrm{FeO}$ \\
Tuffaceous Sediments $(\mathrm{df}=8)$ & None \\
\hline
\end{tabular}


Arsenic in all tuff samples was negatively correlated with $\mathrm{Al}_{2} \mathrm{O}_{3}$, and positively correlated with $\mathrm{FeO}$ and $\mathrm{Sb}$. Different categories of tuffs displayed different correlations between arsenic and other elements, although a positive correlation with $\mathrm{FeO}$ was present in multiple categories. The majority of the statistically significant correlations, including the correlation with $\mathrm{FeO}$, were not reflective of strong linear relationships between elements, with $\mathrm{R}^{2}$ values $<0.15$ (Figure 13 ).

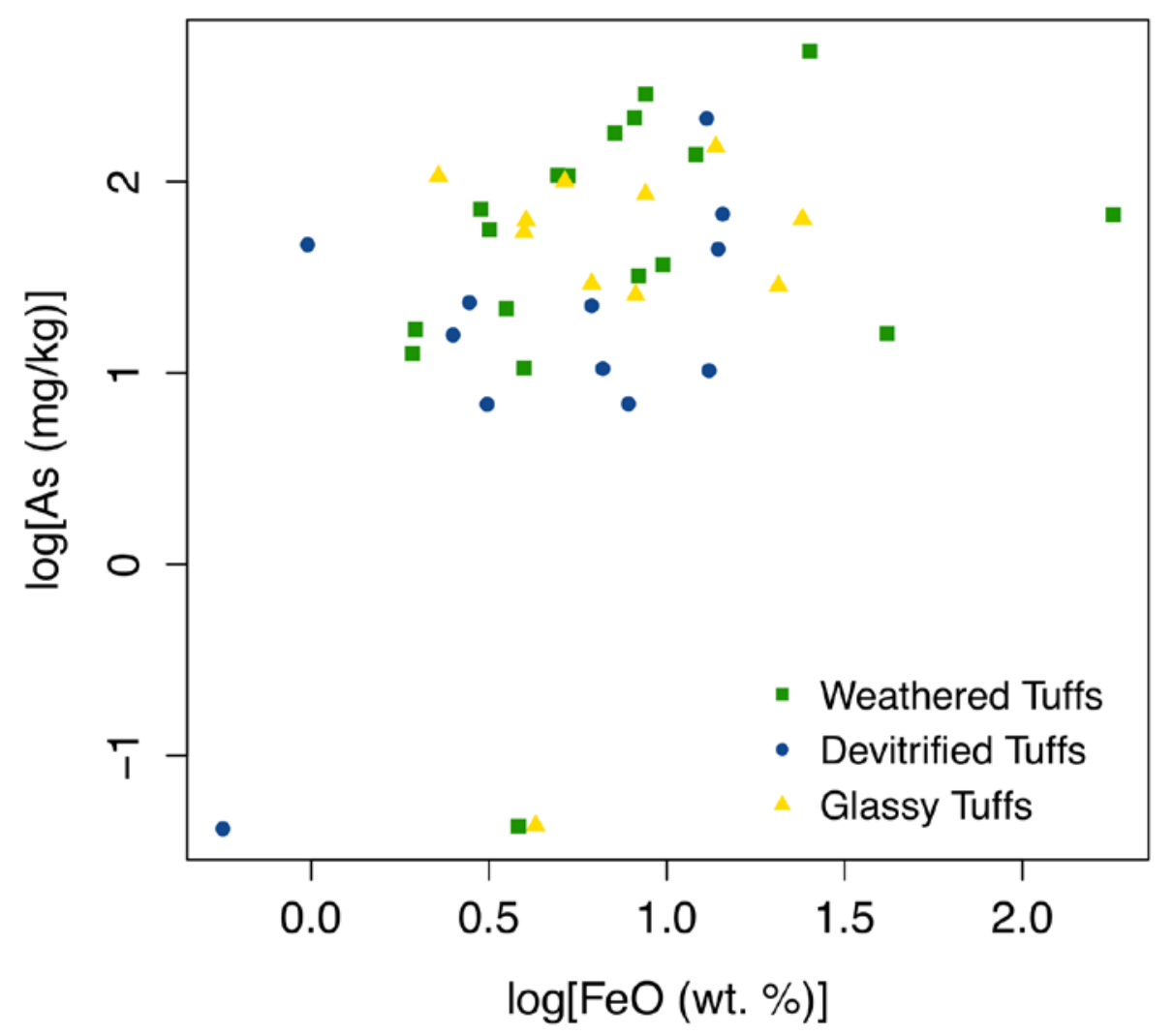

Figure 13. Log transformed Arsenic and FeO concentrations in tuffs and tuffaceous sediments. Although statistically significant positive correlations were found between arsenic and $\mathrm{FeO}$, there is not a strong linear relationship between the elements 


\section{DISCUSSION}

Arsenic concentrations in ash-flow tuffs are higher than previously reported values, and highly heterogenous between and within individual units. Although the median arsenic concentrations do not differ between categories of tuffs, the range of arsenic, particularly the maximum arsenic concentrations, is different between both weathered and unweathered tuffs and devitrified and glassy tuffs. Although $10 \%$ of the samples in this study had arsenic concentrations exceeding $10 \mathrm{mg} \mathrm{kg}^{-1}$ none of those samples were unweathered glassy samples. Together, these results suggest three distinct mechanisms that determine the arsenic concentrations of individual tuff samples: arsenic content of the original source magma, mobility of arsenic during deposition of the unit, and mobility of arsenic during post-depositional alteration processes, both devitrification and weathering.

\section{Composition of Source Magma}

The first factor in determining arsenic levels in a tuff sample is the arsenic content of the original source magma. Although no correlation was found between alumina/alkali ratios and arsenic, previous research has suggested that the arsenic content of volcanic rocks increases with silica content, and less felsic volcanic rocks have lower mean arsenic concentrations than ash-flow tuffs (Onishi and Sandell, 1955). Fractional crystallization of feldspars, other anhydrous silicates, and oxides produces melts enriched in volatiles and incompatible metals, including arsenic (Borisova, 2010). Enrichment driven by fractional crystallization is a likely mechanism for producing arsenic concentrations in 
high-silica tuffs that exceed both the average value of the continental crust, and values found in less silicic volcanic rocks.

Arsenic concentrations can also vary between different silicic magmas. Along with boron, arsenic has been suggested as an indicator of contributions from sedimentary materials and slab-derived fluids in subduction zone magmas (Noll, 1996). Magmas produced by melting of high arsenic sedimentary materials and magmas incorporating a high proportion of slab-derived fluids can contain higher arsenic concentrations than magmas produced in other tectonic settings.

Although the arsenic concentrations of tuff samples in this study displayed a high degree of heterogeneity within individual units it seems likely that the magmatic source plays some role in determining the final arsenic concentrations of individual samples. All of the units in this study that contained at least one sample with arsenic levels exceeding $10 \mathrm{mg} \mathrm{kg}^{-1}$ also contained samples with lower arsenic levels. However, the lower arsenic levels for these units still exceeded the median value of $5.0 \mathrm{mg} \mathrm{kg}^{-1}$ for all tuffs, which suggests that the original source magmas for these units were potentially more arsenic rich than units lacking high arsenic $\left(>10 \mathrm{mg} \mathrm{kg}^{-1}\right)$ samples.

\section{Depositional Processes}

Pyroclastic volcanic eruptions that produce ash-flow tuffs involve substantial and rapid degassing of silicic magmas. Arsenic is known to preferentially partition into the vapor phase, and has been found to be enriched by factors of $10^{2}-10^{3}$ relative to the melt in studies of andesitic magma systems (Symonds, 1987). Unlike more effusive eruption 
mechanisms pyroclastic flows entrain both solid and vapor phase portions of a magma during deposition. The presence of arsenic in the vapor phase during deposition of ashflow tuffs is likely to result in loss of some portion of arsenic from the system as well as heterogeneity of arsenic levels within the unit itself (Borisova, 2010).

While substantial heterogeneity was observed within units the results of this study do not provide definitive conclusions about spatial patterns of arsenic distribution that occur as a result of movement of the vapor phase. The arsenic concentrations in the type section of the Rattlesnake Tuff suggest one possible pattern of spatial distribution. Within a single outcrop samples taken higher in the section, representing the denser, less permeable interior of the unit, display higher arsenic concentrations than un- or partially welded samples from the base of the unit (Figure 12). This suggests that volatile arsenic entrained in the flow may have migrated from the permeable lower portions of the unit during deposition and cooling, and been trapped in the overlying less permeable interior. This same pattern is not seen in the Dinner Creek Tuff.

An additional hypothesis regarding the spatial distribution of arsenic within individual tuffs is that arsenic may decrease with increasing distance from the eruptive center, as a higher proportion of the volatiles are lost as the flow travels further from its source. Distance from the eruptive center is a variable worth exploring in further studies.

\section{Post-Depositional Alteration Processes}

Although the median values were not statistically different between categories of tuffs only weathered and devitrified tuffs included samples with arsenic concentrations 
that exceeded $10 \mathrm{mg} \mathrm{kg}^{-1}$, and unweathered glassy samples contained a much smaller range of arsenic levels than the other categories of tuffs. This suggests that both devitrification and weathering have the potential to concentrate arsenic relative to unaltered tuffs.

The most likely mechanism to explain the potential for arsenic enrichment in devitrified tuffs relative to glassy tuffs is vapor phase mineralization. Vapor phase mineralization occurs primarily in the interiors of thick $(>10 \mathrm{~m})$ ash-flow tuffs, and can be driven by the degassing of $\mathrm{H}_{2} \mathrm{O}, \mathrm{CO}_{2}, \mathrm{~S}$, and other volatile components from pyroclastic glasses during the process of devitrification (Vaniman, 2006). As a result of the wide variety of constituents that are excluded from the structure of feldspars and silicates that form during devitrification, vapor phase mineralogy can be very complex, and can differ substantially between tuffs. Vapor phase minerals include a variety of silicate minerals (alkali feldspar, tridymite, cristobalite, quartz, amphibole, biotite, zircon, monazite, and garnet have all been observed), as well as oxides, carbonates, phosphates, chlorides, and sulfides (Stimac, 1996; Vaniman, 2006). Oxides, phosphates, and sulfide minerals are all likely candidates for arsenic host phases. In addition, the fact that vapor phase mineralization occurs in some, but not all, tuffs may explain why only a portion of the devitrified samples in this study were enriched in arsenic relative to glassy samples.

Unfortunately, identification of vapor phase minerals is difficult, because they tend to be small $(<1-10 \mu \mathrm{m})$, present at low concentrations $(<1 \%$ by volume $)$, fragile, and located on grain surfaces and boundaries between larger crystals (Stimac, 1996). The 
complexity of vapor phase mineralogy and difficulty of identifying individual vapor phase minerals makes the characterization of vapor phase minerals beyond the scope of the solid phase characterization performed in this study. 


\section{CHAPTER 3: ARSENIC MOBILITY IN ASH-FLOW TUFFS AND ASSOCIATED}

\section{SEDIMENTS}

\section{INTRODUCTION}

Despite the widespread association between ash-flow tuffs and elevated groundwater arsenic concentrations, surprisingly little is known about arsenic mobility from these units. Multiple mechanisms have been proposed to explain the mobilization of arsenic from tuffs, including dissolution of volcanic glasses (Nicolli et al., 1989; Johannesson and Tang, 2009), and alkali desorption of arsenic from mineral grain surfaces (Smedley and Kinniburgh, 2002). Although tuffs are typically highly heterogenous and include both glassy and devitrified sections as well as varying degrees of weathering, most research has focused solely on volcanic glasses, and has not considered the alteration processes of devitrification and weathering, or what role those processes may play in mobilizing arsenic.

This study uses 49 tuff samples spanning a range of chemical and mineralogical compositions, as well as 11 samples of tuffaceous sediments to investigate the mobility of arsenic in ash-flow tuffs. Specific objectives of the study are 1) to quantify the amount of arsenic present in tuffs that can be mobilized into the environment by determining total environmentally available arsenic levels and readily leachable arsenic levels and 2) to determine if and how devitrification and weathering influence the amounts of mobile arsenic present in tuffs. 


\section{METHODS}

To investigate the relative mobility of arsenic in tuffs of varying compositions two fractions of arsenic were identified. Both environmentally available and readily leachable fractions were operationally defined. The environmentally available fraction refers to the portion of arsenic mobilized by microwave digestion with concentrated $\mathrm{HNO}_{3}{ }^{-}$, following USEPA Method 3051A, which results in the dissolution of solid phases that are susceptible to chemical alteration under a range of surface geochemical conditions. This method does not recover metals hosted in silicate phases (feldspars, silica polymorphs, or glass), and is frequently referred to a "total recoverable" analytical method, in contrast to USEPA Method 3052 using $\mathrm{HF}+\mathrm{HNO}_{3}{ }^{-}+\mathrm{HCl}$, which is a "total total" method (Chen, 1998; US Environmental Protection Agency, 1996a).

The readily leachable fraction refers to the fraction of arsenic (and other elements) mobilized by simple mixing with reagent-grade water for a relatively short period of time (18 hours), following ASTM D3987-85. This method is designed to produce a water extract that simulates conditions where the solid phase is the dominant factor in determining the final $\mathrm{pH}$ of the extract (Das, 2007).

\section{Environmentally Available Arsenic}

To determine the environmentally available fraction of elements, samples were digested following USEPA Method 3051A (US Environmental Protection Agency, 1996a). A subsample of crushed and powdered sample was weighed to $1.000 \pm 0.001 \mathrm{~g}$ and placed in a Teflon microwave vessel to which $10 \mathrm{~mL}$ of $17 \mathrm{M}$ trace-metal grade 
$\mathrm{HNO}_{3}{ }^{-}$was subsequently added. Samples were digested using a Milestone Ethos EZ microwave digester for 40 minutes, reaching a maximum temperature of $240^{\circ} \mathrm{C}$ for 20 minutes. Method blanks and standard JR1 from the Japanese Geological Survey were run every 20 samples. Samples were decanted into $50-\mathrm{mL}$ plastic centrifuge tubes and vessels were rinsed three times with $18.2 \mathrm{M} \Omega \mathrm{cm}$ distilled water. The rinse was added to the digested samples, and the centrifuge tubes were filled to $40 \mathrm{~mL}$ with water. Samples were centrifuged at $3000 \mathrm{rpm}$ for 10 minutes. Samples were further diluted (1:1 with water) in plastic test tubes immediately prior to analysis, and mixed by pouring the diluted sample into a second plastic test tube. Samples were analyzed using an Agilent 700 Series ICPOES. Operating conditions for the analysis are listed in Appendix A.

Readily Leachable Arsenic

An additional aliquot of powdered sample was weighed to $1.000 \pm 0.001$, placed in a $50-\mathrm{mL}$ centrifuge tube and combined with $20.0 \mathrm{~mL}$ of $18.2 \mathrm{M} \Omega \mathrm{cm}$ deionized water. Samples were mixed at $20 \mathrm{rpm}$ for 18 hours. After mixing, samples were centrifuged at $3000 \mathrm{rpm}$ for 15 minutes and $\sim 15 \mathrm{~mL}$ of each solution was decanted into a fresh $50-\mathrm{mL}$ centrifuge tube. Samples were acidified using $0.300 \mathrm{~mL}$ of trace-element grade $\mathrm{HNO}_{3}{ }^{-}$in order to preserve the solution for analysis. Samples were analyzed using an Agilent 700 Series ICP-OES. Operating conditions for the analysis are listed in Appendix A. For selected samples the $\mathrm{pH}$ of the resulting solution was determined from the unacidified sample. 


\section{$\mathrm{pH}$ Dependent Extractions}

To determine how $\mathrm{pH}$ influences the leachability of arsenic from tuffs, the procedure for determining readily leachable arsenic was repeated with varying $\mathrm{pH}$ levels on selected samples. Five tuff samples with the highest total arsenic concentrations were selected from the glassy (BC1, DVC4, PG3, RST6, RST10), devitrified (DC6, MK2, RST11, RST13, SR2), and weathered (FD3, FD4, LG1, LG2, LG4) categories. Leaching

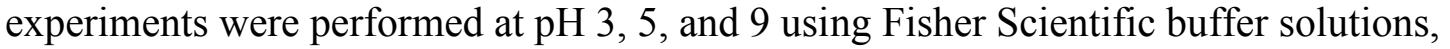
and at $\mathrm{pH} 11$ using a buffer solution prepared in the lab using reagent grade $\mathrm{NaOH}$ and $\mathrm{NaHCO}_{3}$ (Table 15). Specific buffers were selected primarily to avoid the use of potassium phosphate, a common component of buffer solutions, in order to avoid introducing phosphate anions into solution, as phosphate can behave as a competing anion and decrease the sorption of arsenic.

Table 15. Buffer solutions used to control $\mathrm{pH}$ levels in $\mathrm{pH}$ specific leaching experiments.

\begin{tabular}{|c|c|c|}
\hline Name & Composition & $\mathrm{pH}$ \\
\hline Fisher Chemical SB97-500 Buffer Solution & $\begin{array}{l}\text { Potassium Acid Phthalate } \\
\text { Hydrochloric Acid }\end{array}$ & 3 \\
\hline Fisher Chemical SB102-1 Buffer Solution & $\begin{array}{l}\text { Potassium Acid Phthalate } \\
\text { Sodium Hydroxide }\end{array}$ & 5 \\
\hline \multirow[t]{2}{*}{ Fisher Chemical SB114-1 Buffer Solution } & $\begin{array}{l}\text { Boric Acid } \\
\text { Potassium Chloride } \\
\text { Sodium Hydroxide }\end{array}$ & 9 \\
\hline & $\begin{array}{l}\text { Sodium Hydroxide } \\
\text { Sodium Bicarbonate }\end{array}$ & 11 \\
\hline
\end{tabular}

One gram of powdered sample was placed in a $50-\mathrm{mL}$ centrifuge tube and combined with $20.0 \mathrm{~mL}$ of buffer solution. Samples were mixed at $20 \mathrm{rpm}$ for 18 hours. 
After mixing, samples were centrifuged at $3000 \mathrm{rpm}$ for 15 minutes. Following centrifuging $\sim 15 \mathrm{~mL}$ of solution was decanted into fresh $50-\mathrm{mL}$ centrifuge tubes. Samples were acidified using $0.300 \mathrm{~mL}$ of trace element grade $\mathrm{HNO}_{3}{ }^{-}$to preserve the solution for analysis. Unfortunately, rectangular euhedral crystals were observed forming on the wall of the centrifuge tubes holding the $\mathrm{pH} 3$ and $\mathrm{pH} 5$ solutions, potentially the result of oxidation of the potassium acid phthalate in the buffer solutions by $\mathrm{HNO}_{3}{ }^{-}$, and the low $\mathrm{pH}$ extracts were not analyzed. The high $\mathrm{pH}$ solutions were analyzed using an Agilent 700 Series ICP-OES. Operating conditions for the analysis are listed in Appendix A. 


\section{RESULTS}

\section{QC Results}

Check standards were run during ICP-OES analysis as a check on instrumental accuracy, and results are listed in Appendix A. For environmentally available arsenic samples, three analytical sessions were conducted, and results for individual elements varied slightly between sessions. Most elements consistently produced values that were within $\pm 10 \%$ of the standard value, with the exception $\mathrm{Na}$ and $\mathrm{Si}$. Na was measured at values up to $118 \%$ of the check standard value during the first run, but was consistently within $\pm 10 \%$ of the standard value during subsequent runs. Si was not measured during the first run, but was measured at values exceeding the check standard value by up to $400 \%$ during subsequent sessions. Si values increased over the course of both runs, and values in excess of check standard values were likely the result of insufficient rinsing of the element between analyses of different samples. For the second and third sessions neither S and P were present in the check standard, but were still measured at low levels (up to $30 \mathrm{ppb}$ for $\mathrm{S}$ ) in check standard and blanks.

For readily leachable arsenic samples two analytical sessions were conducted. For both sessions the check standard results were similar to those for the environmentally available samples. Na and $\mathrm{Si}$ were consistently measured with values exceeding those of the check standards, and $\mathrm{P}$ and $\mathrm{S}$ were measured at low levels in check standards and blanks, despite not being present in those standards. 
Three samples analyzed for environmentally available arsenic were analyzed in duplicate. Relative percent differences for arsenic in the samples range from 2.5 to $7.6 \%$.

Table 16. Relative percent differences for duplicate samples analyzed via EPA Method 3051a.

\begin{tabular}{lccc}
\hline \hline & $\begin{array}{c}\text { WU1 RPD } \\
(\%)\end{array}$ & $\begin{array}{c}\text { MK1 RPD } \\
(\%)\end{array}$ & $\begin{array}{c}\text { MK2 RPD } \\
(\%)\end{array}$ \\
\hline $\mathrm{Al}$ & 0.24 & 1.18 & 0.37 \\
$\mathrm{As}$ & 7.64 & 3.53 & 2.49 \\
$\mathrm{Ba}$ & 0.06 & 0.83 & 0.45 \\
$\mathrm{Ca}$ & 0.41 & 1.62 & 0.38 \\
$\mathrm{Cd}$ & 4.07 & 1.72 & 5.17 \\
$\mathrm{Ce}$ & 0.03 & 0.94 & 0.91 \\
$\mathrm{Co}$ & 0.40 & 0.56 & 1.50 \\
$\mathrm{Cr}$ & 0.50 & 1.46 & 0.12 \\
$\mathrm{Cu}$ & 0.00 & 0.58 & 0.32 \\
$\mathrm{Fe}$ & 0.05 & 0.98 & 0.11 \\
$\mathrm{La}$ & 0.12 & 1.23 & 0.82 \\
$\mathrm{Mg}$ & 0.06 & 0.72 & 0.44 \\
$\mathrm{Mn}$ & 0.04 & 1.00 & 0.38 \\
$\mathrm{Na}$ & 0.61 & 1.10 & 0.01 \\
$\mathrm{Ni}$ & 0.45 & 0.79 & 2.00 \\
$\mathrm{P}$ & 0.03 & 0.36 & 0.42 \\
$\mathrm{~Pb}$ & 1.31 & 4.04 & 1.66 \\
$\mathrm{~S}$ & 0.92 & 2.54 & 0.41 \\
$\mathrm{Sm}$ & 2.01 & 0.54 & 0.00 \\
$\mathrm{Sr}$ & 0.05 & 1.11 & 0.49 \\
$\mathrm{~V}$ & 0.18 & 1.09 & 0.46 \\
$\mathrm{Zn}$ & 0.20 & 0.74 & 0.62 \\
\hline
\end{tabular}

All water extractions were performed in duplicate, and selected sample RPDs are displayed in Table 17, full RPD results can be found in Appendix A. Relative percent differences for arsenic ranged from $1.32 \%$ to $6.65 \%$. The low levels of elements present in the water extracts produced many non-detections, as well as higher RPDs for many elements than occurred for other experiments. 
Table 17. Relative percent differences for water extractions analyzed in duplicate.

\begin{tabular}{lccc}
\hline \hline & $\begin{array}{c}\text { LG1 RPD } \\
(\%)\end{array}$ & $\begin{array}{c}\text { RST10 RPD } \\
(\%)\end{array}$ & $\begin{array}{c}\text { DST2 RPD } \\
(\%)\end{array}$ \\
\hline $\mathrm{Al}$ & 26.2 & 21 & 40.6 \\
$\mathrm{As}$ & 1.32 & $\mathrm{NA}$ & 6.65 \\
$\mathrm{Ba}$ & 32.1 & 13.5 & 18.1 \\
$\mathrm{Ca}$ & 20.5 & 12.5 & 0.59 \\
$\mathrm{Cu}$ & 1.18 & 8.16 & 4.36 \\
$\mathrm{Fe}$ & 7.29 & 19.6 & 46.9 \\
$\mathrm{La}$ & 16.5 & $\mathrm{NA}$ & 40.2 \\
$\mathrm{Mg}$ & 13.5 & 12.7 & 19.8 \\
$\mathrm{Mn}$ & $\mathrm{NA}$ & $\mathrm{NA}$ & 39.4 \\
$\mathrm{Mo}$ & $\mathrm{NA}$ & $\mathrm{NA}$ & $\mathrm{NA}$ \\
$\mathrm{Na}$ & 1.87 & 0.31 & 3.28 \\
$\mathrm{P}$ & 1.02 & 0.18 & 19.5 \\
$\mathrm{~S}$ & 5.92 & 1.22 & 3.14 \\
$\mathrm{Si}$ & 1.65 & 10.6 & 9.03 \\
$\mathrm{Sr}$ & 30.6 & 15.7 & 14.4 \\
$\mathrm{Ti}$ & 0.46 & 18.4 & 35.9 \\
$\mathrm{~V}$ & 18.5 & 0.29 & 1.70 \\
$\mathrm{Zn}$ & 6.99 & 13.0 & 43.9 \\
\hline
\end{tabular}

\section{Environmentally Available Arsenic}

Complete results for the environmentally available fraction are listed in Appendix C. Two samples (LG4 and SR2) were identified as outliers using Grubbs test for outliers. Arsenic concentrations in tuffs were positively skewed and appeared to be lognormally distributed, so the data was log transformed, The mean environmentally available arsenic concentration present in all tuff samples, excluding the two outliers, is $2.2 \mathrm{mg} \mathrm{kg}^{-1}$, the median environmentally available arsenic concentration is $1.8 \mathrm{mg} \mathrm{kg}^{-1}$, and the geometric mean of arsenic present in the environmentally available fraction is $1.2 \mathrm{mg} \mathrm{kg}^{-1}$ (Table 18). 
Table 18. Environmentally available fraction of arsenic present in ash-flow tuffs and tuffaceous sediments. Numbers in parentheses indicate values that include samples identified as outliers.

\begin{tabular}{lccccc}
\hline \hline & $\begin{array}{c}\text { Mean } \\
(\mathrm{mg} / \mathrm{kg})\end{array}$ & $\begin{array}{c}\text { Geometric } \\
\text { Mean } \\
(\mathrm{mg} / \mathrm{kg})\end{array}$ & $\begin{array}{c}\text { Median } \\
(\mathrm{mg} / \mathrm{kg})\end{array}$ & $\begin{array}{c}\text { Standard } \\
\text { Deviation } \\
(\mathrm{mg} / \mathrm{kg})\end{array}$ & $\begin{array}{c}\text { Median } \\
\text { Average } \\
\text { Deviation } \\
(\mathrm{mg} / \mathrm{kg})\end{array}$ \\
\hline All Tuffs $\mathrm{n}=47(49)$ & $2.2(4.1)$ & $1.2(1.4)$ & $1.8(1.8)$ & $2.1(9.9)$ & $2.3(2.4)$ \\
Weathered Tuffs $\mathrm{n}=19(20)$ & $3.3(5.8)$ & $2.4(2.8)$ & $2.9(3.0)$ & $2.3(12.7)$ & $2.4(2.4)$ \\
Unweathered Tuffs $\mathrm{n}=28(29)$ & $1.2(2.3)$ & $0.63(0.74)$ & $0.43(0.57)$ & $1.4(5.7)$ & $0.34(0.54)$ \\
$\quad$ Devitrified n = 15 (16) & $2.8(6.6)$ & $1.9(2.4)$ & $2.3(2.4)$ & $2.1(13.8)$ & $0.71(0.78)$ \\
$\quad$ Glassy $\mathrm{n}=13$ & 1.8 & 0.23 & 0.7 & 2.1 & 0 \\
Tuffaceous Sediments $\mathrm{n}=11$ & 2.4 & 1.1 & 1.4 & 3.1 & 1.7 \\
\hline
\end{tabular}

Shapiro-Wilk tests of normality were performed on log transformed arsenic concentrations for all tuffs, tuffaceous sediments, and the different categories of tuff samples. At a significance level of $\alpha=0.05$, all tuffs, unweathered tuffs, and glassy tuffs were found to be non-normally distributed (Table 19). Details of statistical methods can be found in Appendix B.

Table 19. Test statistics (W) and p-values for Shapiro-Wilk tests of normality.

\begin{tabular}{lcc}
\hline \hline & $\mathrm{W}$ & $\mathrm{p}$-Value \\
\hline All Tuffs $\mathrm{n}=46$ & 0.883 & $2.40 \mathrm{E}-04$ \\
Weathered Tuffs $\mathrm{n}=18$ & 0.935 & 0.137 \\
Unweathered Tuffs $\mathrm{n}=29$ & 0.804 & $4.39 \mathrm{E}-04$ \\
Devitrified $\mathrm{n}=16$ & 0.935 & 0.467 \\
Glassy $\mathrm{n}=13$ & 0.327 & $1.21 \mathrm{E}-06$ \\
Tuffaceous Sediments $\mathrm{n}=10$ & 0.918 & 0.306 \\
\hline
\end{tabular}

Brown-Forsythe tests for equality of variances were performed on log

transformed arsenic concentrations for all groups of samples (Table 12). At a significance level of $\alpha=0.05$, both devitrified and glassy and weathered and unweathered tuffs were found to have unequal variances. 
Table 20. Test statistics, number of samples, and p-values for Brown-Forsythe tests of equal variances.

\begin{tabular}{lcccc}
\hline \hline & Test Stat & n1 & n2 & p-Value \\
\hline Tuffs v. Tuffaceous Sediments & 0.0471 & 47 & 11 & 0.829 \\
Weathered v. Unweathered Tuffs & 6.038 & 19 & 28 & 0.018 \\
Devitrified v. Glassy Tuffs & 5.282 & 15 & 13 & 0.051 \\
\hline
\end{tabular}

Non-parametric Mann-Whitney-Wilcoxon tests were performed on the log transformed solid arsenic concentrations in the environmentally available fraction. Environmentally available arsenic was found to be significantly different between both weathered and unweathered tuffs and glassy and devitrified tuffs (Table 21). Unweathered tuffs have significantly less arsenic in the environmentally available fraction than weathered tuffs, and glassy tuffs have significantly less arsenic in the environmentally available fraction than devitrified tuffs.

Table 21. Test statistic (U), number of samples, and p-values for Man-Whitney-Wilcoxon tests of equality performed on sample categories.

\begin{tabular}{lcccc}
\hline \hline & $\mathrm{U}$ & $\mathrm{n} 1$ & $\mathrm{n} 2$ & $\mathrm{p}$-Value \\
\hline Tuffs v. Tuffaceous Sediments & 236 & 47 & 11 & 0.736 \\
Weathered v. Unweathered Tuffs & 101.5 & 19 & 28 & $3.15 \mathrm{E}-04$ \\
Devitrified v. Glassy & 131 & 15 & 13 & $2.61 \mathrm{E}-05$ \\
\hline
\end{tabular}

Although unweathered tuffs are significantly different than weathered tuffs it appears that difference is driven primarily by the very low levels of environmentally available arsenic found in unweathered glassy tuffs in comparison to the other categories, rather than differences produced by weathering in both glassy and devitrified tuffs. When compared directly there is no significant difference between weathered tuffs and unweathered devitrified tuffs (Figure 14). 


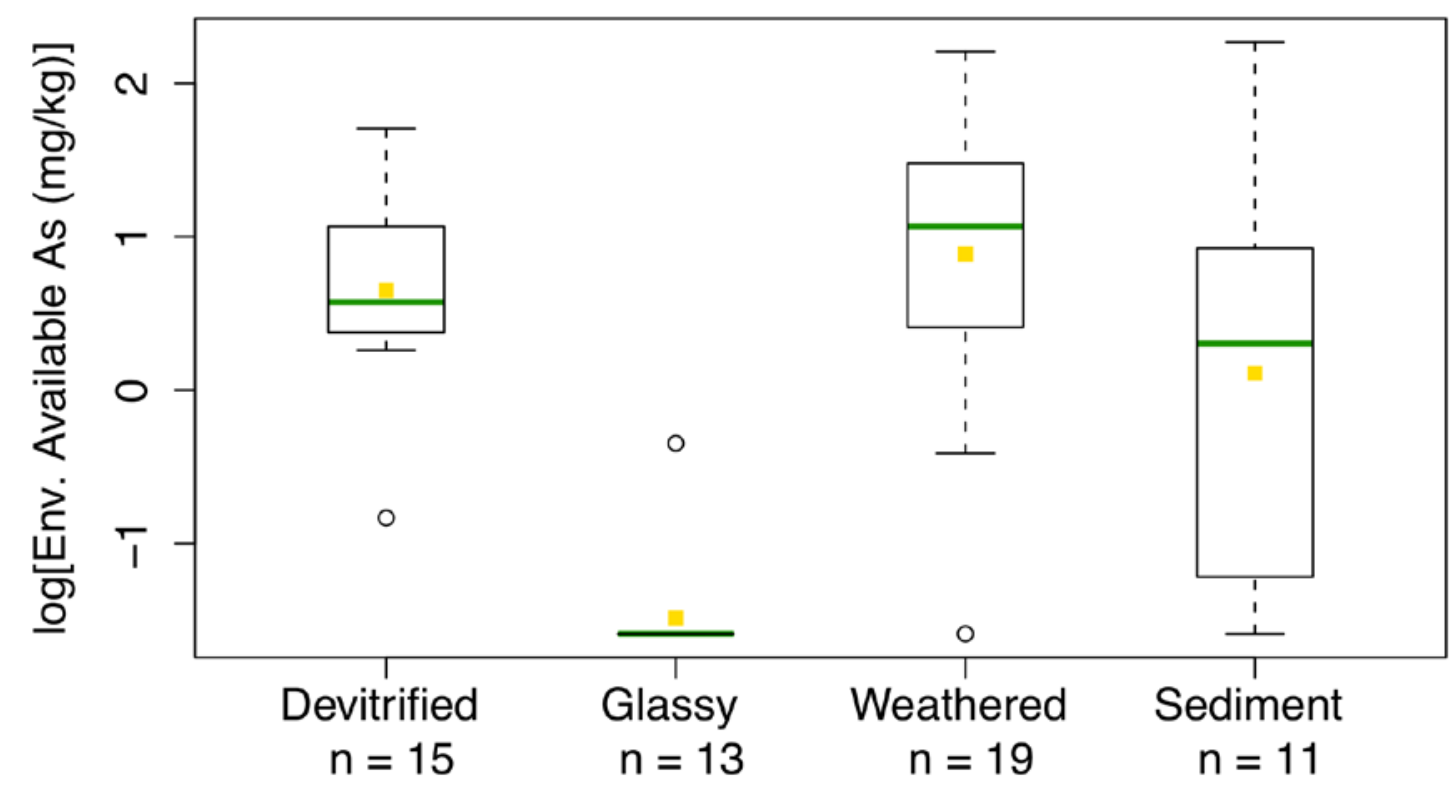

Figure 14. Environmentally available fraction of arsenic present in tuffs and tuffaceous sediments. Yellow squares indicate mean values. In unweathered glassy tuffs significantly less of the total arsenic is present in the environmentally available fraction than is found in devitrified or weathered tuffs, or tuffaceous sediments.

When the weathered tuff category is broken into originally glassy and originally devitrified samples the difference between glassy and devitrified samples is more apparent. Weathering does not produce a higher proportion of environmentally available arsenic in devitrified tuffs, but does produce a significantly higher proportion of environmentally available arsenic in glassy tuffs (Figure 15). 
Devitrified Tuffs

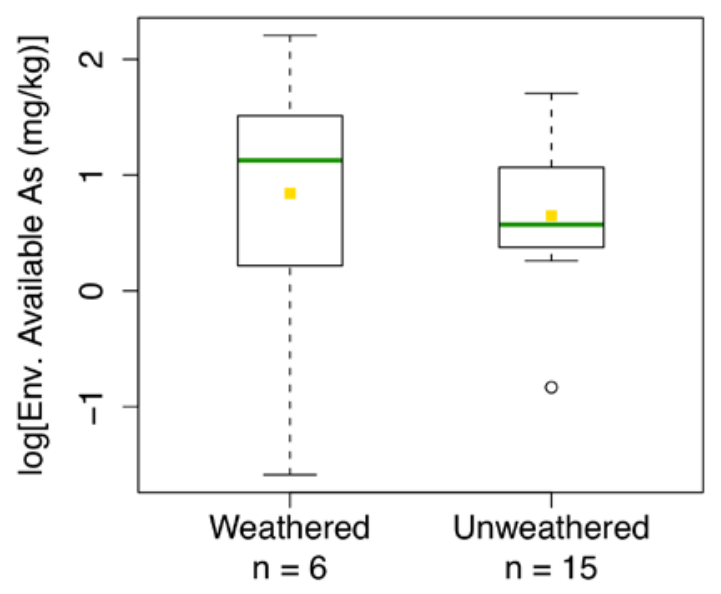

Glassy Tuffs

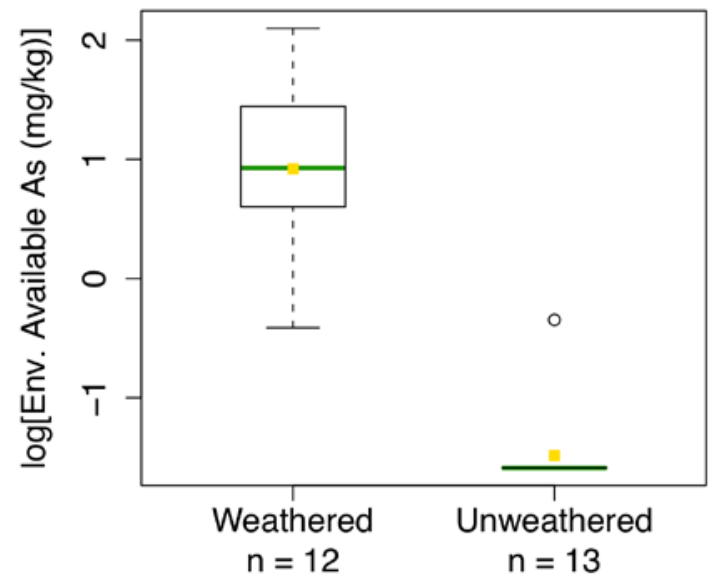

Figure 15. Environmentally available fraction of arsenic present in devitrified and glassy tuffs, by degree of weathering. Yellow squares indicate mean values. Weathering produces substantial differences in the environmentally available fraction of arsenic in glassy tuffs, but the difference between weathered and unweathered devitrified tuffs is not significant.

There are statistically significant positive correlations between environmentally available arsenic and total arsenic in all categories of samples except unweathered glassy tuffs (Figure 16). For devitrified and weathered tuffs, as well as tuffaceous sediments, regressions between total and available arsenic remain statistically significant $(\mathrm{p}<0.05)$ even when samples identified as outliers are removed. 


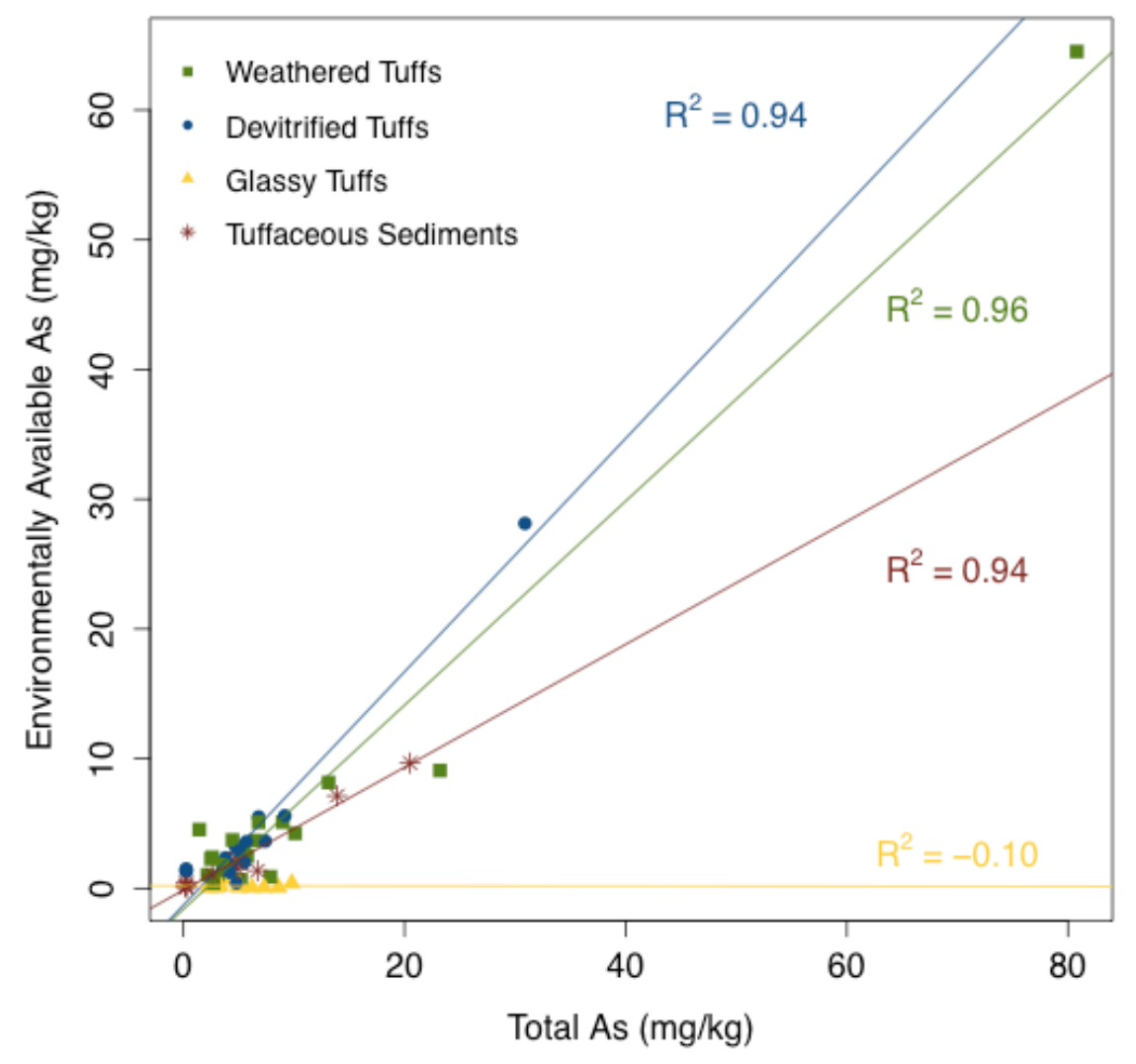

Figure 16. Environmentally available arsenic as a function of total arsenic concentrations. There is a direct relationship between total and available arsenic in all categories except glassy tuffs.

\section{Readily Leachable Arsenic}

The majority of tuff samples, including all unweathered glassy samples, produced levels of readily leachable arsenic below the method detection limit (MDL) of $102 \mu \mathrm{g}$ $\mathrm{kg}^{-1}$. Among the samples that produced detectable levels of arsenic, the geometric mean concentration was $236 \mu \mathrm{g} \mathrm{kg}^{-1}$, and the median concentration was $219 \mu \mathrm{g} \mathrm{kg}^{-1}$ (Table 22). 
Table 22. Readily leachable fraction of arsenic present in ash-flow tuffs and tuffaceous sediments. Values in parentheses indicate values that include samples below the MDL of $102 \mu \mathrm{g} / \mathrm{kg}$.

\begin{tabular}{cccccc}
\hline \hline & $\begin{array}{c}\text { Mean } \\
(\mu \mathrm{g} / \mathrm{kg})\end{array}$ & $\begin{array}{c}\text { Geometric } \\
\text { Mean } \\
(\mu \mathrm{g} / \mathrm{kg})\end{array}$ & $\begin{array}{c}\text { Median } \\
(\mu \mathrm{g} / \mathrm{kg})\end{array}$ & $\begin{array}{c}\text { Standard } \\
\text { Deviation } \\
(\mu \mathrm{g} / \mathrm{kg})\end{array}$ & $\begin{array}{c}\text { Median } \\
\text { Absolute } \\
\text { Deviation } \\
(\mu \mathrm{g} / \mathrm{kg})\end{array}$ \\
\hline All Tuffs $\mathrm{n}=9(49)$ & $266(90.5)$ & $236(67.6)$ & $219(51.1)$ & $131(99.6)$ & $159(0)$ \\
Weathered Tuffs $\mathrm{n}=5(20)$ & $282(109)$ & $258(76.5)$ & $219(51.1)$ & $135(120)$ & $111(0)$ \\
Unweathered Tuffs $\mathrm{n}=4(29)$ & $245(77.9)$ & $212(62.1)$ & $248(51.1)$ & $143(82.7)$ & $178(0)$ \\
Devitrified $\mathrm{n}=4(16)$ & $245(96.8)$ & $212(71.3)$ & $248(51.1)$ & $143(105)$ & $178(0)$ \\
Glassy $\mathrm{n}=13$ & $\mathrm{ND}$ & ND & ND & ND & ND \\
Tuffaceous Sediments $\mathrm{n}=7(11)$ & 1232 & $1134(367)$ & $2174(192)$ & 1330 & $1270(208)$ \\
\hline
\end{tabular}

For statistical purposes non-detect values were replaced with a value of $0.5 \mathrm{x}$ MDL (Antweiler, 2008; Clark, 1998). Arsenic levels in the leachable fraction were positively skewed, and appeared to be lognormally distributed, so values were log transformed and Shapiro-Wilk tests of normality were performed on arsenic concentrations for tuffs, tuffaceous sediments, and the different categories of tuff samples. At a significance level of $\alpha=0.05$, all categories of tuffs and tuffaceous sediments were found to be normally distributed, with the exception of glassy tuffs where all samples had identical values (Table 23). Details of statistical methods can be found in Appendix B.

Table 23. Test statistics (W) and p-values for Shapiro-Wilk tests of normality.

\begin{tabular}{lcc}
\hline \hline & $\mathrm{W}$ & $\mathrm{p}$-Value \\
\hline All Tuffs $\mathrm{n}=46$ & 0.498 & $1.03 \mathrm{E}-11$ \\
Weathered Tuffs $\mathrm{n}=18$ & 0.596 & $2.68 \mathrm{E}-06$ \\
Unweathered Tuffs $\mathrm{n}=29$ & 0.412 & $1.07 \mathrm{E}-09$ \\
$\quad$ Devitrified $\mathrm{n}=16$ & 0.554 & $3.84 \mathrm{E}-06$ \\
$\quad$ Glassy $\mathrm{n}=13$ & $\mathrm{NA}$ & $\mathrm{NA}$ \\
Tuffaceous Sediments $\mathrm{n}=10$ & 0.787 & 0.006 \\
\hline
\end{tabular}


Parametric $\mathrm{F}$ tests for equality of variances were performed on log transformed readily leachable arsenic values. At a significance level of $\alpha=0.05$, tuffs and tuffaceous sediments, as well as devitrified and glassy tuffs, were found to have unequal variances. The variances of weathered and unweathered tuffs were not found to be statistically distinct (Table 24).

Table 24. Test statistics (F), numerator and denominator degrees of freedom, and p-values for $\mathrm{F}$ tests of eqaulity of variances.

\begin{tabular}{lcccc}
\hline \hline & F & df1 & df2 & p-Value \\
\hline Tuffs v. Tuffaceous Sediments & 8.9 & 10 & 48 & $9.38 \mathrm{E}-08$ \\
Weathered v. Unweathered Tuffs & 0.52 & 28 & 19 & 0.113 \\
Devitrified v. Glassy & Inf & 16 & 11 & $<2.2 \mathrm{e}-16$ \\
\hline
\end{tabular}

Two sample students t-tests were performed on log transformed arsenic levels in the different categories of samples. At a significance level of $\alpha=0.05$, the means of glassy and devitrified tuffs were found to be unequal, while weathered and unweathered tuffs were not found to be statistically distinguishable (Table 25).

Table 25. Test statistic (t), number of samples, and p-values for two sample students t-tests of equality performed on sample categories.

\begin{tabular}{lcccc}
\hline \hline & $\mathrm{t}$ & $\mathrm{n} 1$ & $\mathrm{n} 2$ & $\mathrm{p}$-Value \\
\hline Tuffs v. Tuffaceous Sediments & 2.92 & 49 & 11 & 0.015 \\
Weathered v. Unweathered Tuffs & -1.07 & 20 & 29 & 0.295 \\
Devitrified v. Glassy & 2.02 & 16 & 13 & 0.060 \\
\hline
\end{tabular}

Unlike the total or environmentally available fractions, the readily leachable fraction did show a significant difference between tuffs and tuffaceous sediments (Figure 17, Table 25). Tuffaceous sediments contain both much higher arsenic concentrations and a much larger range of readily leachable arsenic concentrations than all categories of tuff 
samples. Both weathered and devitrified samples display a wider range of readily leachable arsenic levels than glassy tuffs (Figure 17).

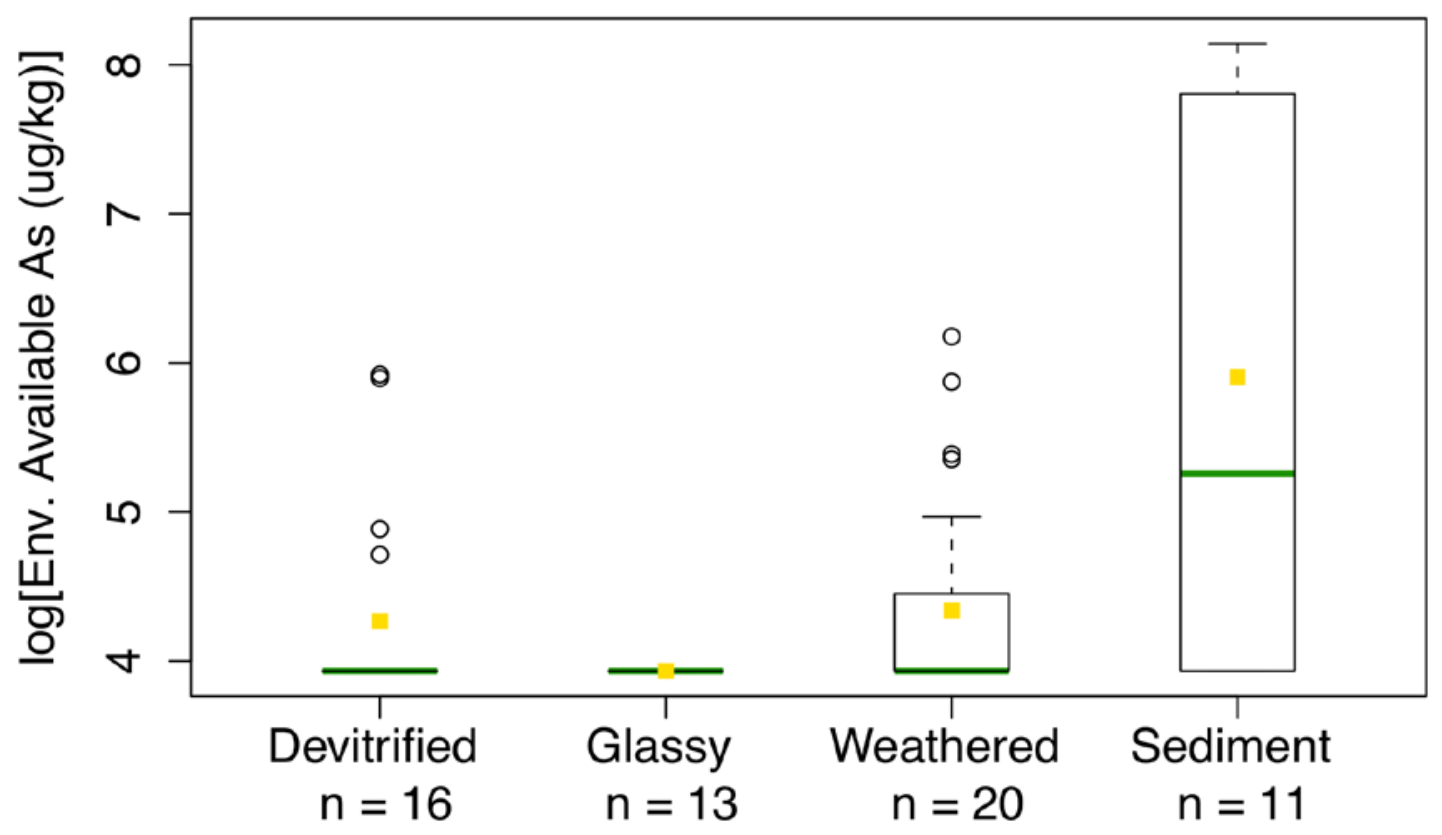

Figure 17. Readily leachable arsenic contents of ash-flow tuffs and tuffaceous sediments. Yellow boxes represent mean values. Tuffaceous sediments contained significantly more readily leachable arsenic than all categories of tuffs. Devitrified and weathered tuffs showed a greater range of readily leachable arsenic values than unweathered glassy tuffs.

Unlike the environmentally available fraction of arsenic, the readily leachable fraction shows no correlation with total arsenic for any category of sample (Figure 18). 


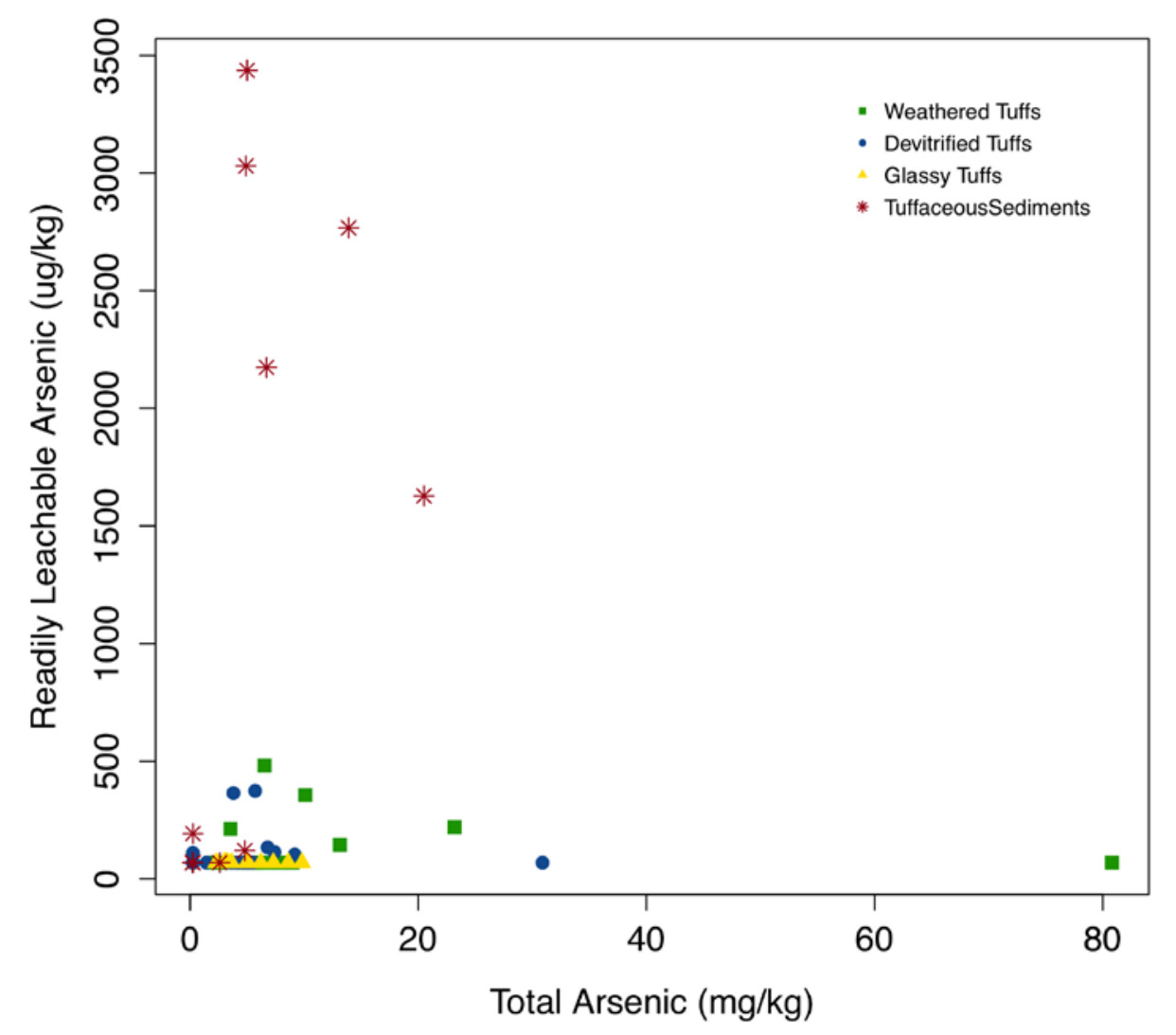

Figure 18. Readily leachable arsenic as a function of total arsenic present in samples. There is no correlation between the total amount of arsenic present in tuffs and sediments and the amount present in the readily leachable fraction.

Although the majority of tuff samples did not produce detectable levels of arsenic during water leaching experiments, individual samples of both devitrified and weathered tuffs and tuffaceous sediments did produce relatively high aqueous arsenic concentrations (Table 26). 
Table 26. Aqueous arsenic concentrations produced by water leaching experiments. Descriptive statistical values only include samples that exceeded method detection limits.

\begin{tabular}{lccccc}
\hline \hline & $\begin{array}{c}\text { Mean } \\
(\mathrm{ug} / \mathrm{L})\end{array}$ & $\begin{array}{c}\text { Median } \\
(\mathrm{ug} / \mathrm{L})\end{array}$ & $\begin{array}{c}\text { Std } \\
\text { Dev } \\
(\mathrm{ug} / \mathrm{L})\end{array}$ & $\begin{array}{c}\text { Min } \\
(\mathrm{ug} / \mathrm{L})\end{array}$ & $\begin{array}{c}\text { Max } \\
(\mathrm{ug} / \mathrm{L})\end{array}$ \\
\hline Tuffs $(\mathrm{n}=18)$ & 8.1 & 5.3 & 7.1 & $1.7 *$ & 24.0 \\
Weathered $(\mathrm{n}=8)$ & 9.7 & 8.9 & 8.0 & 2.0 & 24.0 \\
Devitrified $(\mathrm{n}=10)$ & 6.8 & 4.4 & 6.3 & 1.7 & 18.7 \\
Sediments $(\mathrm{n}=7)$ & 95.4 & 108.7 & 66.5 & 6.2 & 171.9 \\
\hline * Value is equivalent to the instrument detection limit of $1.7 \mathrm{ug} / \mathrm{L}$, and \\
should be considered semi-quantitative.
\end{tabular}

Overall, $12 \%$ of tuff samples and $45 \%$ of tuffaceous sediments produced aqueous arsenic concentrations exceeding EPA MCLs in only 18 hours, with some sediment samples approaching 20x the MCL of $10 \mathrm{ppb}$ (Figure 19). 


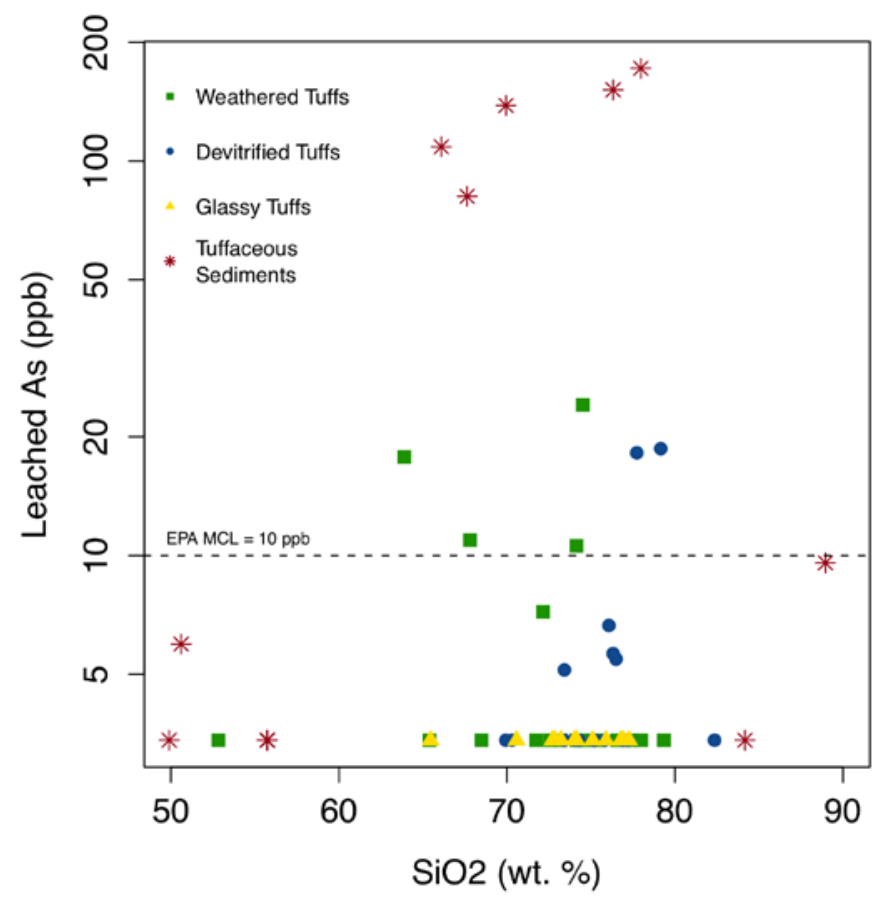

Figure 19. Aqueous arsenic concentrations produced by water leaching experiments. Weathered and devitrified tuffs and tuffaceous sediments all produced aqueous arsenic concentrations exceeding regulatory limits.

$\mathrm{pH}-$ Dependent Arsenic Mobility

Mean arsenic values increased as solution $\mathrm{pH}$ was increased between $\mathrm{pH} 9$ and pH 11 for both devitrified and weathered tuffs, while glassy tuffs produced no arsenic concentrations above detection limits at either $\mathrm{pH}$ (consistent with the results from the unbuffered solutions). The increase in arsenic was minor for devitrified tuffs (92 to 124 $\mu \mathrm{g} \mathrm{kg}^{-1}$ ) but substantial for weathered tuffs (197 to $1068 \mu \mathrm{g} \mathrm{kg}^{-1}$ ).

Patterns of arsenic mobility become clearer when the results of the controlled $\mathrm{pH}$ leaching experiments are compared with the readily leachable fraction of arsenic for the same samples. Unfortunately, the final $\mathrm{pH}$ of the readily leachable solutions was not 
measured for all samples. Of the solutions that were measured, $\mathrm{pH}$ levels varied between 6.2 and 8.9 with a mean value of 8.0. Arsenic concentrations of weathered tuffs at the circum-neutral $\mathrm{pH}$ conditions of the readily leachable extractions were slightly lower than arsenic concentrations at $\mathrm{pH} \mathrm{9,} \mathrm{and} \mathrm{arsenic} \mathrm{concentrations} \mathrm{appear} \mathrm{to} \mathrm{increase} \mathrm{at} \mathrm{varying}$ rates with increases in $\mathrm{pH}$ (Figure 20). In contrast, arsenic concentrations in devitrified tuffs actually decrease slightly between circum-neutral conditions and $\mathrm{pH} 9$, and then increase slightly at $\mathrm{pH} 11$, producing no clear relationship between $\mathrm{pH}$ and leachable arsenic in devitrified samples (Figure 20). Although the standard error bars for the devitrified and weathered samples overlap, a Mann-Whitney-Wilcoxon test confirms that the arsenic concentrations are significantly different $(\mathrm{p}=0.03)$. 


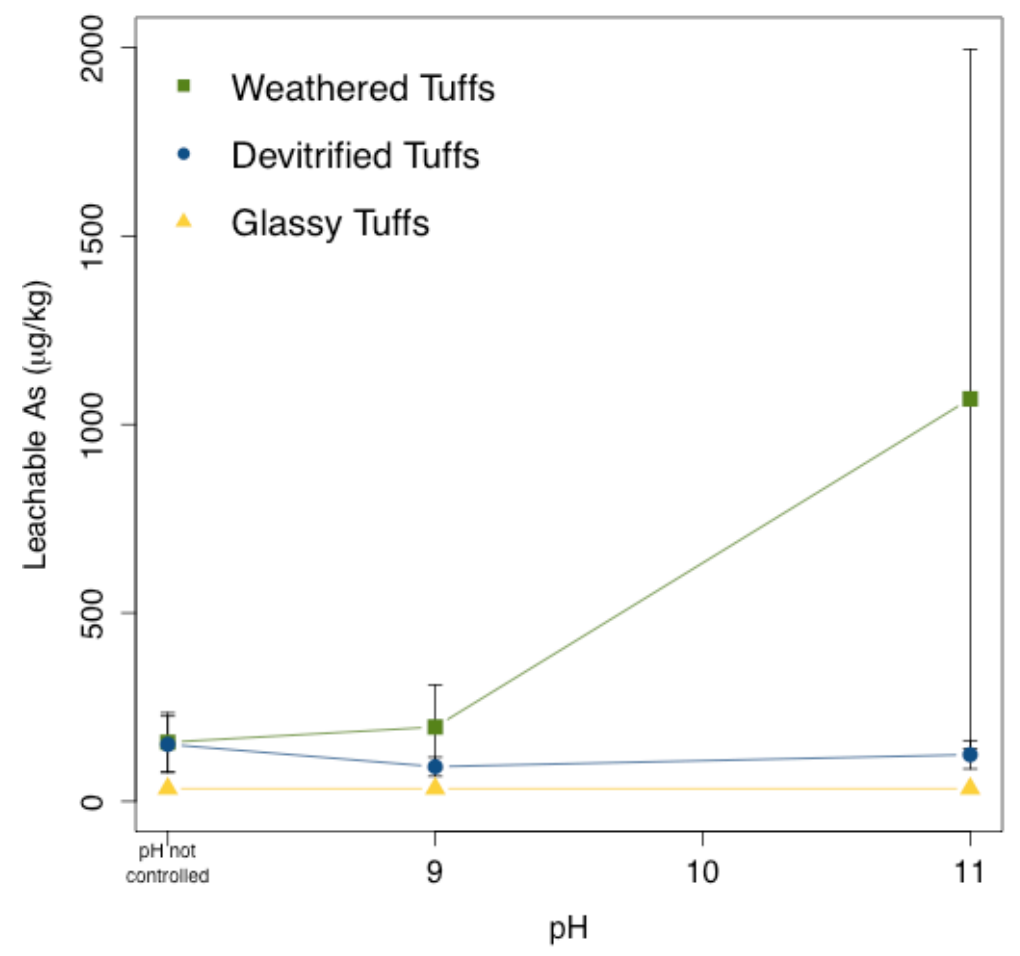

Figure 20. Arsenic concentrations from leaching experiments with uncontrolled $\mathrm{pH}$ compared with concentrations produced at $\mathrm{pH} 9$ and 11. In weathered tuffs arsenic concentrations increased slightly from the circum-neutral conditions of the uncontrolled leachate experiments to $\mathrm{pH} 9$, while arsenic concentrations decreased slightly between circum-neutral conditions and $\mathrm{pH} 9$.

\section{Elemental Correlations}

For both fractions of mobile arsenic tests of correlation between arsenic and other elements were performed on log transformed data with outliers excluded using the nonparametric Spearman's rank correlation coefficient. In both the environmentally available fraction and the readily leachable fraction arsenic displayed statistically significant $(\mathrm{p}<$ $0.05)$ correlations with a variety of elements (Table 27). 
Table 27. Statistically significant $(\mathrm{p}<0.05)$ elemental correlations with arsenic. Italicized elements showed a negative correlation with arsenic, while un-italicized elements showed a positive correlation.

\begin{tabular}{|c|c|c|}
\hline & $\begin{array}{c}\text { Environmentally } \\
\text { Available Fraction }\end{array}$ & $\begin{array}{l}\text { Readily Leachable } \\
\text { Fraction }\end{array}$ \\
\hline All Tuffs $(n=47)$ & $\begin{array}{c}\mathrm{Al}, \mathrm{Ca}, \mathrm{Cd}, \mathrm{Ce}, \mathrm{Co}, \\
\mathrm{Cu}, \mathrm{Fe}, \mathrm{La}, \mathrm{Pb}, \mathrm{Sm}, \mathrm{Sr}, \\
\mathrm{Ti}, \mathrm{V}, \mathrm{Zn}\end{array}$ & $\begin{array}{c}\mathrm{Al}, \mathrm{Ba}, \mathrm{Cu}, \mathrm{Fe}, \mathrm{Si}, \mathrm{Ti}, \mathrm{V}, \\
\mathrm{Zn}\end{array}$ \\
\hline Weathered Tuffs $(n=19)$ & $\mathrm{Ce}, C o, \mathrm{La}, P, S, V$ & $\mathrm{Al}, \mathrm{Fe}, \mathrm{Si}, \mathrm{Ti}, \mathrm{Zn}$ \\
\hline Unweathered Tuffs $(\mathrm{n}=28)$ & $\begin{array}{l}\mathrm{Ba}, \mathrm{Cd}, \mathrm{Ce}, \mathrm{Co}, \mathrm{Cu}, \\
\mathrm{Fe}, \mathrm{La}, \mathrm{Mn}, \mathrm{Mo}, \mathrm{Na} \\
\mathrm{Ni}, \mathrm{P}, \mathrm{Pb}, \mathrm{Sm}, \mathrm{V}, \mathrm{Zn}\end{array}$ & Mo, V \\
\hline Devitrified Tuffs $(\mathrm{n}=15)$ & $\mathrm{Mn}, \mathrm{S}, \mathrm{V}$ & Mo \\
\hline Glassy Tuffs $(\mathrm{n}=13)$ & None & None \\
\hline Tuffaceous Sediments $(n=11)$ & $\mathrm{Ce}, \mathrm{S}$ & $\mathrm{Ca}, \mathrm{Mo}, \mathrm{S}, \mathrm{Sr}$ \\
\hline
\end{tabular}

In the environmentally available fraction, arsenic is positively correlated with a variety of elements including $\mathrm{Al}, \mathrm{Ca}, \mathrm{Fe}, \mathrm{Sr}$, and $\mathrm{Zn}$. In the readily leachable fraction arsenic is positively correlated with $\mathrm{Al}, \mathrm{Fe}, \mathrm{Si}$ and $\mathrm{Zn}$, among others. Tuffaceous sediments were positively correlated with $\mathrm{S}$ in both the environmentally available and readily leachable fractions. Although the correlation coefficients were statistically significant $(\mathrm{p}<0.05)$, linear regression analysis determined that few of the correlations were reflective of strong linear relationships between arsenic and other elements $\left(\mathrm{R}^{2}<0.60\right)$. The two exceptions to this were the correlations between readily leachable arsenic and Fe in weathered samples, and readily leachable arsenic and Mo in devitrified samples (Figure 21). 


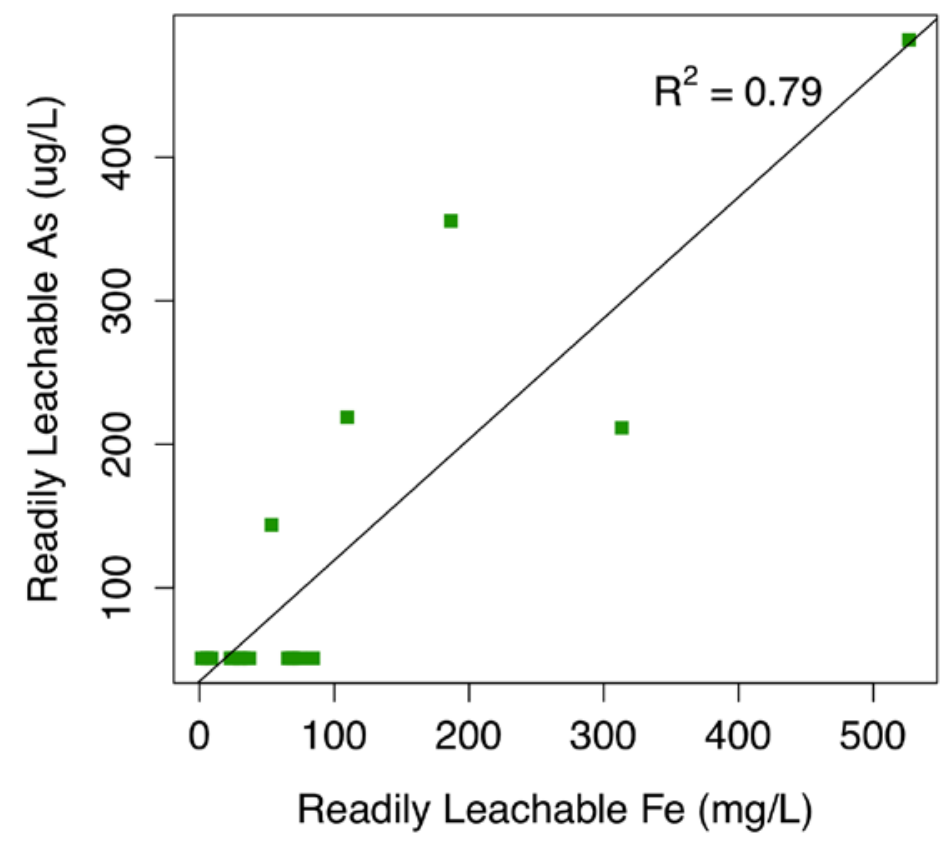

Figure 21. Linear relationship between readily leachable arsenic and iron in weathered tuff samples, $\mathrm{p}=$ $1.8 \mathrm{e}-07$.

\section{DISCUSSION}

\section{Potential Host Phases of Arsenic}

The behavior of arsenic in both mobile fractions provides a number of indications that different host phases of arsenic exist in different categories of tuffs. My results indicate that in glassy tuffs arsenic is hosted in the glass phase. No glassy tuffs produced leachable arsenic under any $\mathrm{pH}$ conditions, indicating that arsenic is neither sorbed to mineral surfaces nor hosted in an easily soluble mineral phase. In addition, glassy tuffs 
contain significantly less environmentally available arsenic than other categories of tuffs, and are the only category of sample that does not show a positive correlation between total arsenic and environmentally available arsenic. This indicates that the bulk of the arsenic in glassy samples in bound in a silicate phase that is not dissolved in the partial digestions used to identify the environmentally available fraction. In glassy tuffs the most abundant silicate phase is the glass itself, which makes up the majority of the volume of glassy tuffs. Glass is also the most likely silicate phase to host arsenic since it is produced by quenching of lavas which can retain relatively high proportions of volatiles in comparison to silicate minerals.

In devitrified tuffs the most likely host phase of arsenic is a non-silicate mineral phase. Devitrified tuffs contain a relatively high percentage of their arsenic in the environmentally available fraction $($ median $=57 \%, \max =90 \%$ ), and there is a strong positive correlation between total and environmentally available arsenic, which indicates that the bulk of the arsenic in these samples is not hosted in a silicate phase, because silicates are resistant to $\mathrm{HNO}_{3}{ }^{-}$treatment. The correlation between total and mobile arsenic is not seen in the readily leachable fraction, indicating that arsenic is not hosted in a highly soluble phase. Finally, leachable arsenic levels in devitrified tuffs do not increase with increasing $\mathrm{pH}$, ruling out sorption to mineral surfaces as a potential host phase of arsenic in these samples.

While these results show that a non-silicate mineral phase is the most likely host of arsenic in devitrified tuffs it is not clear what specific mineral or minerals this might 
be. Vapor phase alteration that occurs during devitrification has the potential to produce a variety of minerals that would be likely host phases (particularly sulfides and phosphates), but as a result of their typical small size and low abundance, these minerals were not identified in the solid phase characterization performed during this study. Vapor phase mineralization is also highly variable, so it is possible that devitrified tuffs could contain multiple mineral phases enriched in arsenic and that these phases could differ between different tuffs.

In weathered tuffs the most likely host phase of arsenic is Fe-oxides and oxyhydroxides, as well as other alteration products including clay surfaces. Similarly to devitrified tuffs, weathered tuffs both contain a high percentage of their total arsenic in the environmentally available fraction and show a strong positive correlation between total and environmentally available arsenic, indicating a non-silicate host phase. In contrast to devitrified tuffs, weathered tuffs do show an increase in leachable arsenic with increasing $\mathrm{pH}$, which indicates that sorption to grain surfaces likely plays a role in the behavior of arsenic. Weathering produces a range of alteration products that are potential sorbents for arsenic, including Fe-oxides and oxyhydroxides, kaolinite and illite clay minerals, and some zeolites, including clinoptilolite (Manning and Goldberg, 1996; Stollenwerk, 2003). Fe-oxides and oxyhydroxides are generally considered the most likely sorbent of arsenic, due to both their ubiquity and high concentration of surface sites. A positive correlation between $\mathrm{Fe}$ and arsenic was found in the readily leachable fraction, although the same relationship was not observed in the environmentally available fraction. 
In glassy tuffs the weathering process produces higher levels of environmentally available arsenic than is present in unweathered tuffs, but this is not the case for devitrified tuffs. In glassy tuffs the relationship between weathered and unweathered samples is relatively straightforward. The differences between environmentally available arsenic in unweathered vs. weathered glassy tuffs, combined with the $\mathrm{pH}$ dependence of arsenic leachability from weathered samples suggests that during weathering arsenic is released from the glass phase and subsequently sorbs to alteration products.

The fate of arsenic during the weathering of devitrified tuffs is much less clear. One possible scenario is that arsenic behaves largely as it does in glassy tuffs, and is released from its non-silicate mineral phase and subsequently sorbs to alteration products. Another potential scenario is that only portions of the arsenic present in the non-silicate mineral host phase(s) is released and subsequently sorbed, producing weathered tuffs that contain both sorbed arsenic and arsenic hosted in minerals, resulting in two distinct arsenic host phases that both produce environmentally available arsenic.

In tuffaceous sediments the potential host phase or phases of arsenic remains more enigmatic than in tuffs themselves. Tuffaceous sediments display the same behavior of arsenic in the environmentally available fraction as weathered and devitrified tuffs (a high percentage of arsenic present in the environmentally available fraction and a strong correlation between total and environmentally available arsenic concentrations) that indicate a non-silicate host phase. In tuffaceous sediments the question of what that phase might be is more difficult to answer. The correlation between arsenic and $\mathrm{S}$ in both 
mobile fractions of the samples suggests that sulfide minerals are a likely host. However, tuffaceous sediments contain a high percentage $($ mean $=27 \%, \max =77 \%)$ of their total arsenic in the readily leachable fraction, and sulfide minerals are not highly soluble and would not be expected to produce high levels of leachable arsenic over short time periods in circum-neutral waters. Although contact with oxygenated waters would be expected to result in redox-driven dissolution of sulfide minerals, the 18 hour time period was likely insufficient for those reactions to fully occur.

One factor that is important to note is that with the exception of TW2, a volcaniclastic conglomerate from the Willamette Valley, all of the sediment samples in this study come from the Owyhee Upland physiographic province of Oregon and were formed in a similar arid climate. It is possible that environmental conditions and depositional processes played a significant role in determining both the overall arsenic concentrations and the host phase of arsenic in these samples. For example, evaporative concentration of arsenic during reworking of the tuffaceous material may have contributed to high levels of arsenic in some sediments. It may not be appropriate to use these samples to draw conclusions about arsenic in tuffaceous sediments from other regions, particularly if those regions have significantly different climates.

\section{Potential Mechanisms of Arsenic Mobilization}

Based on the different host phases tentatively identified for different categories of tuff, the mechanisms by which arsenic is mobilized from those categories will differ as well. In glassy tuffs the most likely mechanism of arsenic mobilization is the relatively 
slow dissolution of the glass phase. This is consistent with previous research that identified dissolution of volcanic glass as a primary geochemical control on arsenic levels in one groundwater system in the American Southwest (Johannesson and Tang, 2009). The fact that dissolution of glass is a relatively slow process, combined with the lack of arsenic concentrations exceeding $10 \mathrm{mg} \mathrm{kg}^{-1}$ in glassy tuff samples, suggests that unweathered glassy tuffs present a lower risk of producing aqueous arsenic concentrations exceeding regulatory limits than other categories of tuff.

The most likely mechanism of mobilizing arsenic from devitrified tuffs is the dissolution of the non-silicate mineral host phase. Two of the unweathered devitrified samples in this study produced aqueous arsenic concentrations exceeding $10 \mu \mathrm{g} \mathrm{L}^{-1}$ in the water extraction experiment, indicating that at least some of the potential minerals hosting arsenic may be relatively soluble. Without a better understanding of what those minerals may be it is unclear what geochemical conditions might present greater risks of arsenic contamination sourced from devitrified tuffs.

In weathered tuffs the most likely mechanism of arsenic mobilization is desorption from mineral grain surfaces. The presence of sorbed arsenic in weathered tuffs means that a variety of geochemical conditions present increased risk of tuff-sourced arsenic contamination. Groundwaters with high $\mathrm{pH}$, reducing conditions, and high concentrations of competing anions, particularly phosphate, can all result in desorption of arsenic from mineral grains and its release into solution. 


\section{CHAPTER 4: CONCLUSIONS}

\section{Conclusions and Conceptual Model}

Arsenic concentrations in high silica ash-flow tuffs have a geometric mean value

of $4.8 \mathrm{mg} \mathrm{kg}^{-1}$, which is consistent with previously reported values and approximately 2.8 times the mean crustal abundance of $1.7 \mathrm{mg} \mathrm{kg}^{-1}$ (Onishi and Sandell, 1955; Wedepohl, 1995). Arsenic levels in tuffs are highly heterogenous both between and within units, and can reach levels exceeding $80 \mathrm{mg} \mathrm{kg}^{-1}$. Additionally, $12 \%$ of ash-flow tuffs and $45 \%$ of tuffaceous sediments are capable of producing aqueous arsenic concentrations that exceed regulatory limits over a short period of time.

In addition to confirming the widespread idea that high silica ash-flow tuffs and tuffaceous sediments are a potential source of geogenic arsenic contamination, the results of this study indicate that the host phases and potential mechanisms of arsenic mobilization differ between categories of tuffs, and suggest a conceptual model for the behavior of arsenic in tuffs. The conceptual model suggested by these results includes factors influencing the total concentrations of arsenic in tuffs, changes in arsenic host phases during both devitrification and weathering, and potential mechanisms for the mobilization of arsenic into the environment (Figure 22). 

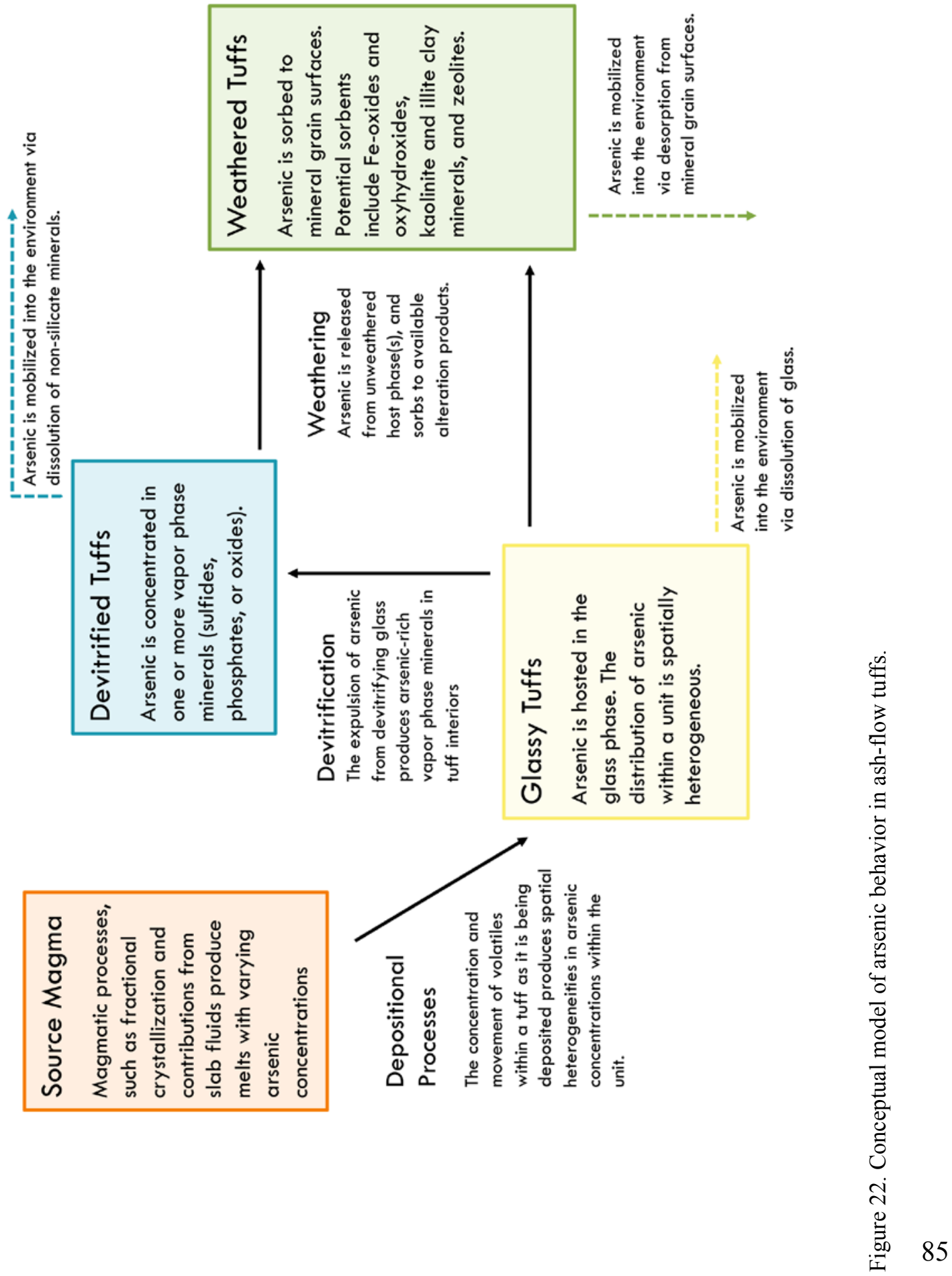
Future Work

Further identification of specific host phases should be pursued, particularly in devitrified tuffs and tuffaceous sediments. While the results of this study indicate that one or more non-silicate mineral phases are the most likely host phase of arsenic in devitrified tuffs it is still unclear what those mineral phases may be. The process of vapor phase mineralization provides a wide range of options, but identification of specific minerals would be valuable in determining what geochemical conditions present an increased risk of arsenic mobilization from devitrified tuffs. In the tuffaceous sediments investigated in this study it is still largely unclear what the host phase of arsenic may be, and how much that may be influenced by environmental conditions during the formation of these units.

Additional exploration into the role of solution chemistry in arsenic mobility should be continued as well. Investigating the leaching behavior of arsenic over a full range of $\mathrm{pH}$ values would provide additional insight into sorption processes in weathered tuffs, and potentially identify additional geochemical conditions that facilitate mobilization of arsenic from other categories of tuffs. Other variables that would be valuable to explore are redox state and concentration of competing anions.

Finally, further investigations into possible patterns of spatial distribution of arsenic within individual tuff units should be pursued. Spatial patterns of arsenic distribution, whether vertical patterns within the interior of the tuff, or lateral patterns varying with distance from the eruptive center, could potentially be of great use in assessing the risk of arsenic contamination at specific geographic locations. This study 
did not investigate possible lateral patterns of arsenic distribution, and provided inconclusive results with regard to vertical patterns of arsenic distribution. 


\section{WORKS CITED}

Amini, M., Abbaspour, K. C., Berg, M., Winkel, L., Hug, S. J., Hoen, E., Yang, H., and Johnson, C. A., 2008, Statistical Modeling of Geogenic Arsenic Contamination in Groundwater: Environmental Science \& Technology, v. 42, no. 10, p. 3669 33675.

Antweiler, R. C., Taylor, H.E., 2008, Evaluation of statistical treatments of left-censored environmental data using coincident uncensored data sets: I. Summary statistics: Environmental Science \& Technology, v. 42, p. 3732 - 3738.

Borisova, A. Y., Pokrovski, G.S., Pichavant, M., Freydier, R., and Candaudap, F., 2010, Arsenic enrichment in hydrous peraluminous melts: Insights from femtosecond laser ablation-inductively coupled plasma-quadrupole mass spectrometry, and in situ X-ray absorption fine structure spectrocsopy.: American Mineralogist, v. 95, p. 1095-1104.

Brown, K. G., and Ross, G. L., 2002, Arsenic, drinking water, and health: A position paper of the American Council on Science and Health: Regulatory Toxicology and Pharmacology, v. 36, p. 162-174.

Casentini, B., Pettine, M., and Millero, F., 2010, Release of Arsenic from Volcanic Rocks through Interactions with Inorganic Anions and Organic Ligands: Aquatic Geochemistry, v. 16, no. 3, p. 373-393.

Chen, M., Ma, L.Q., 1998, Comparison of four USEPA digestion methods for trace metal analysis using certified and Florida soils: Journal of Environmental Quality, v. 27, no. 6, p. $1294-1300$.

Clark, J. U., 1998, Evaluation of censored data methods to allow statistical comparisons among very small samples with below detection observations: Environmental Science \& Technology, v. 32, p. 177 - 183.

Cullen, W. R., and Reimer, K. J., 1989, Arsenic speciation in the environment: Chemical Reviews, v. 89, no. 4, p. 713-764.

Das, G. P., 2007, Ash weathering controls on contaminant leachability [Doctor of Philosophy: University of North Carolina at Charlotte, 305 p.

Davis, J. A., and Kent, D. B., 1990, Surface complexation modeling in aqueous geochemistry, in Hochella, M. F., and White, A. F., eds., Mineral-Water interface geochemistry: Washington, D.C., Mineralogical Society of America, p. 177-248.

Dixit, S., and Hering, J., 2003, Comparison of Arsenic(V) and Arsenic(III) Sorbtion onto Iron Oxide Minerals: Implications for Arsenic Mobility: Environmental Science \& Technology, v. 37, no. 18, p. 7.

Ferns, M. L., Madin, I.P., and Taubeneck, W.H., 2001, Reconnaissance Geologic Map of the La Grande 30'X60' quadrangle, Baker, Grant, Umatilla, and Union Counties, Oregon: Oregon Department of Geology and Mineral Industries, scale 1:100,000.

Fiantis, D., Nelson, M., Shamshuddin, J., Goh, T. B., and Van Ranst, E., 2010, Determination of geochemical weathering indicies and trace elements content of new volcanic ash deposits from Mt. Talang (West Sumatra) Indonesia: Eurasian Soil Science, v. 43, no. 13, p. 1477-1485. 
Fisher, R. V., and Schmincke, H.-U., 1984, Pyroclastic rocks, Berlin, Springer-Verlag, 471 p.:

Goldberg, S., 2002, Competetive adsoption of arsenate and arsenite on oxides and clay minerals: Soil Science Society of America Journal, v. 66, no. 2, p. 413-421.

Goldblatt, E. L., Van Denburgh, S. A., and Marsland, R. A., 1963, The unusual and widespread occurance of arsenic in well waters of Lane County Oregon: Lane County Health Department Report.

Hinkle, S. R., and Polette, D. J., 1999, Arsenic in ground water of the Willamette Basin, Oregon: U.S. Geological Survey, Water-Resources Investigation Report 98-4205.

Hooper, P. R., Binger, G.B., and Lees, K.R., 2002, Ages of the Steens and Columbia River flood basalts and their relationship to extension related calc-alkalic volcanism in eastern Oregon: Geological Society of America Bulletein, v. 110, p. 43-50.

Istok, J. D., Rautman, C. A., Flint, L. E., and Flint, A. L., 1994, Spatial Variability in Hydrologic Properties of a Volcanic Tuff: Ground Water, v. 32, no. 5, p. 751-760.

Jain, A., and Loeppert, R. H., 2000, Effect of competing anions in the adsorption of arsenate and arsenite by ferrihydrite: Journal of Environmental Quality, v. 29, p. 1422-1430.

Jang, J.-H., and Dempsey, B., 2008, Coadsorption of Arsenic(III) and Arsenic(V) onto Hydrous Ferric Oxide: Effects on Abiotic Oxidation of Arsenic(III), Extraction Efficiency, and Model Accuracy: Environmental Science \& Technology, v. 42, no. 8 , p. 5 .

Johannesson, K. H., and Tang, J., 2009, Conservative behavior of arsenic and other oxyanion-forming trace elements in an oxic groundwater flow system.: Journal of Hydrology, v. 378, p. 13-28.

Langmuir, D., 1997, Aqueous Environmental Geochemistry, Upper Saddle River, NJ, Prentice-Hall, Inc., 600 p.:

Lipman, P. W., 2006, Geologic map of the Central San Juan Caldera Cluster, southwestern Colorado, in Survey, U. S. G., ed., p. 34.

Manning, B. A., and Goldberg, S., 1996, Modeling Arsenate Competetive Adsorption on Kaolinite, Montmorillonite and Illite: Clays and Clay Minerals, v. 44, no. 5, p. 609-623.

Manning, B. A., and Goldberg, S., 1997, Adsorption and stability of arsenic(III) at the clay mineral-water interface: Environmental Science \& Technology, v. 31, no. 7, p. 2005-2011.

McClaughry, J. D., Ferns, M.L., Streck, M.J., Patridge, K.A., and Gordon, C.I., 2009, Paleogene calderas of central and eastern Oregon: Eruptive sources of widespread tuffs of the John Day and Clarno Formations, in O'Connor, J. E., Dorsey, R.J., and Madin, I.P., ed., Volcanoes to vineyards: geologic field trips through the dynamic landscape of the Pacific northwest: Geological Society of America field guide 15, p. 407-434.

McClaughry, J. D., Wiley, T.J., Ferns, M.L., and Madin, I.P., 2010, Digital geologic map of the wouthern Willamette Valley, Benton, Lane, Linn, Marion, and Polk Counties, Oregon, in Industries, O. D. o. G. a. M., ed., p. 116. 
Nadakavukaren, J. J., Ingerman, R. L., and Jeddeloh, G., 1984, Seasonal variation of arsenic concentration in well water in Lane County Oregon: Bulletin of Environmental Contamination and Toxicology, v. 33, no. 3, p. 264-269.

Ng, J. C., Wang, J., and Shraim, A., 2003, A global health problem caused by arsenic from natural sources: Chemosphere, v. 52, p. 1353-1359.

Nicolli, H. B., Suriano, J. M., Gomez Peral, M. A., Ferpozzi, L. H., and Baleani, O. H., 1989, Groundwater contamination with arsenic and other trace elements in an area of the Pampa province of Cordoba, Argentia: Environmental Geology and Water Sciences, v. 14, p. 3-16.

Noble, D. C., Ressel, M. W., Lechler, P. J., and Connors, K. A., 2004, Magamtic As, Sb, $\mathrm{Cs}, \mathrm{Bi}, \mathrm{Tl}$, and other elements in glassy volcanic rocks of the Julcani District, Peru, and the Carlin Trend, Nevada: Boletin de la Sociedad Geologica del Peru, v. 97, p. 29-50.

Noll, P. D., Newsome, H.E., Leeman, W.P., and Ryan, J.R., 1996, The role of hydrothermal fluids in the production of subduction zone magams: Evidence from siderophile and chalcophile trace elements and boron: Geochemica et Cosmochimica Acta, v. 60, p. 587 - 611.

Onishi, H., and Sandell, E. B., 1955, Geochemistry of arsenic: Geochemica et Cosmochimica Acta, v. 7, p. 1-33.

Patridge, K. A., 2010, Kaboom! A look back at the volcanic past of the John Day Basin., in Service, N. P., ed.: Denver, CO.

Ravenscroft, P., Brammer, H., and Richards, K. S., 2009, Arsenic pollution: a global synthesis, Chichester, United Kingdon, John Wiley \& Sons.

Retalleck, G. J., Bestland, E.A., and Fremd, T.J., 2000, Eocene and Oilgocene paleosols of Central Oregon: Geological Society of America Special Paper, v. 344, p. 192.

Rhine, E. D., Onesios, K., Serfes, M. E., Reinfelder, J. R., and Young, L. Y., 2008, Arsenic Transformation and Mobilization from Minerals by the Arsenite Oxidizing Strain WAO: Environmental Science \& Technology, v. 42, no. 5, p. 6.

Ross, C. S., and Smith, R. L., 1980, Ash flow tuffs: their origin, geologic relations, and identification and Zones and zonal variations in welded ash flows, p. 159.

Ryker, S. J., 2003, Arsenic in ground water used for drinking water in the United States, in Welch, A. H., and Stollenwerk, K. G., eds., Arsenic in groundwater: occurence and geochemistry: Norwell, MA, Kluwer Academic Publishers, p. 165-178.

Sherrod, D. R., and Pickthorn, L.B.G., 1992, Geologic map of the west half of Klamath Falls 1 degree by 2 degrees quadrangle, south-central Oregon: U.S. Geological Survey, Miscellaneous Investigation Series Map I-2182, scale 1:250,000.

Shimoda, S., 1969, New data for Tosudite: Clays and Clay Minerals, v. 17, p. 179 - 184.

Smedley, P. L., and Kinniburgh, D. G., 2002, A review of the source, behavior and distribution of arsenic in natural waters: Applied Geochemistry, v. 17, p. 517-569.

Smith, G. A., Manchester, S.R., Ashwill, M., McIntosh, W.C., and Conrey, R.M. , 1998, Late Eocene-early Oligocene tectonism, volcanism, and floristic change near Gray Butte, central Oregon: Geological Society of America Bulletein, v. 110, p. $759-778$. 
Stimac, J., Hickmott, D., Abell, R., Larocque, A.C.L., Broxton, D., Gardner, J., Chipera, S., Wolff, J., and Gauerke, E., 1996, Redistribution of $\mathrm{Pb}$ and other volatile trace metals during eruption, devitrification, and vapor-phase crystallization of the Bandelier Tuff, New Mexico: Journal of Volcanology and Geothermal Research, v. 73 , p. $245-266$.

Stollenwerk, K. G., 2003, Geochemical Processes Controlling Transport of Arsenic in Groundwater: A Review of Adsorption, in Welch Alan, H., and Stollenwerk, K. G., eds., Arsenic in Ground Water: Geochemistry and Occurence: Norwell, MA, Kluwer Academic Publishers.

Streck, M. J., Grunder, A., 1995, Crystallization and welding variations in a widespread ignimbrite sheet: the Rattlesnake Tuff, eastern Oregon: Bulletin of Volcanology, v. 57, p. $151-160$.

Streck, M. J., Grunder, A., 1997, Compositional gradients and gaps in high-silica rhyolites of the Rattlesnake Tuff, Oregon: Journal of Petrology, v. 38, no. 1, p. $133-163$.

Streck, M. J., Johnson, J.A., and Grunder, A.L., 1999, Field guide to the Rattlesnake Tuff and High Lava Plains near Burns, Oregon: Oregon Geology, v. 61, p. 64 - 76.

Symonds, R. B., Rose, W. I., Reed, M.H., Lichte, F.E., Finnegan, D.L., 1987, Volatilization, transport, and sublimation of metallic and non-metallic elements in high temperature gases at Merapi Volcano, Indonesia: Geochemica et Cosmochimica Acta, v. 51, p. 2083 - 2101.

US Environmental Protection Agency, 1996a, Method 3051A: Microwave assisted acid digestion of sediments, sludges, soils, and oils., in Waste, O. o. S., ed.

US Environmental Protection Agency, 1996b, Method 3052: Microwave assisted acid digestion of siliceous and organically based matrices., in Waste, O. o. S., ed.

Vaniman, D., 2006, Tuff mineralogy, in Heiken, G., ed., Tuffs - their properties, uses, hydrology, and resources, Geological Society of America Special Paper 408, p. 11-15.

Weaver, S. D., Gibson, L. L., Houghton, B. F., and Wilson, C. J. N., 1990, Mobility of rare earth and other elements during crystallization of peralkaline silicic lavas: Journal of Volcanology and Geothermal Research, v. 43, p. 57-70.

Wedepohl, K. H., 1995, The composition of the continental crust: Geochimica et Cosmochimica Acta, v. 59, no. 7, p. 1217-1232.

Welch, A. H., Westjohn, D. B., Helsel, D. R., and Wanty, R. B., 2000, Arsenic in ground water of the United States: Ground Water, v. 38, no. 4, p. 589 - 604.

Whanger, P. D., Weswing, P. H., and Stoner, J. C., 1977, Arsenic levels in Oregon waters: Environmental Health Perspectives, v. 19, p. 139-143.

Zielinski, R. A., 1982, The mobility of uranium and other elements during alteration of rhyolite ash to montmorillonite: a case study in the Troublesome Formation, Colorado, U.S.A.: Chemical Geology, v. 35, p. 185-204. 
Table A1. Operating conditions for ICP-OES analysis of total digests.

\begin{tabular}{lc}
\hline \hline Condition & Value \\
\hline Power (kW) & 1.4 \\
Replicate Read Time (s) & 45 \\
Instrument Stabilization Delay (s) & 25 \\
Sample Uptake Delay (s) & 25 \\
Max Rinse Time (s) & 90 \\
Number of Replicates & 3 \\
PolyBoost & On \\
\hline
\end{tabular}

Table A2. Operating conditions for ICP-OES analysis of partial digests.

\begin{tabular}{lc}
\hline \hline Condition & Value \\
\hline Power (kW) & 1.4 \\
Replicate Read Time (s) & 45 \\
Instrument Stabilization Delay (s) & 25 \\
Sample Uptake Delay (s) & 20 \\
Max Rinse Time (s) & 30 \\
Number of Replicates & 3 \\
PolyBoost & On \\
\hline
\end{tabular}

Table A3. Operating conditions for ICP-OES analysis of water extracts and $\mathrm{pH}$ leaching experiments.

\begin{tabular}{lc}
\hline \hline Condition & Value \\
\hline Power (kW) & 1.3 \\
Replicate Read Time (s) & 45 \\
Instrument Stabilization Delay (s) & 25 \\
Sample Uptake Delay (s) & 20 \\
Max Rinse Time (s) & 60 \\
Number of Replicates & 3 \\
PolyBoost & On \\
\hline
\end{tabular}


Table A4. Check standard and blank results from analytical session of 3/2/2012. QC1 contains $100 \mathrm{ppb}$, and QC2 contains $50 \mathrm{ppb}$, of all elements except Ga, P, S, and Sn.

\begin{tabular}{lccccc}
\hline \hline & & & & & \\
Element and Wavelength & QC Blank a & QC1a & QC2a & Method Blank & QC1b \\
& & & & & \\
\hline Al 237.312 & 2.40 & 104.84 & 58.71 & 6.41 & 107.33 \\
As 188.980 & ND & 102.83 & 50.78 & ND & 102.23 \\
Ba 455.403 & ND & 107.51 & 50.90 & ND & 109.04 \\
Ca 317.933 & ND & 105.89 & 56.10 & 4.07 & 106.63 \\
Cd 214.439 & ND & 104.19 & 55.09 & ND & 102.59 \\
Ce 407.347 & ND & 105.34 & 4.32 & ND & 107.99 \\
Co 228.615 & ND & 105.25 & 51.04 & ND & 105.61 \\
Cr 267.716 & 1.50 & 105.58 & 63.90 & 1.59 & 105.24 \\
Cu 327.395 & 1.12 & 106.00 & 44.16 & 1.46 & 106.99 \\
Fe 238.204 & ND & 103.69 & 144.61 & 3.89 & 103.56 \\
La 398.852 & ND & 105.94 & 0.02 & ND & 106.91 \\
Mg 279.078 & ND & 103.90 & 53.01 & 1.49 & 105.00 \\
Mn 260.568 & ND & 104.83 & 50.82 & ND & 103.57 \\
Na 588.995 & ND & 118.04 & 66.08 & 3.66 & 114.47 \\
Nd 399.467 & 1.86 & 103.99 & 0.29 & 1.37 & 104.57 \\
Ni 231.604 & ND & 103.30 & 52.56 & ND & 102.08 \\
P 177.434 & 4.41 & 116.39 & 5.95 & 6.24 & 135.93 \\
Pb 220.353 & ND & 105.17 & 50.47 & ND & 104.26 \\
S 181.972 & 4.03 & 109.39 & 12.37 & ND & 103.21 \\
Sm 356.827 & N9.54 & 104.24 & 39.21 & 39.22 & 106.84 \\
Sr 407.771 & ND & 106.11 & 51.36 & ND & 107.64 \\
V 311.837 & ND & 103.47 & 43.60 & ND & 104.39 \\
Zn 202.548 & ND & 132.89 & 43.31 & ND & 133.43 \\
\hline
\end{tabular}


Table A5. Check standard and blank results from analytical session of 10/25/2012. QC1 contains $100 \mathrm{ppb}$, and QC2 contains $50 \mathrm{ppb}$, of all elements except $\mathrm{P}$ and $\mathrm{S}$.

\begin{tabular}{lccccccc}
\hline Element and & QC Blank a & QC1a & QC2a & Method Blank & QC Blank b & QC1b & QC2b \\
& & & & & & & \\
\hline Al 237.312 & 3.81 & 108.93 & 53.81 & 22.49 & 5.93 & 112.60 & 57.07 \\
As 188.980 & ND & 97.51 & 43.66 & ND & ND & 98.13 & 45.24 \\
Ba 455.403 & ND & 101.92 & 50.67 & ND & ND & 96.64 & 47.30 \\
Ca 317.933 & 6.82 & 129.77 & 64.26 & 9.60 & 8.02 & 132.26 & 66.69 \\
Cd 214.439 & ND & 102.90 & 49.51 & ND & ND & 107.28 & 52.63 \\
Ce 407.347 & 1.57 & 100.21 & 49.79 & 2.23 & 1.58 & 92.64 & 46.66 \\
Co 228.615 & ND & 101.78 & 49.76 & ND & ND & 104.93 & 51.68 \\
Cr 267.716 & ND & 101.23 & 49.50 & ND & ND & 103.04 & 50.49 \\
Cu 327.395 & ND & 103.22 & 49.60 & ND & ND & 100.03 & 47.50 \\
Fe 238.204 & ND & 104.22 & 50.08 & 14.17 & 1.67 & 107.12 & 52.50 \\
La 398.852 & ND & 104.09 & 52.28 & ND & ND & 98.90 & 48.31 \\
Mg 279.078 & ND & 103.20 & 48.93 & 3.90 & ND & 108.21 & 52.37 \\
Mn 260.568 & ND & 101.01 & 49.79 & ND & ND & 102.52 & 50.50 \\
Mo 202.032 & ND & 96.82 & 45.31 & ND & ND & 96.12 & 44.83 \\
Na 588.995 & 3.73 & 103.99 & 45.43 & 12.49 & 7.94 & 106.29 & 50.87 \\
Nd 399.467 & 1.48 & 101.15 & 52.23 & 1.53 & 1.66 & 92.91 & 45.18 \\
Ni 231.604 & ND & 101.04 & 49.78 & ND & ND & 104.27 & 51.61 \\
P 177.434 & 3.92 & 1.20 & 1.80 & 3.15 & 2.77 & ND & ND \\
Pb 220.353 & ND & 102.56 & 50.30 & ND & ND & 103.25 & 51.01 \\
S 181.972 & ND & 3.25 & -1.97 & 31.96 & 24.68 & 29.71 & 26.38 \\
Si 185.005 & ND & 134.45 & 63.17 & 99.47 & ND & 125.17 & 46.87 \\
Sm 356.827 & 14.73 & 90.94 & 41.71 & 14.73 & 14.68 & 79.93 & 33.29 \\
Sr 407.771 & ND & 101.06 & 51.29 & ND & ND & 94.47 & 47.09 \\
Ti 334.941 & ND & 100.51 & 50.10 & ND & ND & 96.42 & 47.70 \\
V 311.837 & ND & 100.69 & 50.11 & 1.04 & ND & 99.54 & 48.97 \\
Zn 202.548 & ND & 118.21 & 51.40 & ND & ND & 126.22 & 57.10 \\
\hline
\end{tabular}




\begin{tabular}{|c|c|}
\hline$\tilde{d}^{\circ}$ & 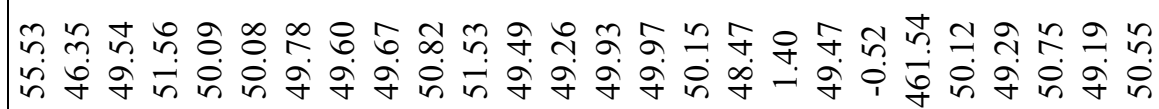 \\
\hline & 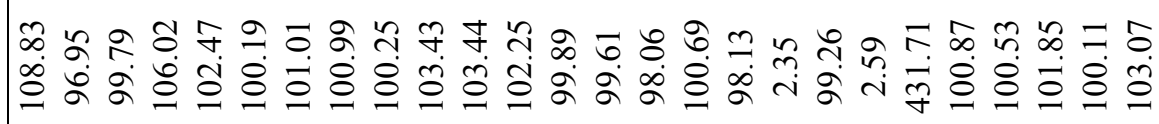 \\
\hline & 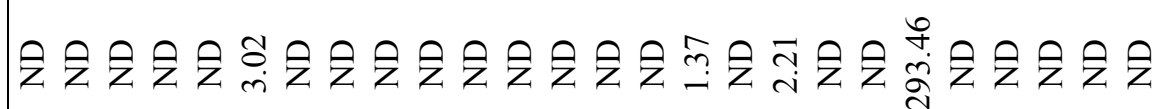 \\
\hline & 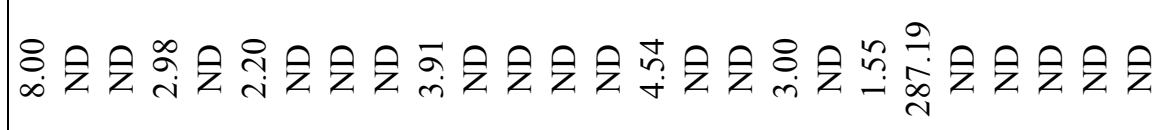 \\
\hline & 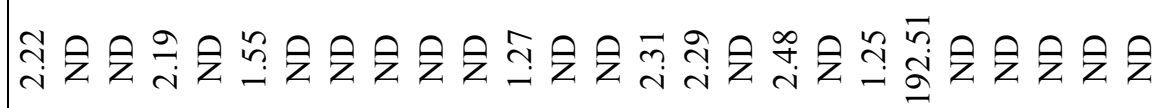 \\
\hline & 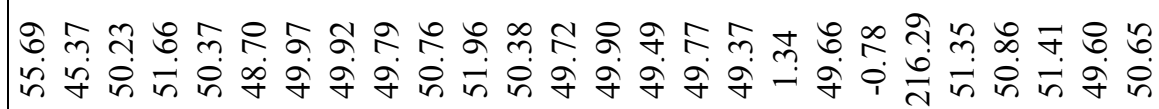 \\
\hline & 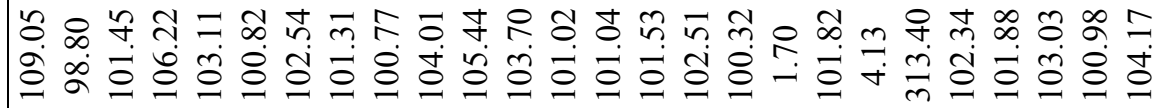 \\
\hline & 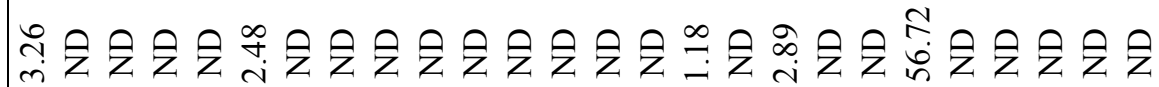 \\
\hline & 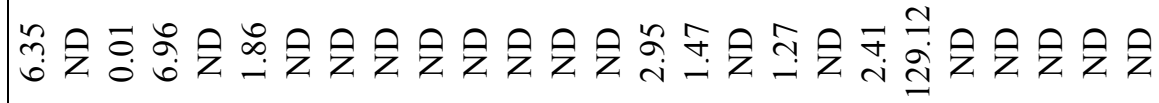 \\
\hline & 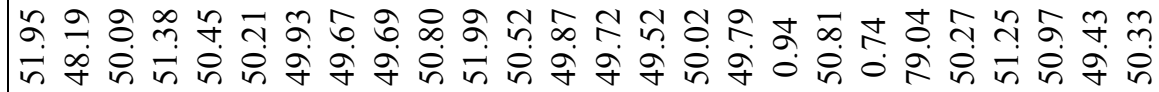 \\
\hline & 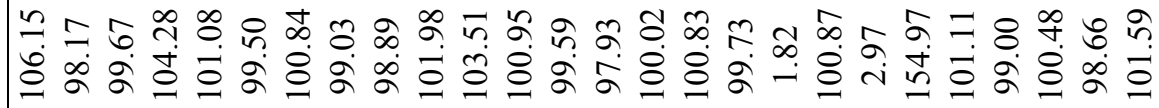 \\
\hline & 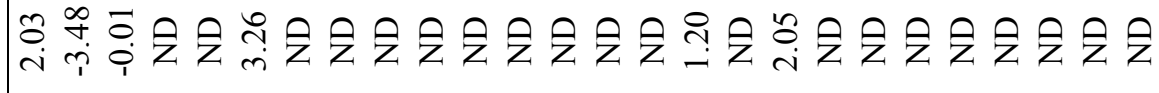 \\
\hline & \\
\hline
\end{tabular}




\section{APPENDIX B: DETAILS OF STATISTICAL METHODS}

All statistical analysis performed in R Version 2.11.1

\# All analysis!

$\operatorname{rm}(\operatorname{list}=1 \mathrm{~s}())$

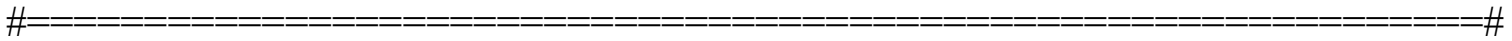

\# Investigating Alk/Alumina ratios and As

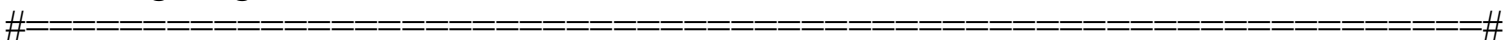

load(" /Documents/Thesis/Analysis/AllData.Rdata")

\# Calculate Alumina/Alkali ratios in molar percents (not wt \%)

molmajors $\$ \mathrm{AlkAl}<-$ molmajors $\$ \mathrm{Al} /($ molmajors $\$ \mathrm{Na} 2 \mathrm{O}+$ molmajors $\$ \mathrm{~K} 2 \mathrm{O})$

\# Look for correlations with As

cor.test(molmajors $\$ A$ lkAl, totaldata $\$ A s)$

\# Use AllPlots.R script to plot here.

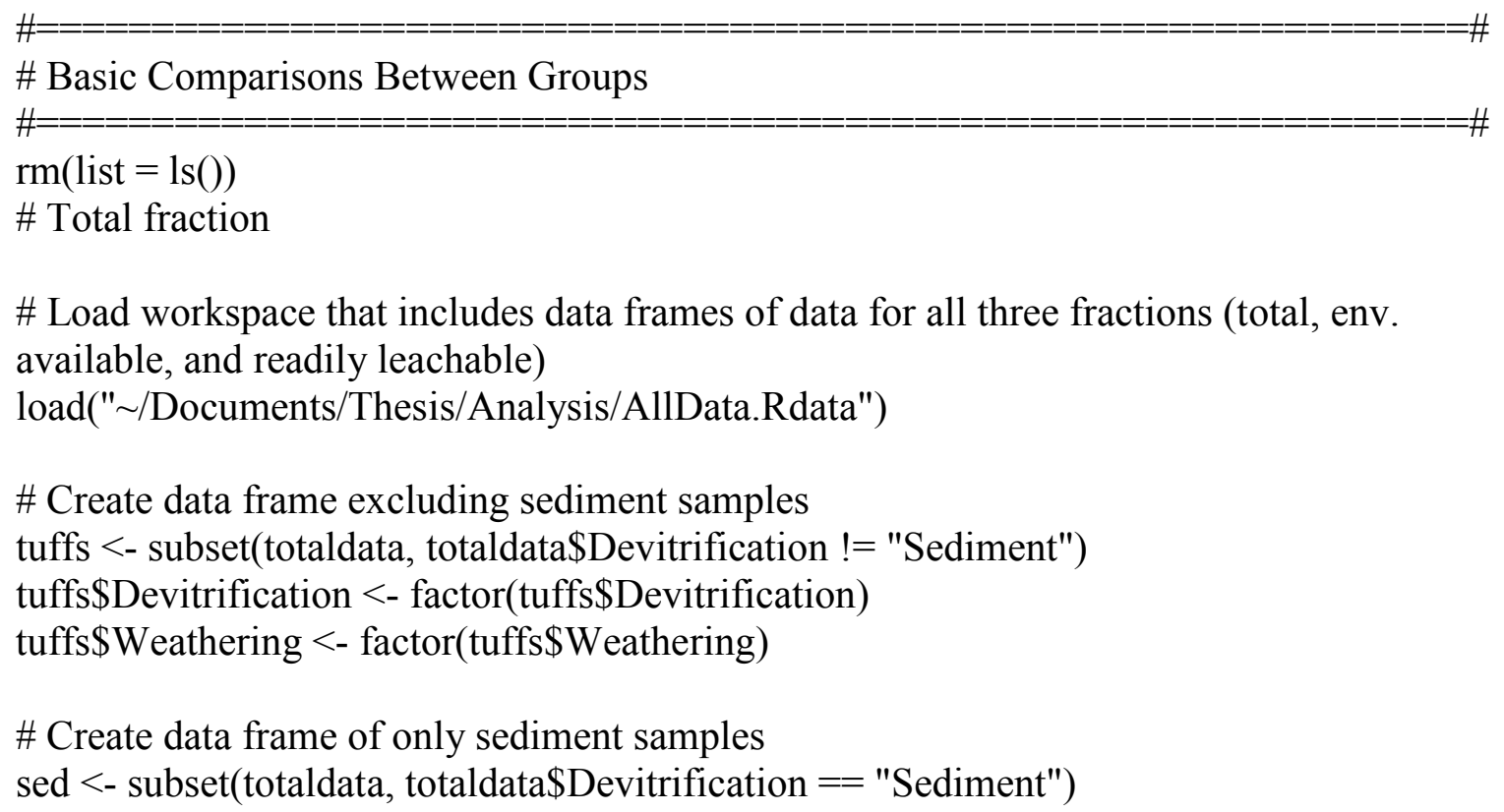

\# Load workspace that includes data frames of data for all three fractions (total, env. available, and readily leachable) load(" /Documents/Thesis/Analysis/AllData.Rdata")

\# Create data frame excluding sediment samples tuffs $<-$ subset(totaldata, totaldata\$Devitrification != "Sediment") tuffs $\$$ Devitrification $<$ - factor(tuffs\$Devitrification) tuffs\$Weathering $<$ - factor(tuffs\$Weathering)

\# Create data frame of only sediment samples sed $<-$ subset(totaldata, totaldata $\$$ Devitrification $==$ "Sediment") 
\# Create data frame of unweathered samples only

unweathered <- subset(tuffs, Weathering == "Unweathered")

\# Create data frame of weathered samples only

weathered <- subset(tuffs, Weathering == "Weathered")

\# Create data frame of devitrified samples only

devit <- subset(unweathered, Devitrification == "Devitrified")

\# Create data frame of glassy samples only

glassy $<-$ subset(unweathered, Devitrification == "Glassy")

\# Compare tuffs and sediments

wilcox.test(tuffs\$As, sed\$As)

kruskal.test(tuffs\$As, sed\$As)

boxplot(tuffs $\$ A s$, sed $\$ A s)$

\# Compare weathered and unweathered samples

wilcox.test (As $\sim$ Weathering, tuffs)

kruskal.test(As $\sim$ Weathering, tuffs)

boxplot(As $\sim$ Weathering, tuffs, ylab = "As (mg/kg)", main = "Total As")

\# Compare glassy and devitrified samples

wilcox.test(As Devitrification, unweathered)

kruskal.test(As $\sim$ Devitrification, unweathered)

boxplot(As $\sim$ Devitrification, unweathered, ylab = "As $(\mathrm{mg} / \mathrm{kg}) "$, main = "Total As")

\# Calculate mean/median/SD values for categories

mean(tuffs $\$ A s)$

median(tuffs $\$ A s$ )

$\operatorname{sd}($ tuffs $\$ A s)$

mean(sed\$As)

median(sed\$As)

$\operatorname{sd}(\operatorname{sed} \$ A s)$

mean(unweathered\$As)

median(unweathered $\$ A s$ )

sd(unweathered\$As)

mean(weathered\$As)

median(weathered\$As)

sd(weathered\$As) 


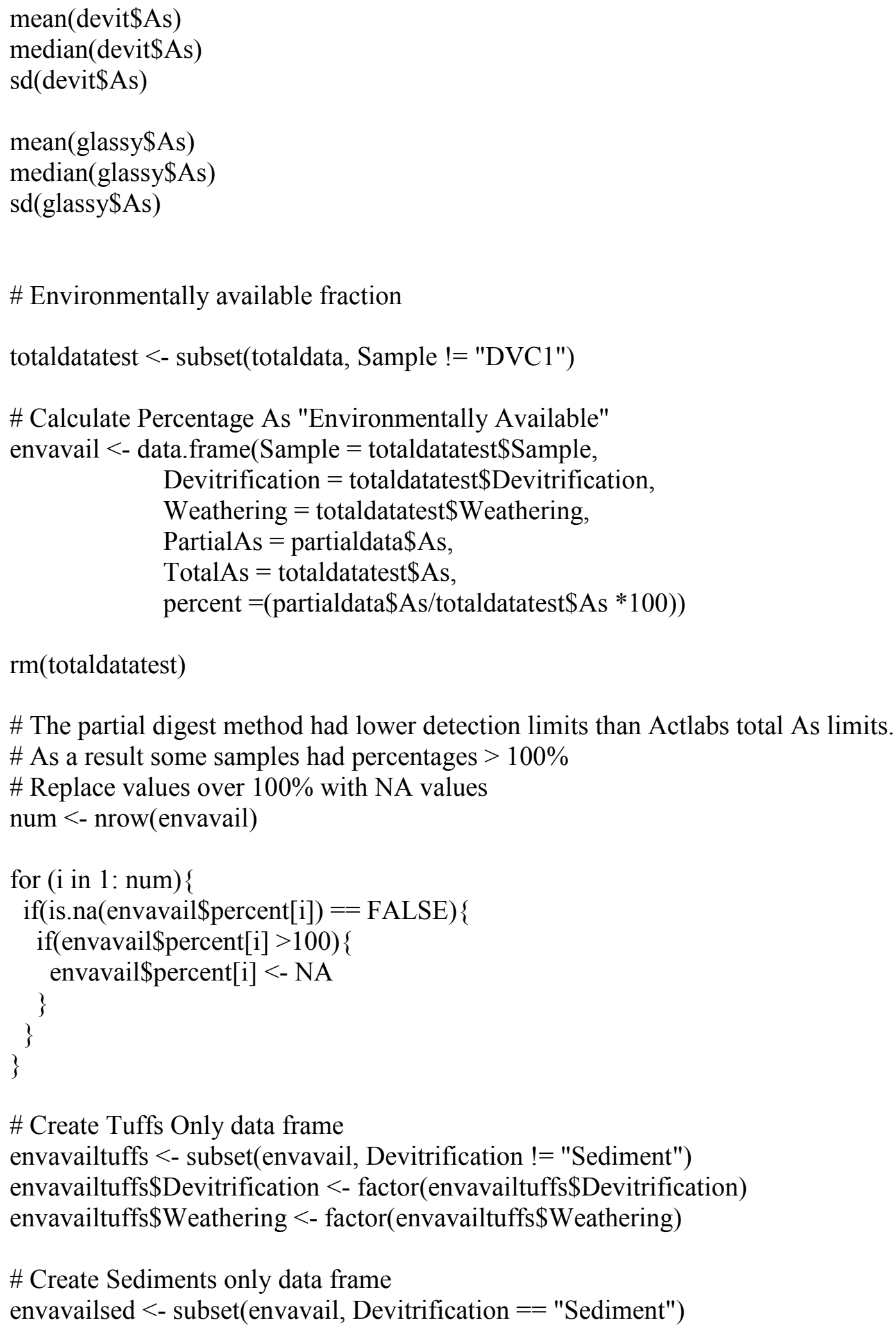


envavailsed\$Devitrification $<$ - factor(envavailsed\$Devitrification)

envavailsed\$Weathering <- factor(envavailsed\$Weathering)

\# Create data frame of unweathered samples only

envavailunw $<$ - subset(envavailtuffs, Weathering == "Unweathered")

\# Create data frame of weathered samples only

envavailw <- subset(envavailtuffs, Weathering == "Weathered")

\# Create data frame of devitrified samples only

envavaildevit $<-$ subset(envavailunw, Devitrification == "Devitrified")

\# Create data frame of glassy samples only

envavailglassy <- subset(envavailunw, Devitrification == "Glassy")

\# Test for normality

shapiro.test(envavailtuffs\$PartialAs)

shapiro.test(envavailsed\$PartialAs)

shapiro.test(envavailunw\$PartialAs)

shapiro.test(envavailw\$PartialAs)

shapiro.test(envavaildevit\$PartialAs)

shapiro.test(envavailglassy\$PartialAs)

\# Compare tuffs and sediments

wilcox.test(envavailtuffs\$percent, envavailsed\$percent)

wilcox.test(envavailtuffs\$PartialAs, envavailsed\$PartialAs)

\# Compare weathered and unweathered samples

wilcox.test(percent $\sim$ Weathering, envavailtuffs)

wilcox.test(PartialAs $\sim$ Weathering, envavailtuffs)

kruskal.test(percent $\sim$ Weathering, envavailtuffs)

kruskal.test(PartialAs $\sim$ Weathering, envavailtuffs)

boxplot(percent $\sim$ Weathering, envavailtuffs, ylab = "As (\%)", main = "Available As")

boxplot(PartialAs $\sim$ Weathering, envavailtuffs, ylab = "As (mg/kg)", main = "Available As")

\# Compare divitrified and glassy samples.

wilcox.test(percent $\sim$ Devitrification, envavailunw)

wilcox.test(PartialAs $\sim$ Devitrification, envavailunw)

kruskal.test(percent $\sim$ Devitrification, envavailunw)

kruskal.test(PartialAs $\sim$ Devitrification, envavailunw) 
boxplot(percent $\sim$ Devitrification, envavailunw, ylab = "As (\%)", main = "Available As")

boxplot(PartialAs $\sim$ Devitrification, envavailunw, ylab = "As (mg/kg)", main = "Available As")

\# Calculate descriptive statistics

mean (envavailtuffs\$PartialAs, na.rm = TRUE)

median(envavailtuffs $\$$ PartialAs, na.rm= TRUE)

sd(envavailtuffs\$PartialAs, na.rm = TRUE)

mean (envavailtuffs\$percent, na.rm $=$ TRUE)

median (envavailtuffs\$percent, na.rm $=$ TRUE)

sd(envavailtuffs\$percent, na.rm $=$ TRUE)

mean(envavailsed\$PartialAs, na.rm $=$ TRUE)

median (envavailsed\$PartialAs, na.rm = TRUE)

$\operatorname{sd}($ envavailsed\$PartialAs, na.rm $=$ TRUE $)$

mean(envavailsed\$percent, na.rm $=$ TRUE)

median(envavailsed\$percent, na.rm $=$ TRUE)

sd(envavailsed\$percent, na.rm $=$ TRUE)

mean (envavailunw\$PartialAs, na.rm = TRUE)

median(envavailunw\$PartialAs, na.rm = TRUE)

sd(envavailunw\$PartialAs, na.rm = TRUE)

mean (envavailunw\$percent, na.rm $=$ TRUE)

median(envavailunw\$percent, na.rm = TRUE)

sd(envavailunw\$percent, na.rm = TRUE)

mean(envavailw\$PartialAs, na.rm = TRUE)

median(envavailw\$PartialAs, na.rm = TRUE)

sd (envavailw\$PartialAs, na.rm = TRUE)

mean(envavailw\$percent, na.rm $=$ TRUE)

median(envavailw\$percent, na.rm = TRUE)

sd(envavailw\$percent, na.rm $=$ TRUE $)$

mean(envavaildevit\$PartialAs, na.rm $=$ TRUE)

median(envavaildevit\$PartialAs, na.rm $=\mathrm{T}$ )

sd $($ envavaildevit\$PartialAs, na.rm $=\mathrm{T})$

mean(envavaildevit\$percent, na.rm $=$ TRUE)

median(envavaildevit\$percent, na.rm = TRUE) 


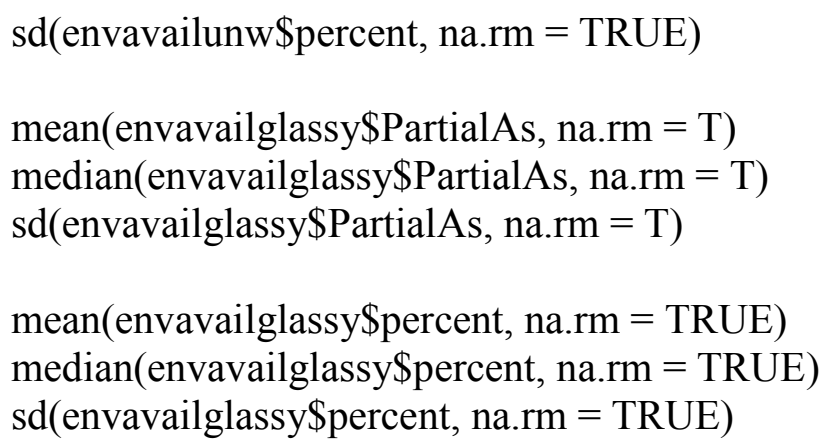

\# Create tuffs only data frame

leachtuffs <- subset(leachable, Devitrification != "Sediment")

leachtuffs\$Devitrification $<$ - factor(leachtuffs\$Devitrification)

leachtuffs\$Weathering $<$ - factor(leachtuffs\$Weathering)

\# Create sediments only data frame

leachsed <- subset(leachable, Devitrification == "Sediment")

leachsed\$Devitrification $<$ - factor(leachsed\$Devitrification)

leachsed\$Weathering <- factor(leachsed\$Weathering)

\# Create data fram of unweathered tuffs only

leachunw $<$ - subset(leachtuffs, Weathering == "Unweathered")

\# Create data frame of weathered tuffs only

leachw $<-$ subset(leachtuffs, Weathering == "Weathered")

\# Create data frame of devitrified tuffs only

leachdevit $<-$ subset(leachunw, Devitrification == "Devitrified")

\# Create data frame of glassy tuffs only

leachglassy $<-$ subset(leachunw, Devitrification == "Glassy")

\# Compare sediments and tuffs 
wilcox.test(leachtuffs\$percent, leachsed\$percent) wilcox.test(leachtuffs\$LeachableAs, leachsed\$LeachableAs) boxplot(leachtuffs\$percent, leachsed\$percent) boxplot(leachtuffs\$LeachableAs, leachsed\$LeachableAs)

\# Compare weathered and unweathered tuffs wilcox.test(percent $\sim$ Weathering, leachtuffs) wilcox.test(LeachableAs $\sim$ Weathering, leachtuffs) kruskal.test(percent $\sim$ Weathering, leachtuffs) kruskal.test(LeachableAs $\sim$ Weathering, leachtuffs) boxplot(percent $\sim$ Weathering, leachtuffs) boxplot(LeachableAs $\sim$ Weathering, leachtuffs)

\# Compare devitrified and glassy tuffs wilcox.test(percent $\sim$ Devitrification, leachunw) wilcox.test(LeachableAs $\sim$ Devitrification, leachunw) kruskal.test(percent $\sim$ Devitrification, leachunw) kruskal.test(LeachableAs $\sim$ Devitrification, leachunw) boxplot(percent $\sim$ Devitrification, leachunw) boxplot(LeachableAs $\sim$ Devitrification, leachunw)

\# Calculate descriptive statistics, excluding samples that were non-detects $\mathrm{ND}<-51.05875$

mean(leachtuffs\$LeachableAs[which(leachtuffs\$LeachableAs > ND)]) median(leachtuffs \$LeachableAs[which(leachtuffs\$LeachableAs > ND)]) sd(leachtuffs\$LeachableAs[which(leachtuffs\$LeachableAs > ND)])

mean(leachsed\$LeachableAs[which(leachsed\$LeachableAs > ND)]) median(leachsed\$LeachableAs[which(leachsed\$LeachableAs > ND)]) sd(leachsed\$LeachableAs[which(leachsed\$LeachableAs > ND)])

mean(leachunw\$LeachableAs[which(leachunw\$LeachableAs $>$ ND)] median(leachunw\$LeachableAs[which(leachunw\$LeachableAs $>$ ND)]) sd(leachunw\$LeachableAs[which(leachunw\$LeachableAs > ND)])

mean(leachw\$LeachableAs[which(leachw\$LeachableAs > ND)] median(leachw\$LeachableAs[which(leachw\$LeachableAs > ND)]) sd(leachw\$LeachableAs[which(leachw\$LeachableAs > ND)])

mean(leachdevit\$LeachableAs[which(leachdevit\$LeachableAs > ND)]) median(leachdevit\$LeachableAs[which(leachdevit\$LeachableAs $>$ ND)]) sd(leachdevit\$LeachableAs[which(leachdevit\$LeachableAs > ND)]) 
mean(leachglassy\$LeachableAs[which(leachglassy\$LeachableAs > ND)]) median(leachglassy\$LeachableAs[which(leachglassy\$LeachableAs > ND)]) sd(leachglassy\$LeachableAs[which(leachglassy\$LeachableAs > ND)])

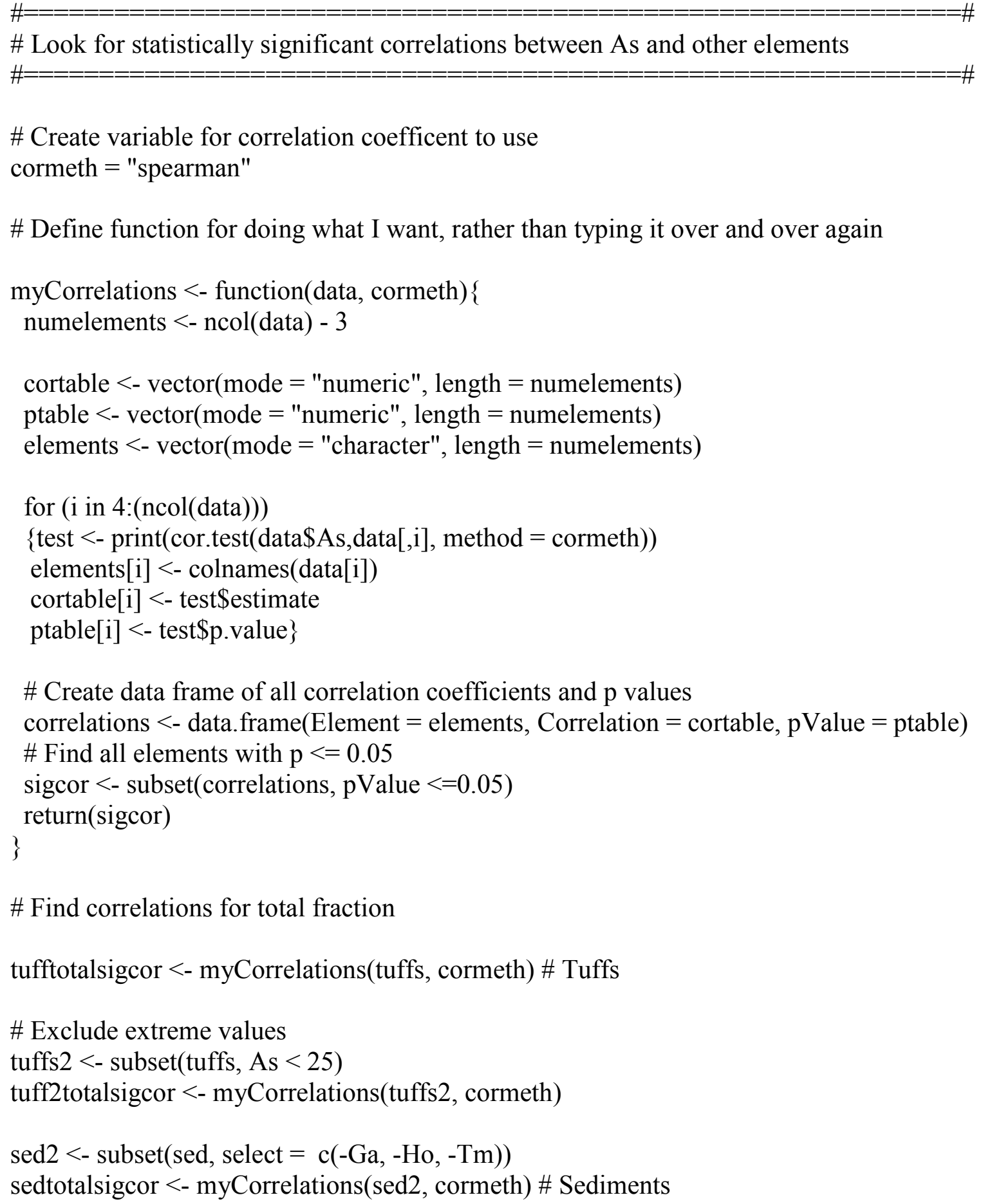


weathtotalsigcor <- myCorrelations(weathered, cormeth) \# Weathered unweathtotalsigcor <- myCorrelations(unweathered, cormeth) \# Unweathered devittotalsigcor $<-$ myCorrelations(devit, cormeth) \# Devitrified glassytotalsigcor <- myCorrelations(glassy, cormeth) \# Glassy

$\operatorname{rm}(\operatorname{sed} 2)$

\# Correlations for the environmentally available fraction

tuffpartial <- subset(partialdata, Devitrification != "Sediment") unweatheredpartial <- subset(partialdata, Weathering == "Unweathered") weatheredpartial <- subset(partialdata, Weathering == "Weathered") devitpartial <- subset(unweatheredpartial, Devitrification == "Devitrified") glassypartial <- subset(unweatheredpartial, Devitrification == "Glassy") sedpartial $<$ - subset(partialdata, Weathering $==$ "Sediment")

tuffpartialsigcor $<-$ myCorrelations(tuffpartial, cormeth) weathpartialsigcor $<$ - myCorrelations(weatheredpartial, cormeth) unweathpartialsigcor $<-$ myCorrelations(unweatheredpartial, cormeth) devitpartialsigcor $<-$ myCorrelations(devitpartial, cormeth) glassypartialsigcor $<-$ myCorrelations(glassypartial, cormeth) sedpartialsigcor $<-$ myCorrelations(sedpartial, cormeth)

\# Correlations for the readily leachable fraction

tuffleach $<$ - subset(leachdata, Devitrification != "Sediment")

weatheredleach $<-$ subset(leachdata, Weathering == "Weathered") unweatheredleach $<$ - subset(leachdata, Weathering == "Unweathered") devitleach <- subset(unweatheredleach, Devitrification == "Devitrified") glassyleach $<-$ subset(unweatheredleach, Devitrification == "Glassy") sedleach $<-$ subset(leachdata, Weathering $==$ "Sediment")

tuffleachsigcor $<-$ myCorrelations(tuffleach, cormeth) weathleachsigcor $<-$ myCorrelations(weatheredleach, cormeth) unweathleachsigcor $<-$ myCorrelations(unweatheredleach, cormeth) devitleachsigcor $<$ - myCorrelations(devitleach, cormeth) glassyleachsigcor $<-$ myCorrelations(glassyleach, cormeth) sedleachsigcor $<-$ myCorrelations(sedleach, cormeth)

\# Analysis of $\mathrm{pH}$ extractions load(" /Documents/Thesis/Analysis/pH.Rdata") pH9 $<-$ subset(pHed, $\mathrm{pH}==9$ ) 


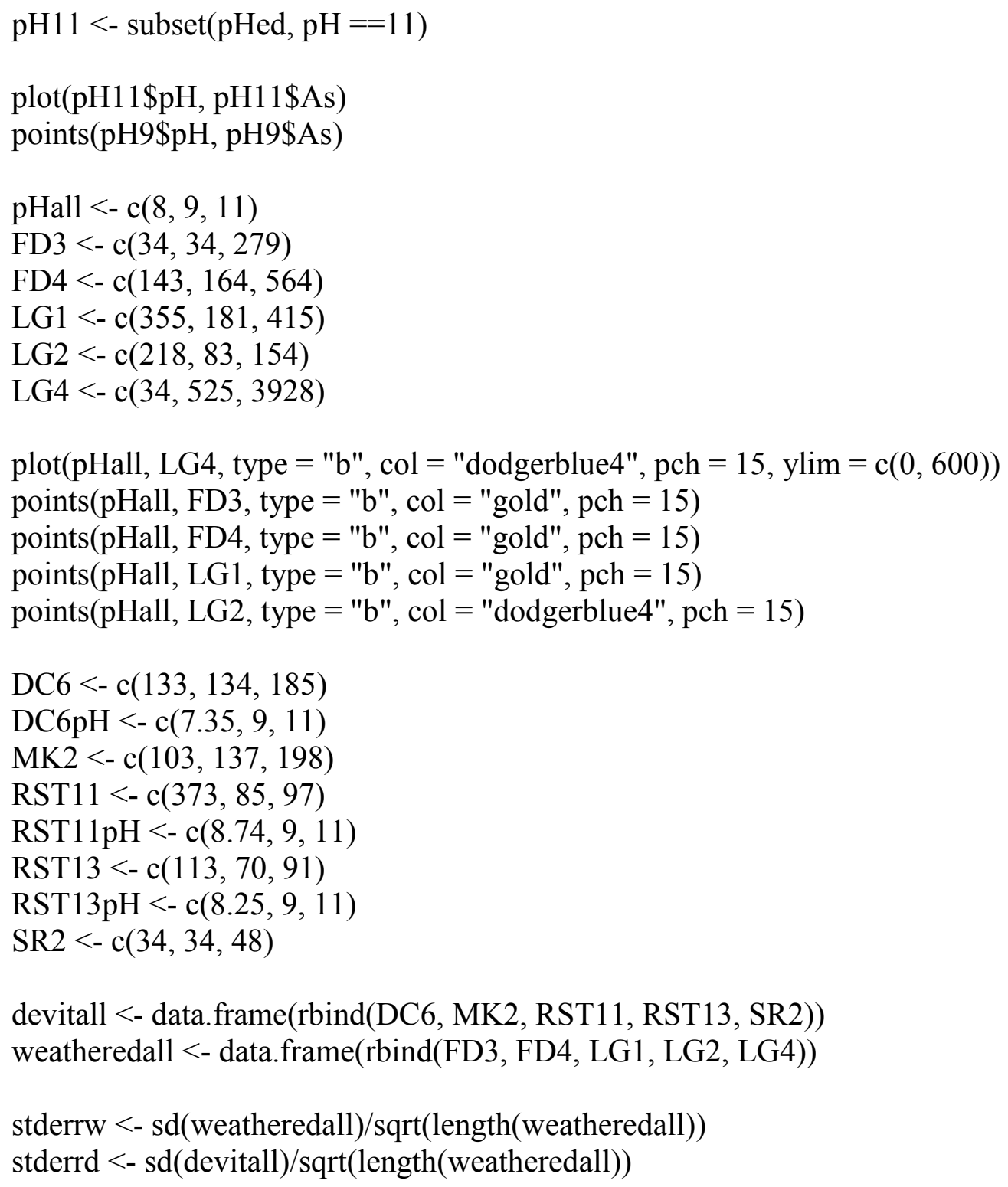


labels = c("9", "10", "11"))

axis $(1$, at $=8$, labels $=" p H$ nothcontrolled", cex.axis $=0.65)$

errbar(pHall, mean(devitall),

(mean(devitall)+stderrd), (mean(devitall)-stderrd),

add = TRUE, col = "dodgerblue4", pch = 20)

errbar(pHall, mean(weatheredall),

(mean(weatheredall)+stderrw), (mean(weatheredall)-stderrw),

add $=$ TRUE, $c o l=$ "chartreuse4", $\mathrm{pch}=20$ )

points(pHall, mean(weatheredall), $\mathrm{pch}=15, \mathrm{col}=$ "chartreuse4", $\mathrm{cex}=1.5$ )

points(pHall, mean(devitall), type $=$ "b", pch $=16, \mathrm{col}=$ "dodgerblue4", cex =1.5)

points(pHall, c $(34,34,34)$, type = "b", pch = 17, col = "gold", cex =1.5)

legendtext <- c("Weathered Tuffs", "Devitrified Tuffs", "Glassy Tuffs")

legendcol <- c("chartreuse4", "dodgerblue4", "gold")

legendpch $<-\mathrm{c}(15,16,17)$

legend $(\mathrm{x}=$ "topleft", legend = legendtext, $\mathrm{col}=$ legendcol, $\mathrm{pch}=$ legendpch, $\operatorname{cex}=1.2$,

bty $=$ "n")

plot(DC6pH, DC6, type = "b", col = "dodgerblue4", ylim = c $(0,600))$

points(pH, FD3, type = "b", col = "chartreuse4")

points(pH, FD4, type = "b", col = "chartreuse4")

points(pH, LG1, type = "b", col = "chartreuse4")

points(pH, LG2, type = "b", col = "chartreuse4")

points(pH, MK2, type = "b", col = "dodgerblue4")

points(RST11pH, RST11, type = "b", col = "dodgerblue4")

points(RST13pH, RST13, type = "b", col = "dodgerblue4")

points(pH, SR2, type = "b", col = "dodgerblue4")

allpH $<-\mathrm{c}(6.36,6.81,8.40,8.28,7.35,8.94,8.37,8.48$,

$8.29,8.65,7.99,8.05,8.74,6.16,6.93$,

$8.43,8.44,7.05,8.65,7.46,8.30,8.23,7.90$,

$8.90,7.92,8.64,8.70,8.90,8.25,8.19$,

$6.94,6.52,7.03,8.84,8.88,7.91,8.01$,

8.56)

mean (allpH)

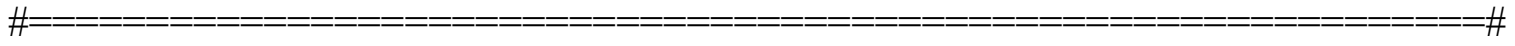

\# Look at aqueous values

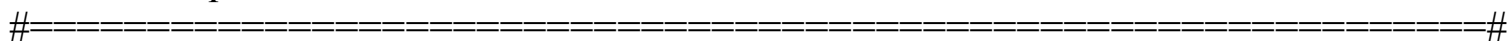

\# Convert back to aqueous concentrations 


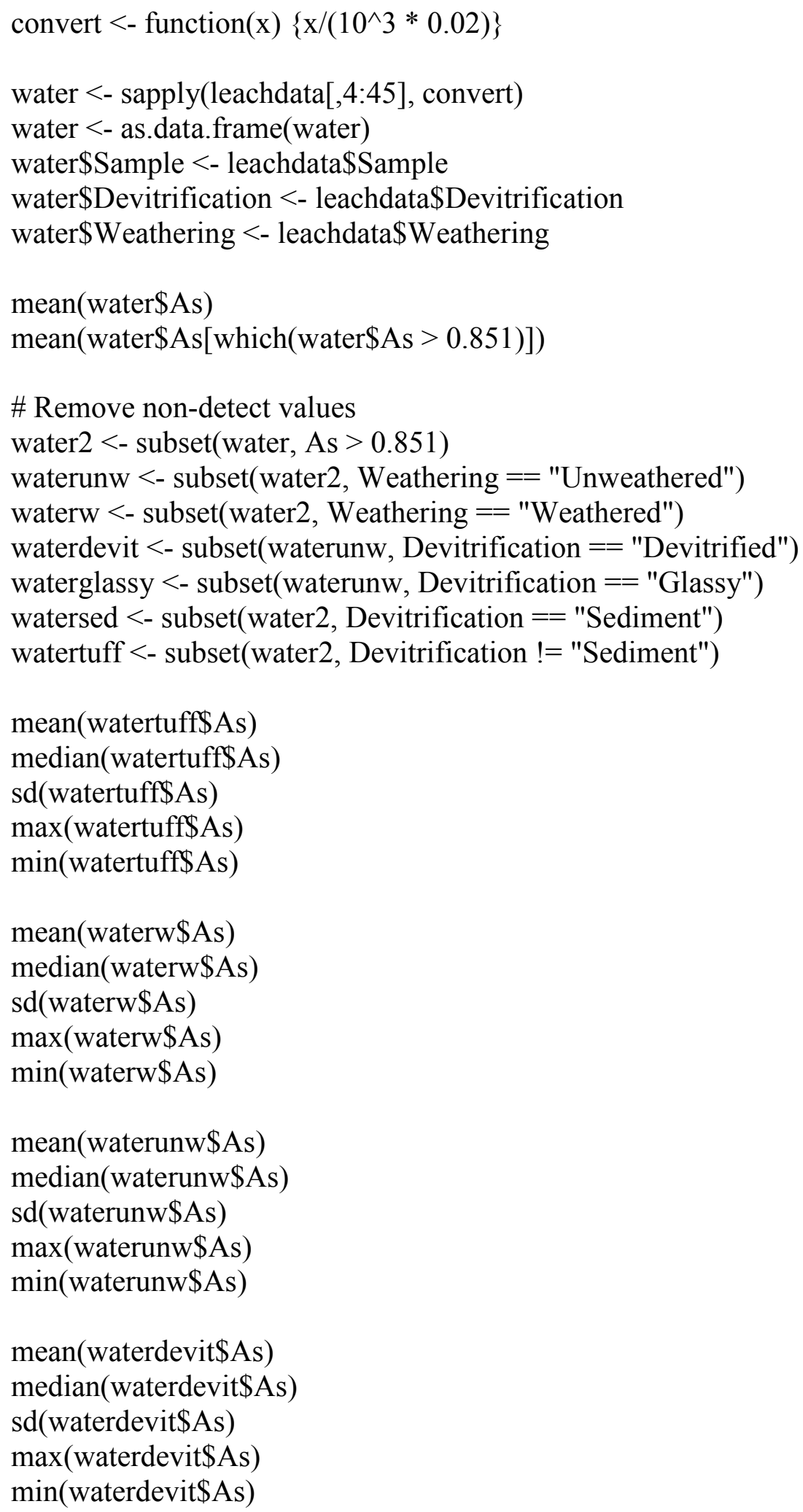




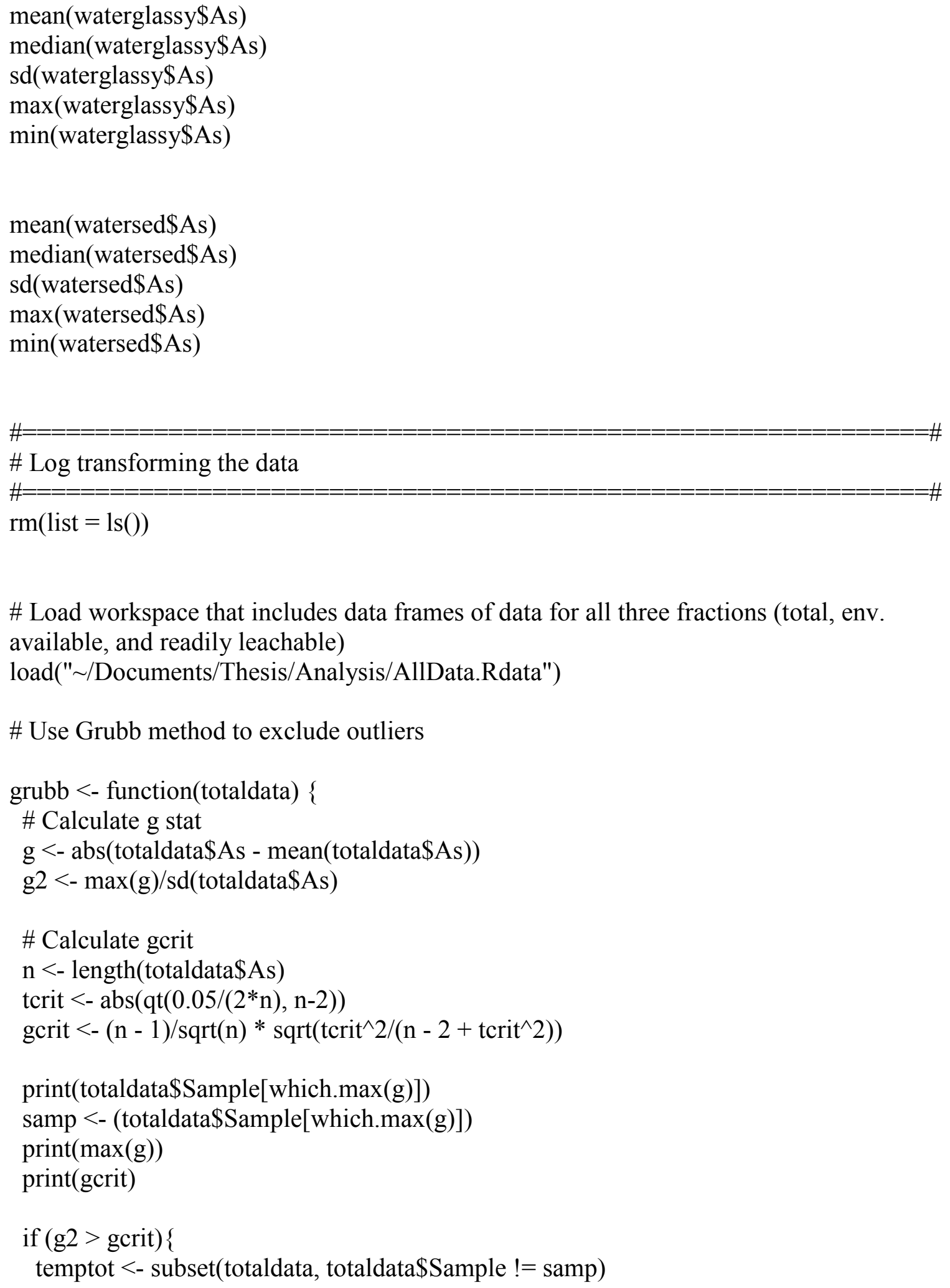




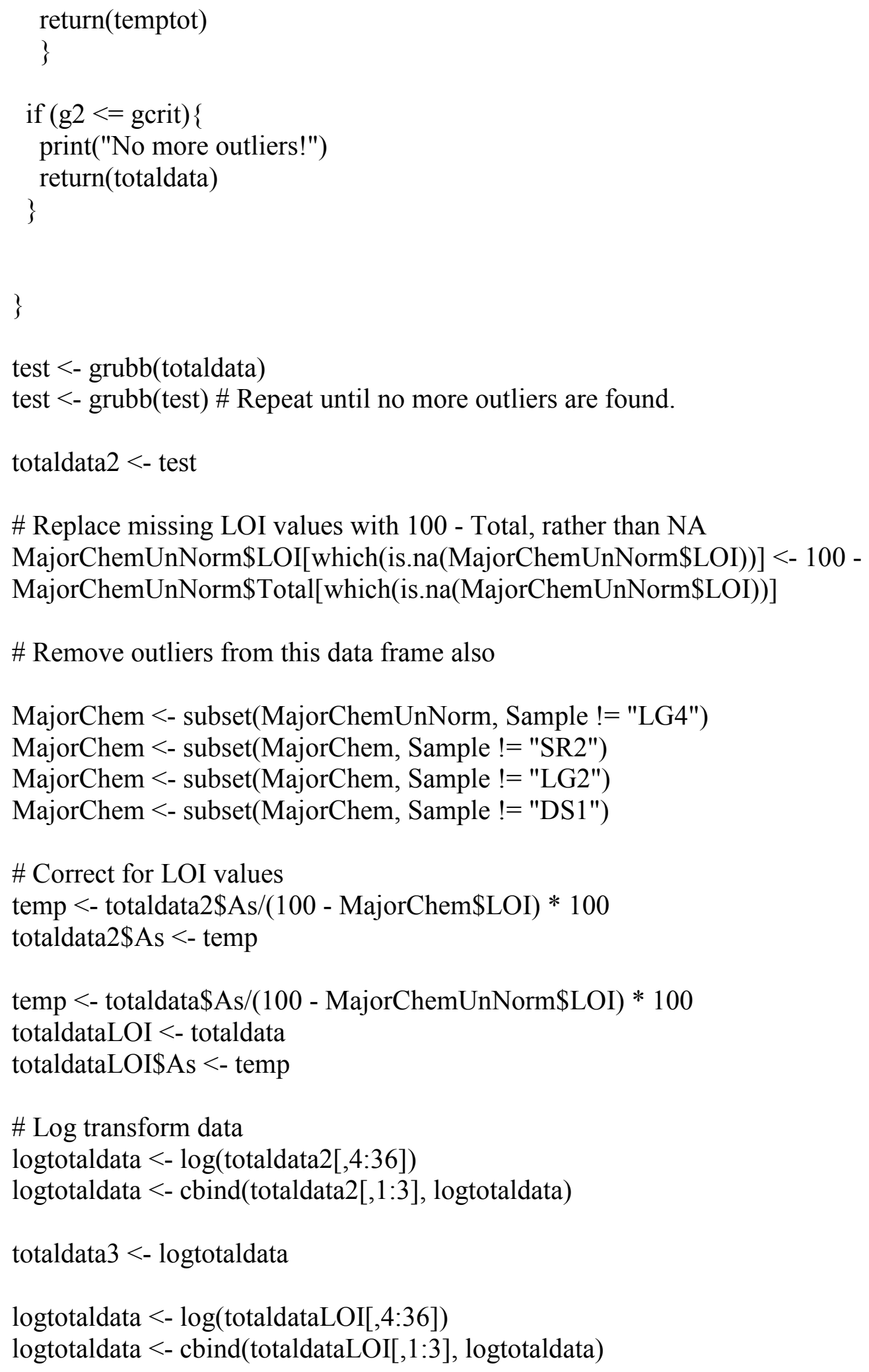




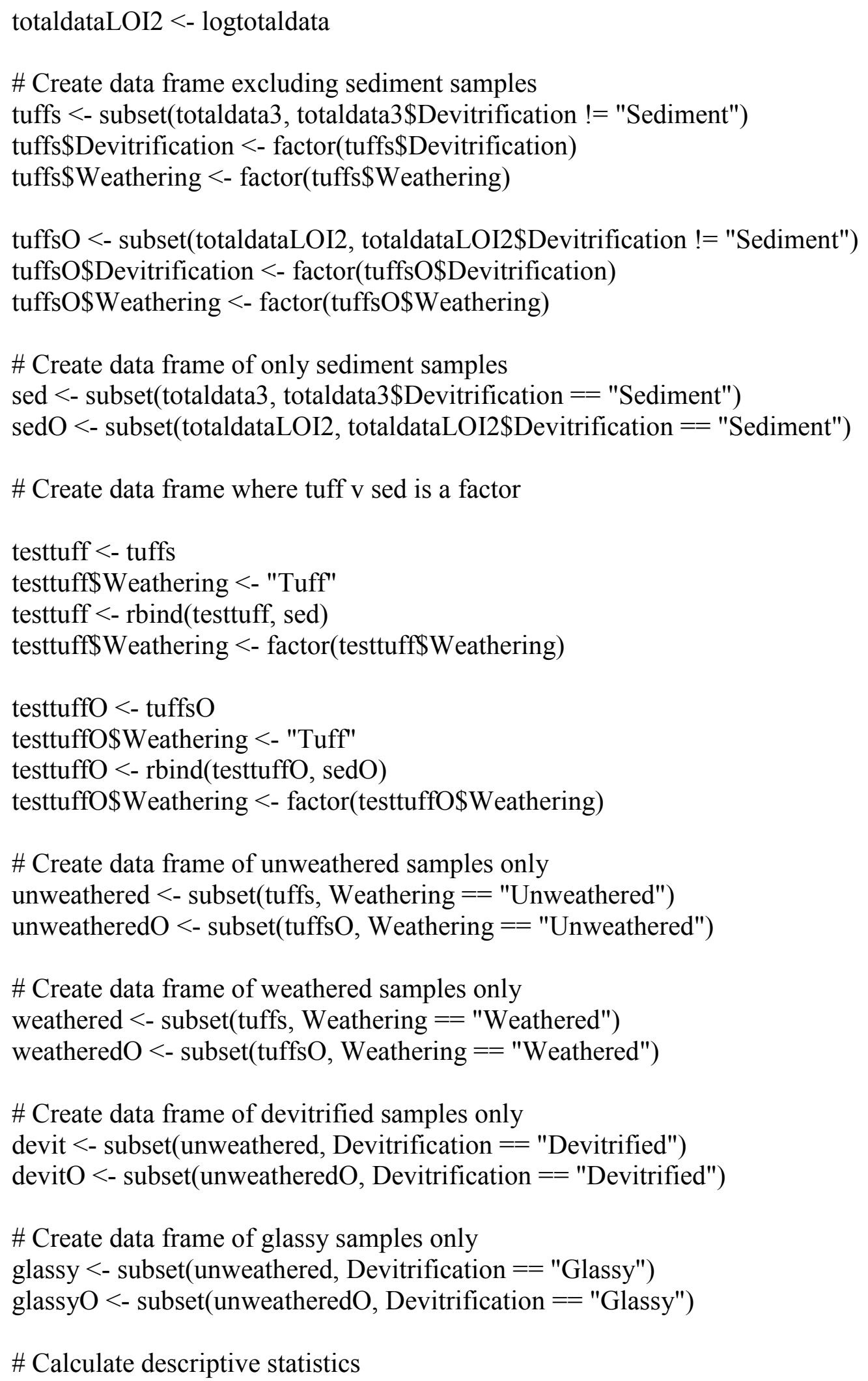




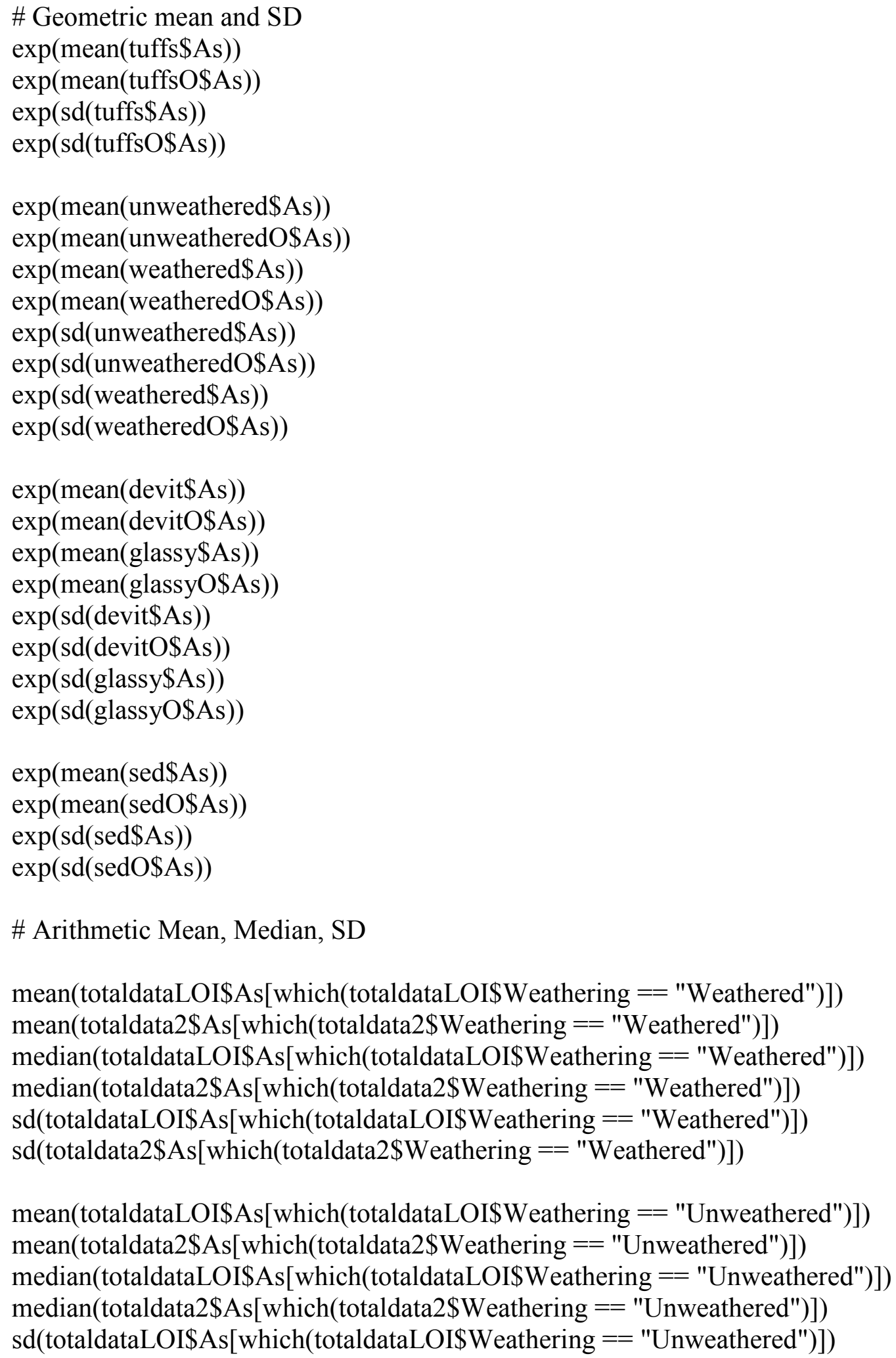


$\operatorname{sd}($ totaldata2\$As[which(totaldata2\$Weathering == "Unweathered")])

mean(totaldataLOI\$As[which(totaldataLOI\$Devitrification == "Devitrified")])

mean(totaldata2\$As[which(totaldata2\$Devitrification == "Devitrified")])

median(totaldataLOI\$As[which(totaldataLOI\$Devitrification == "Devitrified")])

median(totaldata2\$As[which(totaldata2\$Devitrification == "Devitrified")])

sd(totaldataLOI\$As[which(totaldataLOI\$Devitrification == "Devitrified")])

$\operatorname{sd}($ totaldata2\$As[which(totaldata2\$Devitrification == "Devitrified")])

mean(totaldataLOI\$As[which(totaldataLOI\$Devitrification == "Glassy")])

mean(totaldata2\$As[which (totaldata2\$Devitrification == "Glassy")])

median(totaldataLOI\$As[which(totaldataLOI\$Devitrification == "Glassy")])

median(totaldata2\$As[which(totaldata2\$Devitrification == "Glassy")])

sd(totaldataLOI\$As[which(totaldataLOI\$Devitrification == "Glassy")])

$\operatorname{sd}($ totaldata2 $\$ A s[$ which $($ totaldata2\$Devitrification $==$ "Glassy")])

mean(totaldataLOI\$As[which(totaldataLOI\$Devitrification == "Sediment")])

mean(totaldata2\$As[which(totaldata2\$Devitrification == "Sediment")])

median(totaldataLOI\$As[which(totaldataLOI\$Devitrification == "Sediment")])

median(totaldata2 $\$$ As[which(totaldata2 $\$$ Devitrification $==$ "Sediment")])

$\operatorname{sd}($ totaldataLOI\$As[which(totaldataLOI\$Devitrification == "Sediment")])

$\operatorname{sd}($ totaldata2\$As[which $($ totaldata2\$Devitrification $=="$ Sediment")] $)$

\# Test for normality

shapiro.test(tuffs\$As)

shapiro.test(sed\$As)

shapiro.test(weathered\$As)

shapiro.test(unweathered $\$ A s)$

shapiro.test(glassy\$As)

shapiro.test(devit\$As)

\# Compare tuffs and sediments

t.test(tuffs $\$ A s$, sed $\$ A s)$

wilcox.test(tuffs $\$ A s$, sed\$As)

var.test(tuffs $\$ A s$, sed $\$ A s)$

levene.test(testtuff $\$ A s$, testtuff\$Weathering, bootstrap = FALSE)

boxplot(tuffs $\$ A s$, sed $\$ A s)$

\# Compare weathered and unweathered samples

t.test(As $\sim$ Weathering, tuffs)

var.test(As $\sim$ Weathering, tuffs)

wilcox.test(As $\sim$ Weathering, tuffs)

levene.test(tuffs\$As, tuffs\$Weathering) 
boxplot(As $\sim$ Weathering, tuffs, ylab = "As (mg/kg)", main = "Total As")

\# Compare glassy and devitrified samples

t.test(As $\sim$ Devitrification, unweathered)

wilcox.test(As $\sim$ Devitrification, unweathered)

var.test(As $\sim$ Devitrification, unweathered)

kruskal.test(As $\sim$ Devitrification, unweathered)

levene.test (unweathered $\$ A s$, unweathered\$Devitrification)

boxplot(As $\sim$ Devitrification, unweathered, ylab = "As (mg/kg)", main = "Total As")

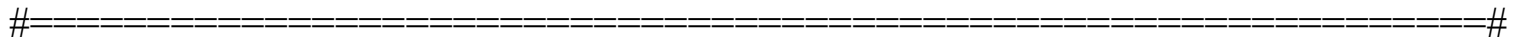

\# Log tranform and remove outliers from Env. Available Fraction

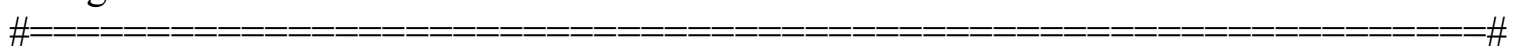

\# Remove outliers

test $<$ - grubb(partialdata)

test $<-$ grubb(test)

partialdata $2<$ - test

\# Log transform the data

logpartialdata $<-\log ($ partialdata2[,4:30])

logpartialdata $<-$ cbind(partialdata2[,1:3], logpartialdata)

logpartialdataO $<-\log ($ partialdata[,4:30])

logpartialdataO $<-$ cbind(partialdata[,1:3], logpartialdataO)

\# Create data frame excluding sediment samples

tuffspartial <- subset(logpartialdata, logpartialdata\$Devitrification != "Sediment")

tuffspartial\$Devitrification $<$ - factor(tuffspartial\$Devitrification)

tuffspartial\$Weathering <- factor(tuffspartial\$Weathering)

tuffspartialO <- subset(logpartialdataO, logpartialdataO\$Devitrification != "Sediment")

tuffspartialO\$Devitrification $<$ - factor(tuffspartialO\$Devitrification)

tuffspartialO\$Weathering <- factor(tuffspartialO\$Weathering)

\# Create data frame of only sediment samples

sedpartial <- subset(logpartialdata, logpartialdata\$Devitrification == "Sediment")

sedpartialO $<$ - subset(logpartialdataO, logpartialdataO\$Devitrification == "Sediment")

\# Create data frame where tuff $\mathrm{v}$ sed is a factor 


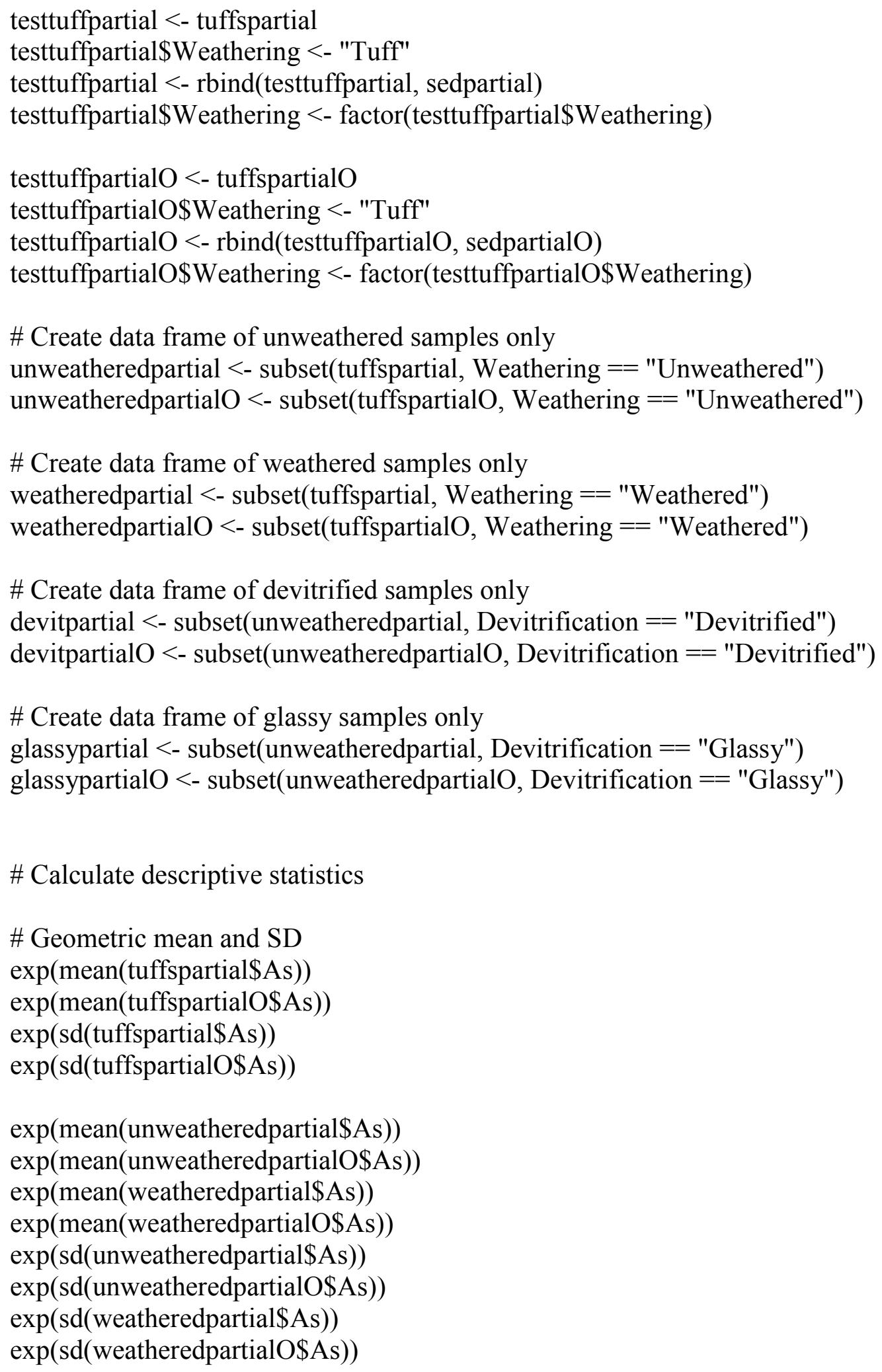




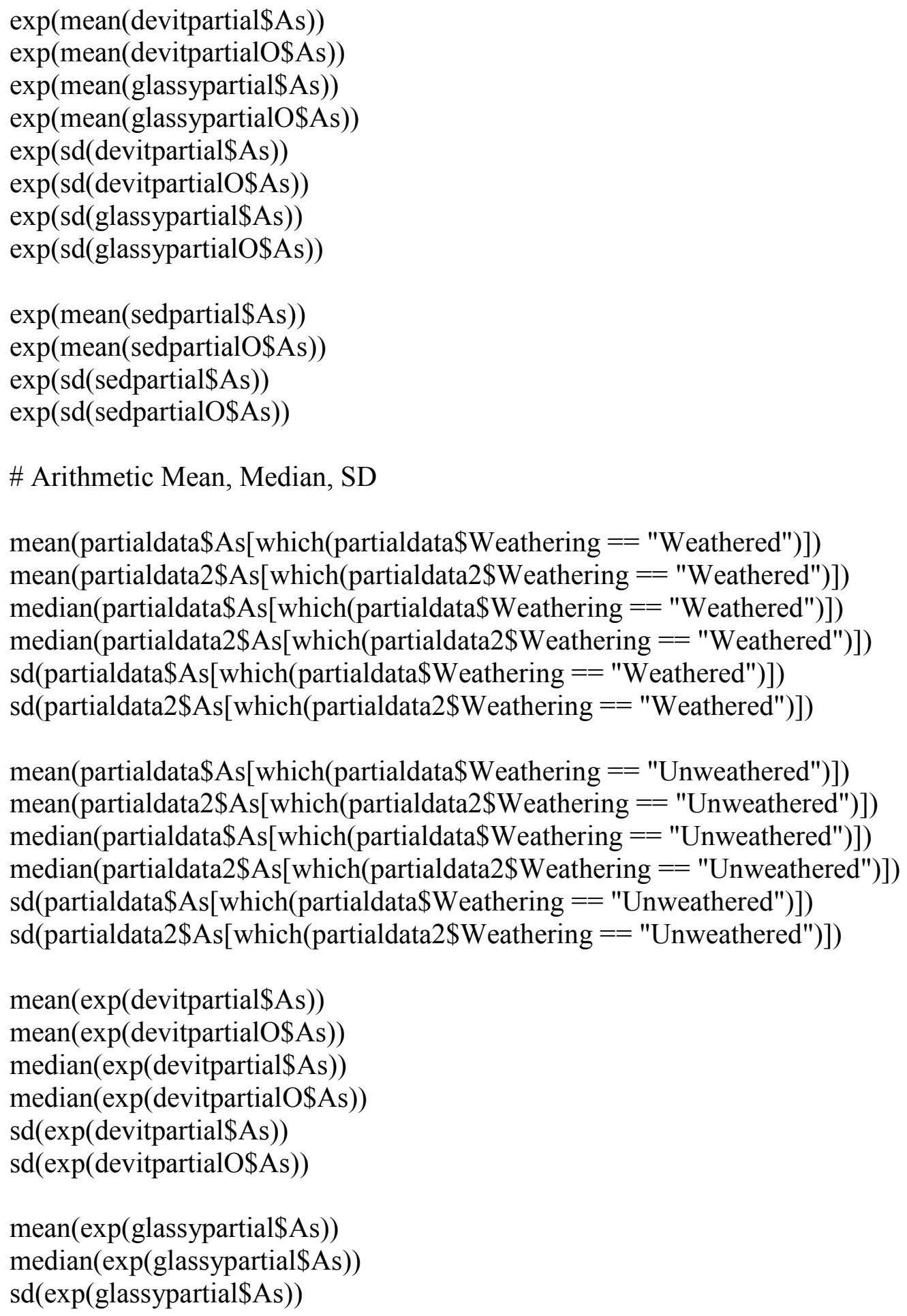


mean(partialdata2\$As[which(partialdata2\$Devitrification $==$ "Sediment")]) median(partialdata\$As[which(partialdata\$Devitrification $==$ "Sediment")]) median(partialdata2\$As[which(partialdata2\$Devitrification == "Sediment")]) $\operatorname{sd}($ partialdata $\$ A s[$ which $($ partialdata\$Devitrification $==$ "Sediment")]) $\operatorname{sd}($ partialdata2\$As[which(partialdata2\$Devitrification $==$ "Sediment")])

mean(partialdata\$As[which(partialdata\$Devitrification != "Sediment")]) mean(partialdata2\$As[which(partialdata2\$Devitrification != "Sediment")]) median(partialdata\$As[which(partialdata\$Devitrification != "Sediment")]) median(partialdata2\$As[which(partialdata2\$Devitrification != "Sediment")]) sd(partialdata\$As[which(partialdata\$Devitrification != "Sediment")]) sd(partialdata2\$As[which(partialdata2\$Devitrification != "Sediment")])

\# Test for normality shapiro.test(tuffspartial\$As) shapiro.test(sedpartial\$As) shapiro.test(weatheredpartial\$As) shapiro.test(unweatheredpartial\$As) shapiro.test(devitpartial\$As) shapiro.test(glassypartial\$As)

\# Compare groups

\# Compare variability

levene.test(testtuffpartial\$As, testtuffpartial\$Weathering) levene.test(tuffspartial\$As, tuffspartial\$Weathering) levene.test(unweatheredpartial\$As, unweatheredpartial\$Devitrification)

\# Compare medians kinda..

wilcox.test(As $\sim$ Weathering, testtuffpartial)

wilcox.test (As $\sim$ Weathering, tuffspartial)

wilcox.test(As $\sim$ Devitrification, unweatheredpartial)

\# Compare weathered and unweathered devitrified and glassy

glassytest $<$ - subset(tuffspartial, Devitrification == "Glassy")

wilcox.test(As $\sim$ Weathering, glassytest)

devittest <- subset(tuffspartial, Devitrification == "Devitrified") wilcox.test(As $\sim$ Weathering, devittest) 
\# Check correlations with total As excluding outliers.

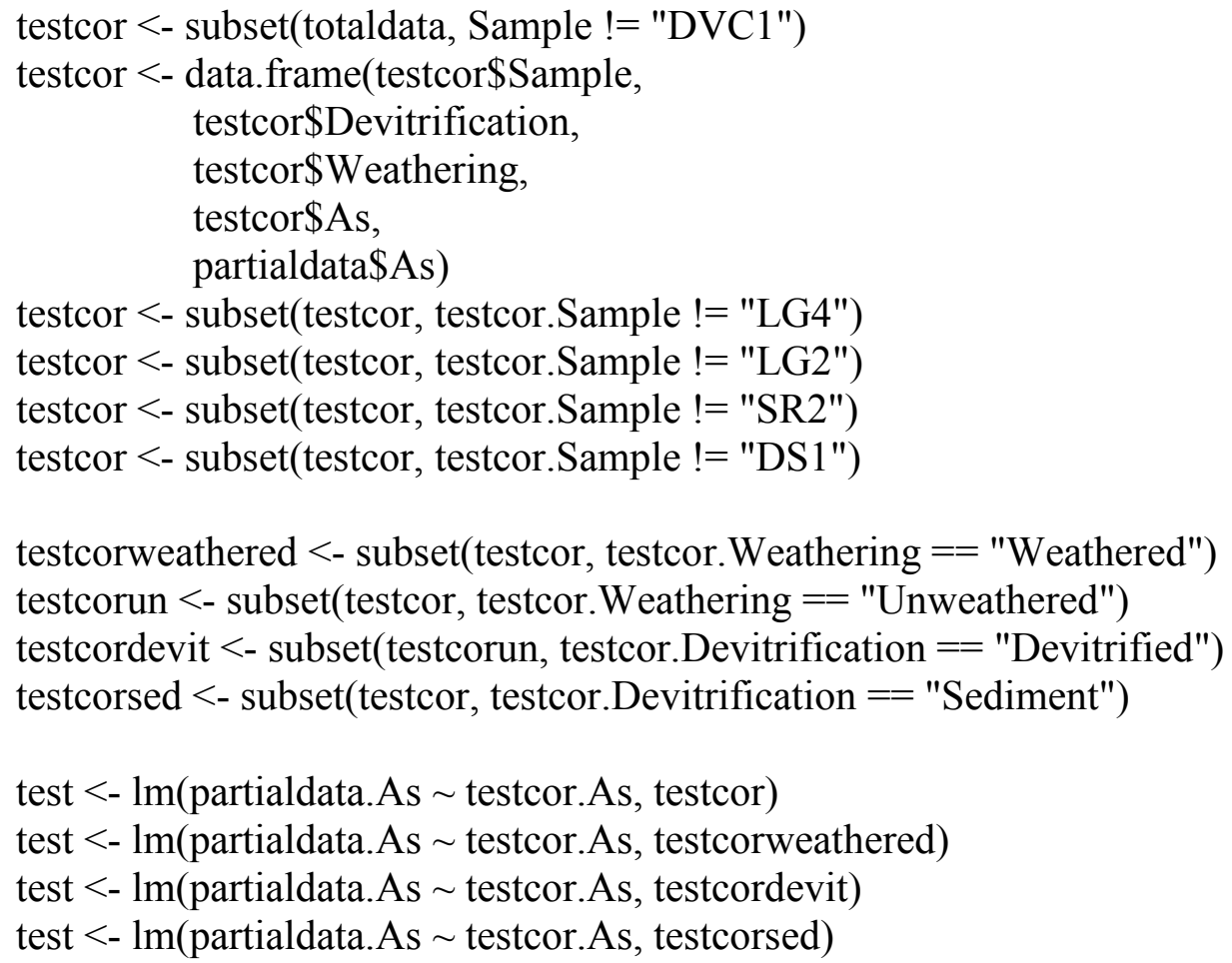

\# Log tranform and remove outliers from Readily Leachable Fraction

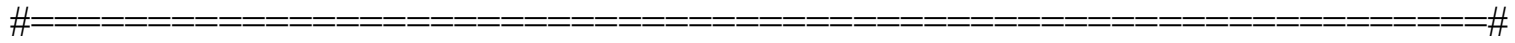

\# Create subset of data frame that only includes As $>$ MDL

leachdata2 <- subset(leachdata, As $>51.05875$ )

\# Log transform the data

logleachdata $<-\log ($ leachdata2[,4:20])

logleachdata $<$ - cbind(leachdata2[,1:3], logleachdata)

logleachdataO $<-\log ($ leachdata[,4:20] $)$

logleachdataO $<$ - cbind(leachdata[,1:3], logleachdataO)

\# Create data frame excluding sediment samples

tuffsleach $<-$ subset(logleachdata, logleachdata\$Devitrification != "Sediment")

tuffsleach\$Devitrification $<$ - factor(tuffsleach\$Devitrification)

tuffsleach\$Weathering $<-$ factor(tuffsleach\$Weathering) 
tuffsleachO <- subset(logleachdataO, logleachdataO\$Devitrification != "Sediment") tuffsleachO\$Devitrification <- factor(tuffsleachO\$Devitrification)

tuffsleachO\$Weathering <- factor(tuffsleachO\$Weathering)

\# Create data frame of only sediment samples

sedleach $<$ - subset(logleachdata, logleachdata\$Devitrification == "Sediment")

sedleachO $<$ - subset $(\operatorname{logleachdataO}$, logleachdataO $\$$ Devitrification $==$ "Sediment")

\# Create data frame where tuff $\mathrm{v}$ sed is a factor

testtuffleach $<-$ tuffsleach

testtuffleach\$Weathering <- "Tuff"

testtuffleach $<$ - rbind(testtuffleach, sedleach)

testtuffleach\$Weathering $<$ - factor(testtuffleach\$Weathering)

testtuffleachO $<$ - tuffsleachO

testtuffleachO\$Weathering <- "Tuff"

testtuffleachO $<$ - rbind(testtuffleachO, sedleachO)

testtuffleachO\$Weathering $<$ - factor(testtuffleachO\$Weathering)

\# Create data frame of unweathered samples only

unweatheredleach $<$ - subset(tuffsleach, Weathering == "Unweathered")

unweatheredleachO $<$ - subset(tuffsleachO, Weathering == "Unweathered")

\# Create data frame of weathered samples only

weatheredleach $<$ - subset(tuffsleach, Weathering == "Weathered")

weatheredleachO $<$ - subset(tuffsleachO, Weathering == "Weathered")

\# Create data frame of devitrified samples only

devitleach <- subset(unweatheredleach, Devitrification == "Devitrified")

devitleachO $<$ - subset(unweatheredleachO, Devitrification == "Devitrified")

\# Create data frame of glassy samples only

glassyleach $<$ - subset(unweatheredleach, Devitrification == "Glassy")

glassyleachO $<$ - subset(unweatheredleachO, Devitrification == "Glassy")

\# Calculate descriptive statistics

\# Geometric mean and SD

$\exp ($ mean(tuffsleach\$As))

$\exp ($ mean(tuffsleachO\$As))

$\exp (\operatorname{sd}($ tuffsleach $\$ A s))$ 


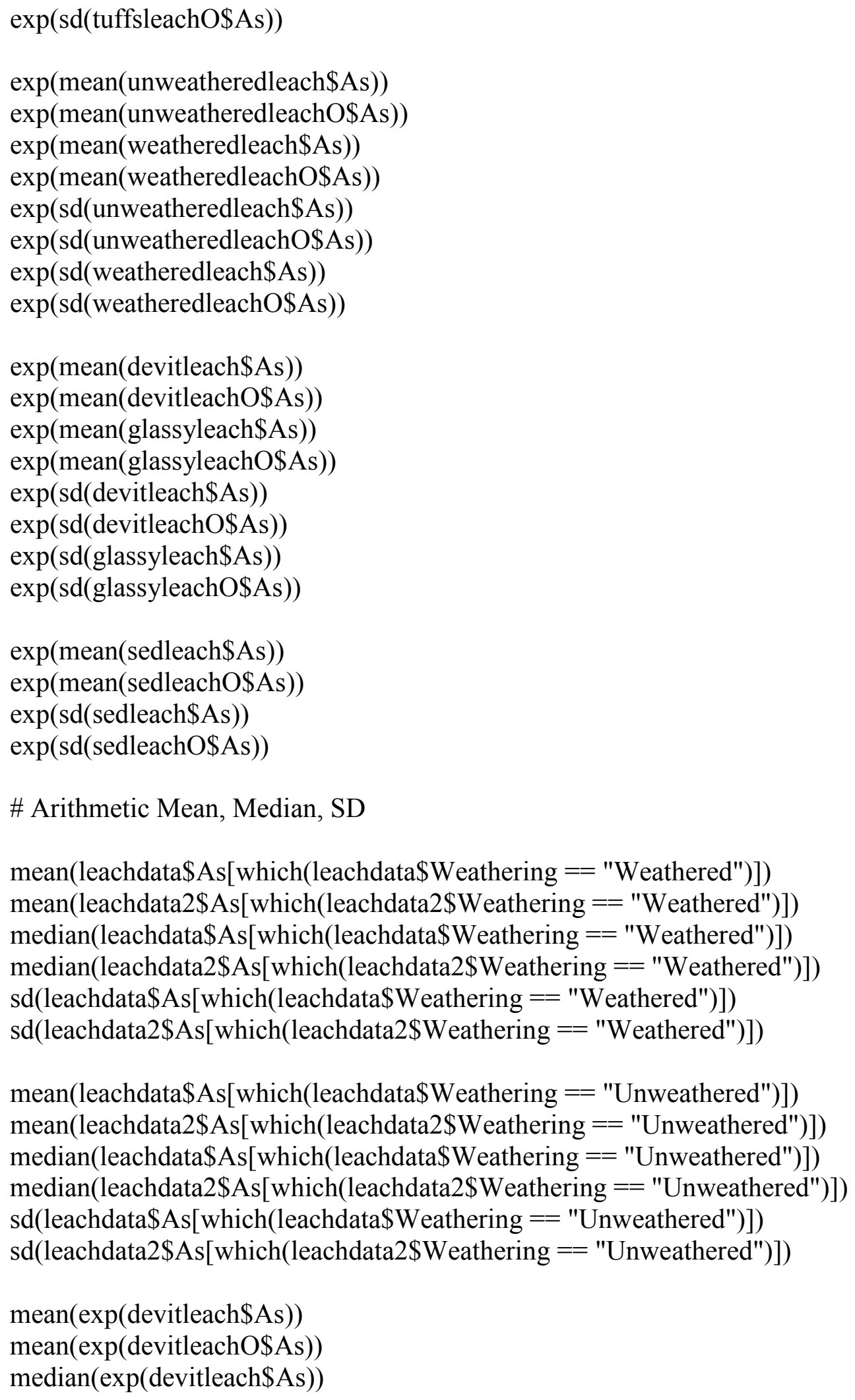


median(exp(devitleachO\$As))

$\operatorname{sd}(\exp (\operatorname{devitleach} \$ A s))$

$\operatorname{sd}(\exp (\operatorname{devitleachO\$ As)})$

mean(leachdata $\$$ As[ which(leachdata $\$$ Devitrification == "Glassy")])

mean(leachdata2\$As[which(leachdata2\$Devitrification == "Glassy")])

median(leachdata $\$ \mathrm{As}[$ which(leachdata\$Devitrification == "Glassy")]

median(leachdata2\$As[which(leachdata2\$Devitrification == "Glassy")])

$\operatorname{sd}($ leachdata $\$ A s[$ which(leachdata $\$$ Devitrification == "Glassy")])

sd(leachdata2\$As[which(leachdata2\$Devitrification == "Glassy")])

mean(leachdata $\$ A s[$ which(leachdata $\$$ Devitrification $==$ "Sediment")]

mean(leachdata2\$As[which(leachdata2\$Devitrification == "Sediment")])

median(leachdata $\$$ As[which(leachdata\$Devitrification == "Sediment")])

median(leachdata2\$As[which(leachdata2\$Devitrification == "Sediment")])

sd(leachdata\$As[which(leachdata \$Devitrification == "Sediment")])

$\operatorname{sd}($ leachdata2\$As[which(leachdata2\$Devitrification == "Sediment")]

mean(leachdata $\$$ As[which(leachdata\$Devitrification != "Sediment")])

mean(leachdata2\$As[which(leachdata2\$Devitrification != "Sediment")])

median(leachdata $\$$ As[which(leachdata $\$$ Devitrification != "Sediment")])

median(leachdata2\$As[which(leachdata2\$Devitrification != "Sediment")])

sd(leachdata\$As[which(leachdata\$Devitrification != "Sediment")])

sd(leachdata2\$As[which(leachdata2\$Devitrification != "Sediment")])

\# Test for normality

shapiro.test(tuffsleachO\$As)

shapiro.test(sedleachO\$As)

shapiro.test(weatheredleachO\$As)

shapiro.test(unweatheredleachO\$As)

shapiro.test(devitleachO\$As)

shapiro.test(glassyleachO\$As)

\# Compare groups

\# Compare variability

levene.test(testtuffleachO\$As, testtuffleachO\$Weathering)

levene.test(tuffsleachO\$As, tuffsleachO\$Weathering)

levene.test(unweatheredleachO\$As, unweatheredleachO\$Devitrification)

var.test(As $\sim$ Weathering, testtuffleachO) 
var.test(As $\sim$ Weathering, tuffsleachO)

var.test(As $\sim$ Devitrification, unweatheredleachO)

\# Compare means

t.test(As $\sim$ Weathering, testtuffleachO, var.equal $=$ FALSE)

t.test(As $\sim$ Weathering, tuffsleachO, var.equal $=$ TRUE)

t.test(As $\sim$ Devitrification, unweatheredleachO, var.equal $=$ FALSE) 


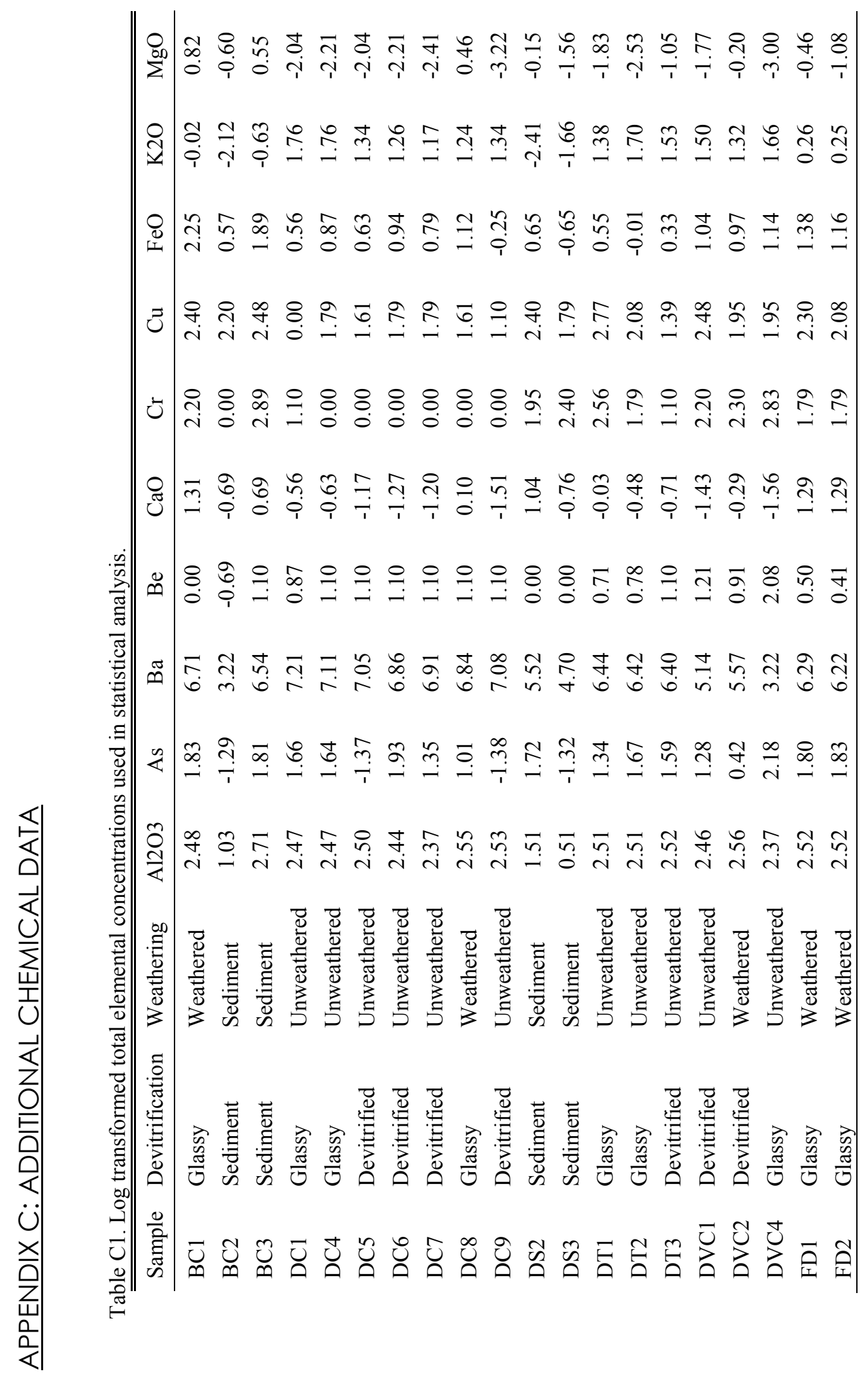




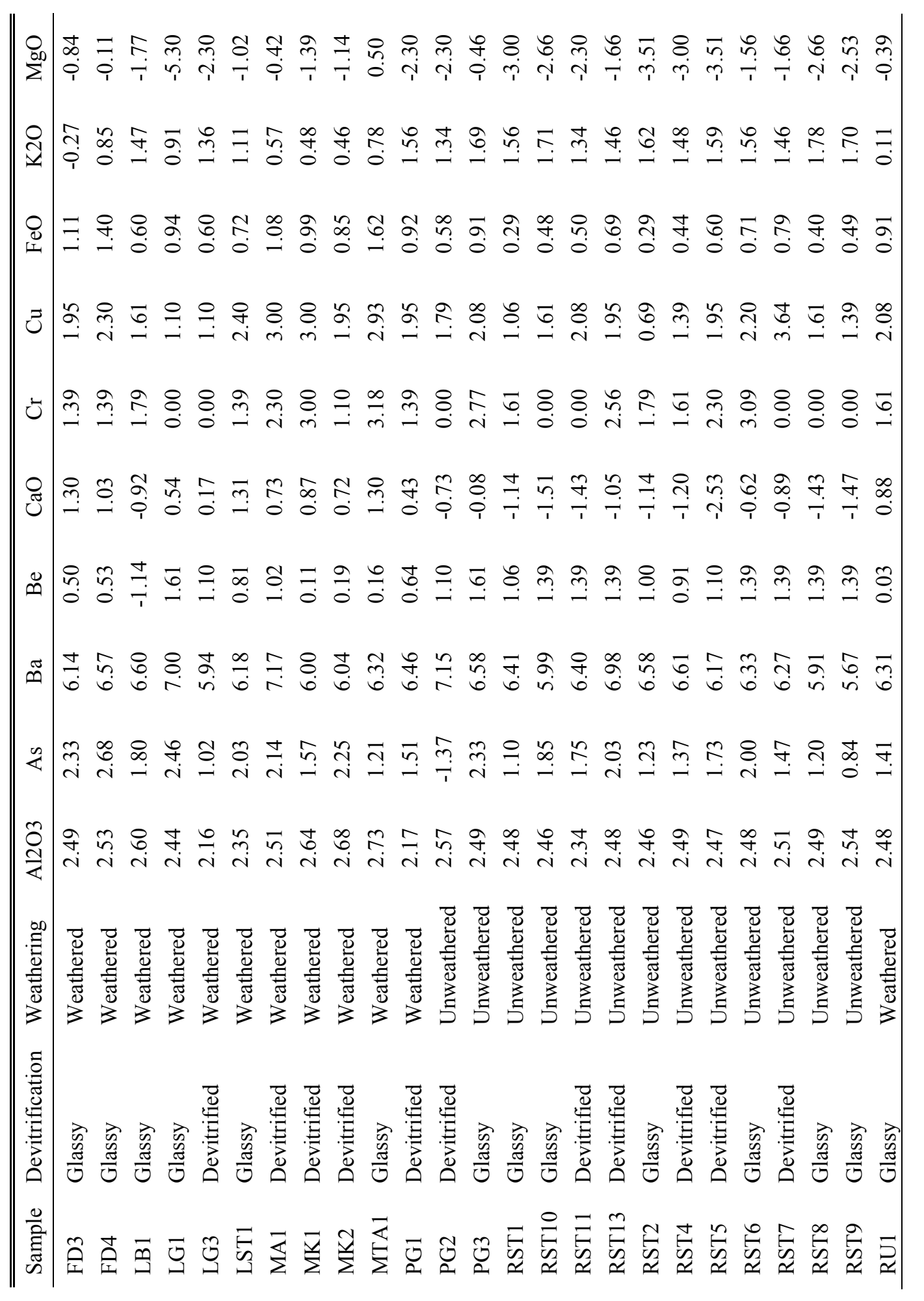




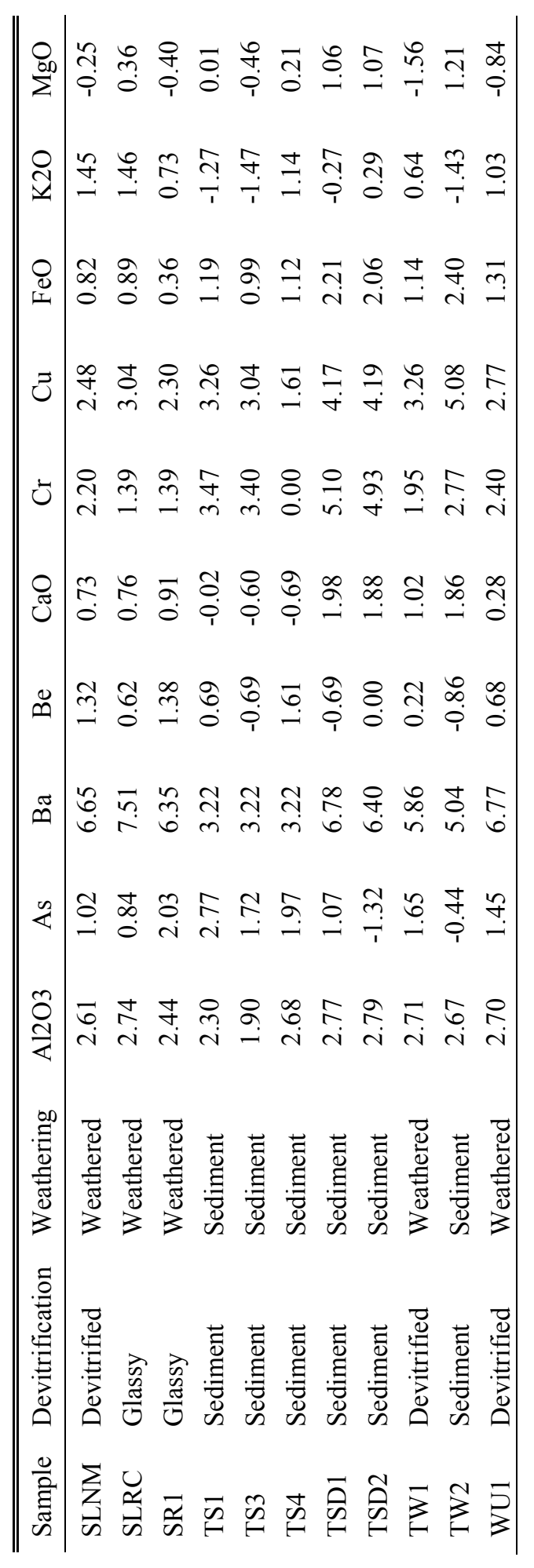




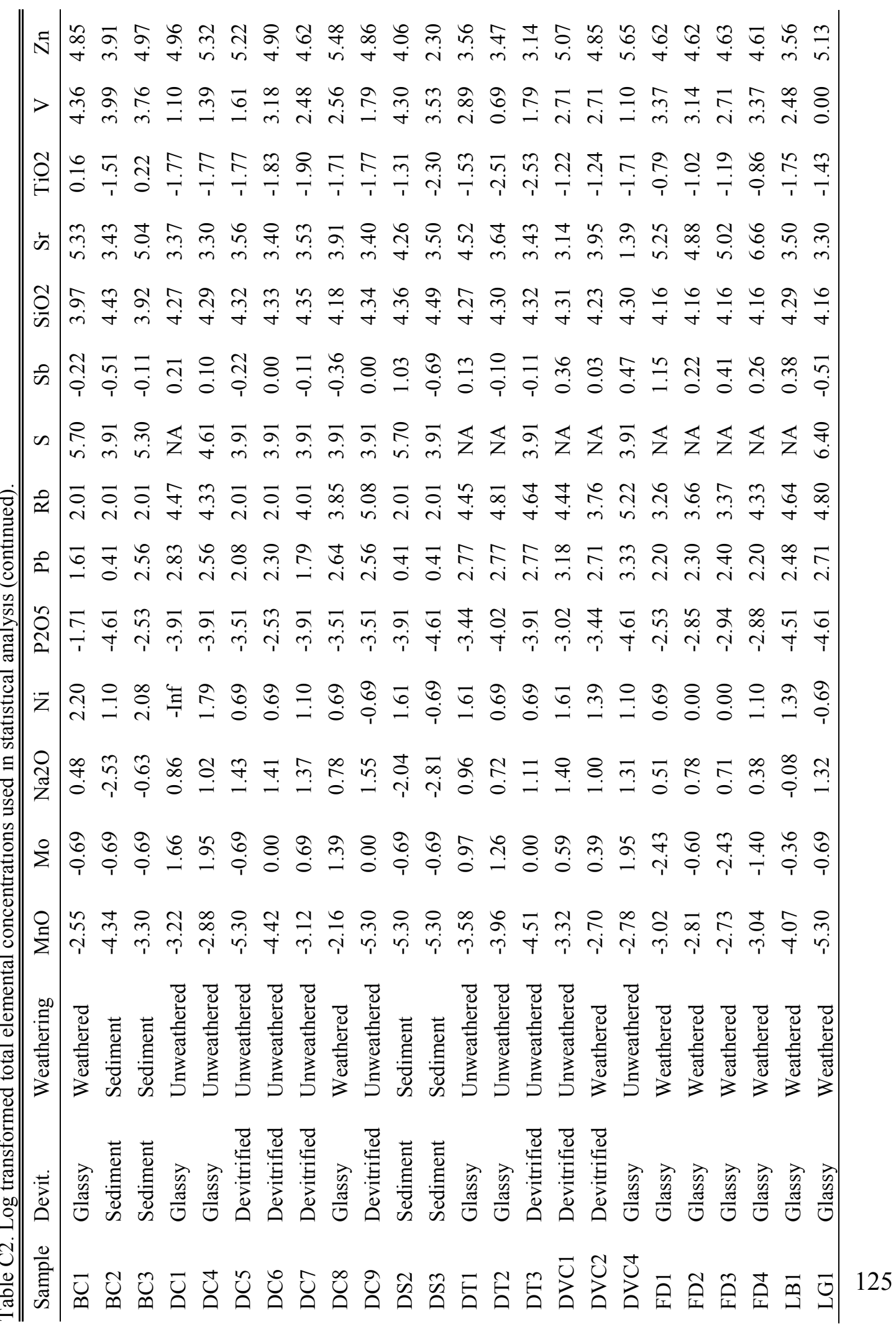




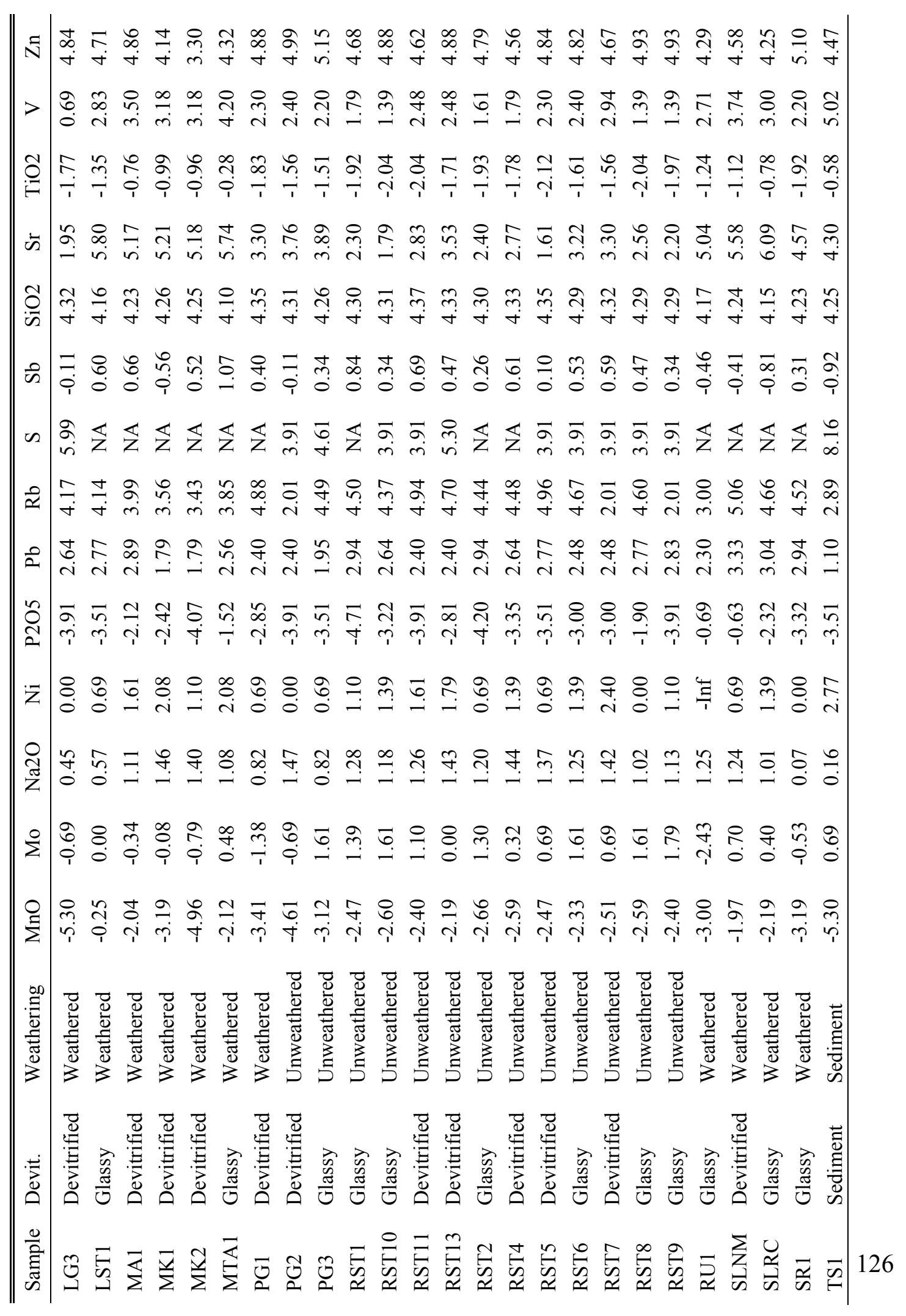




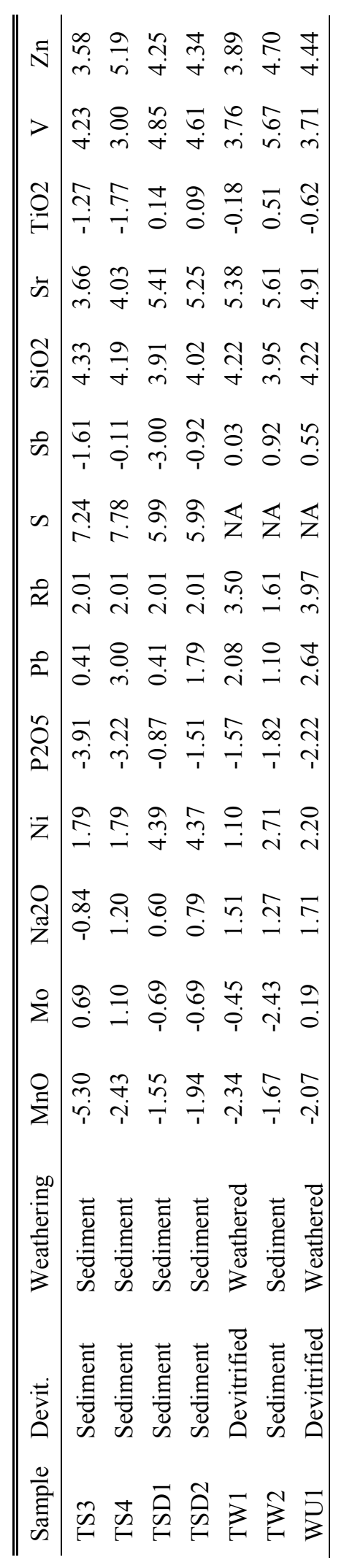




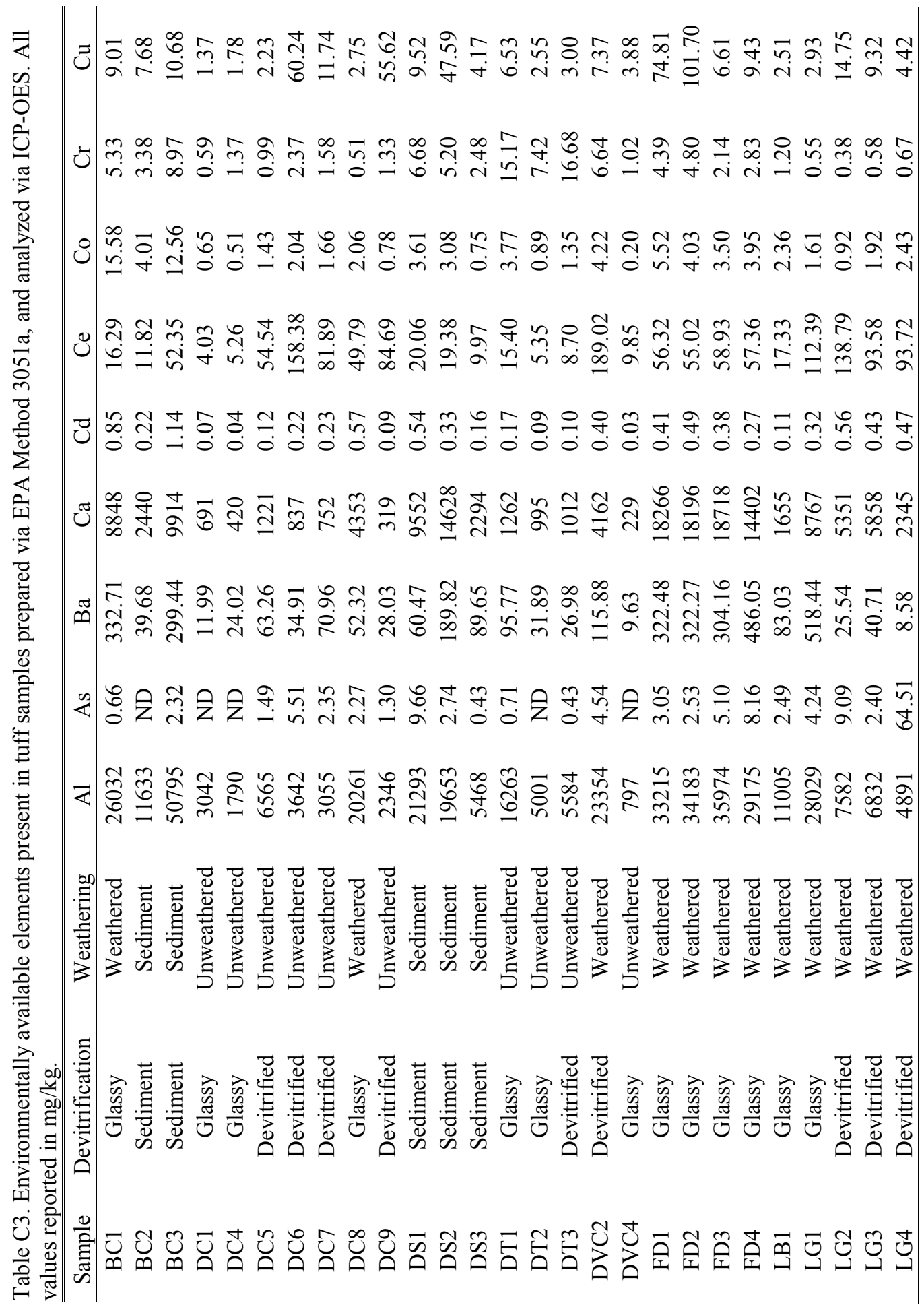




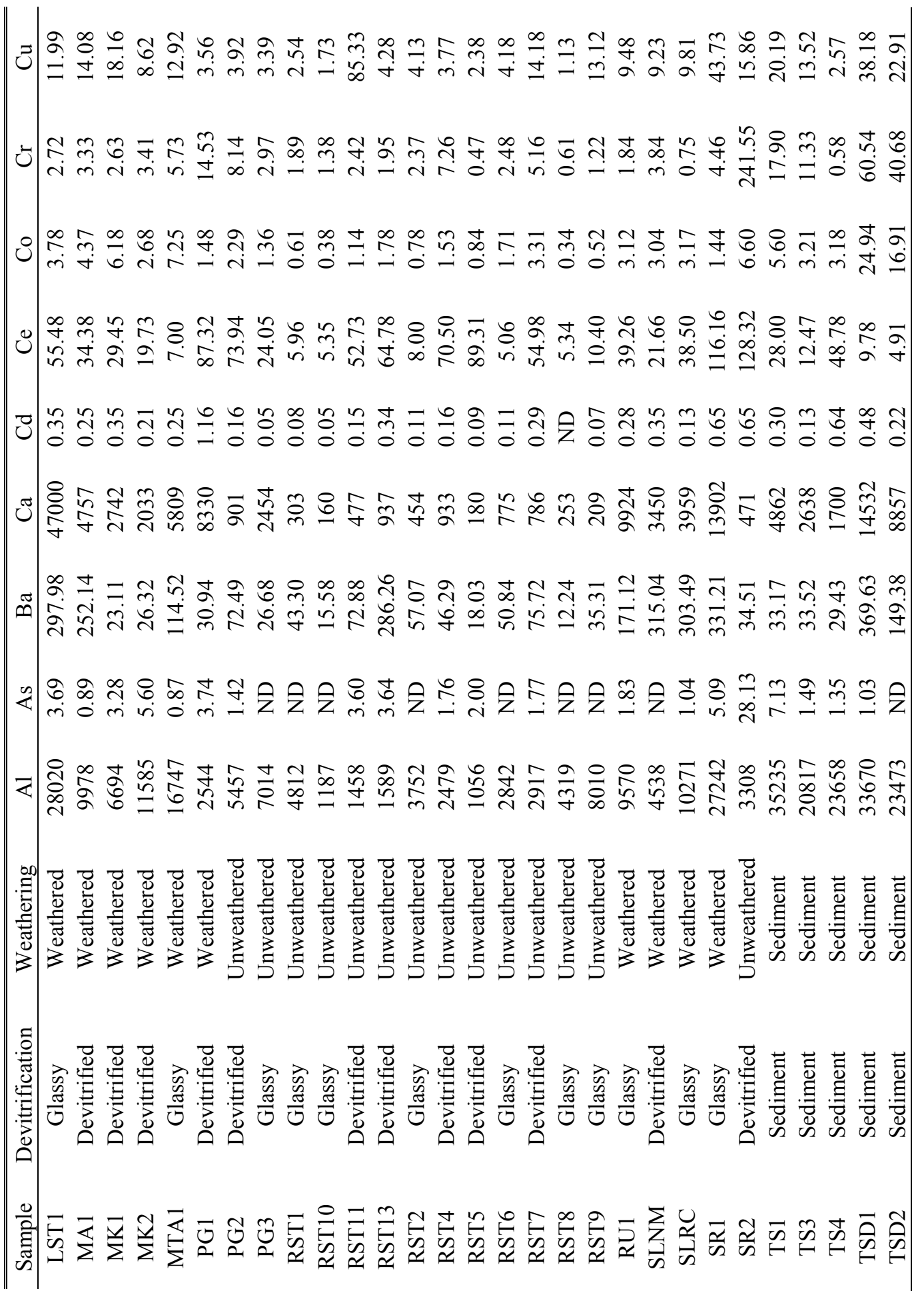




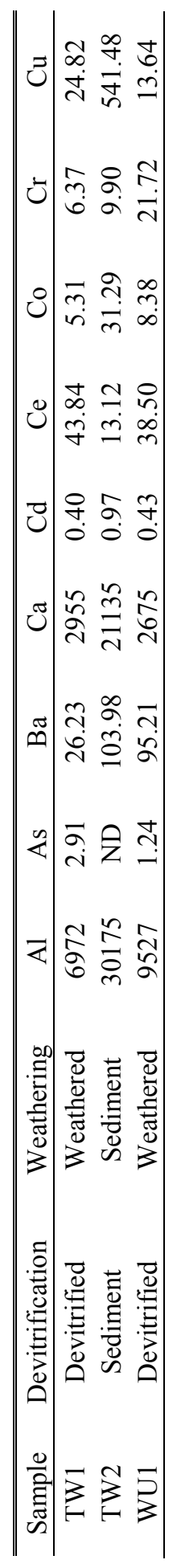




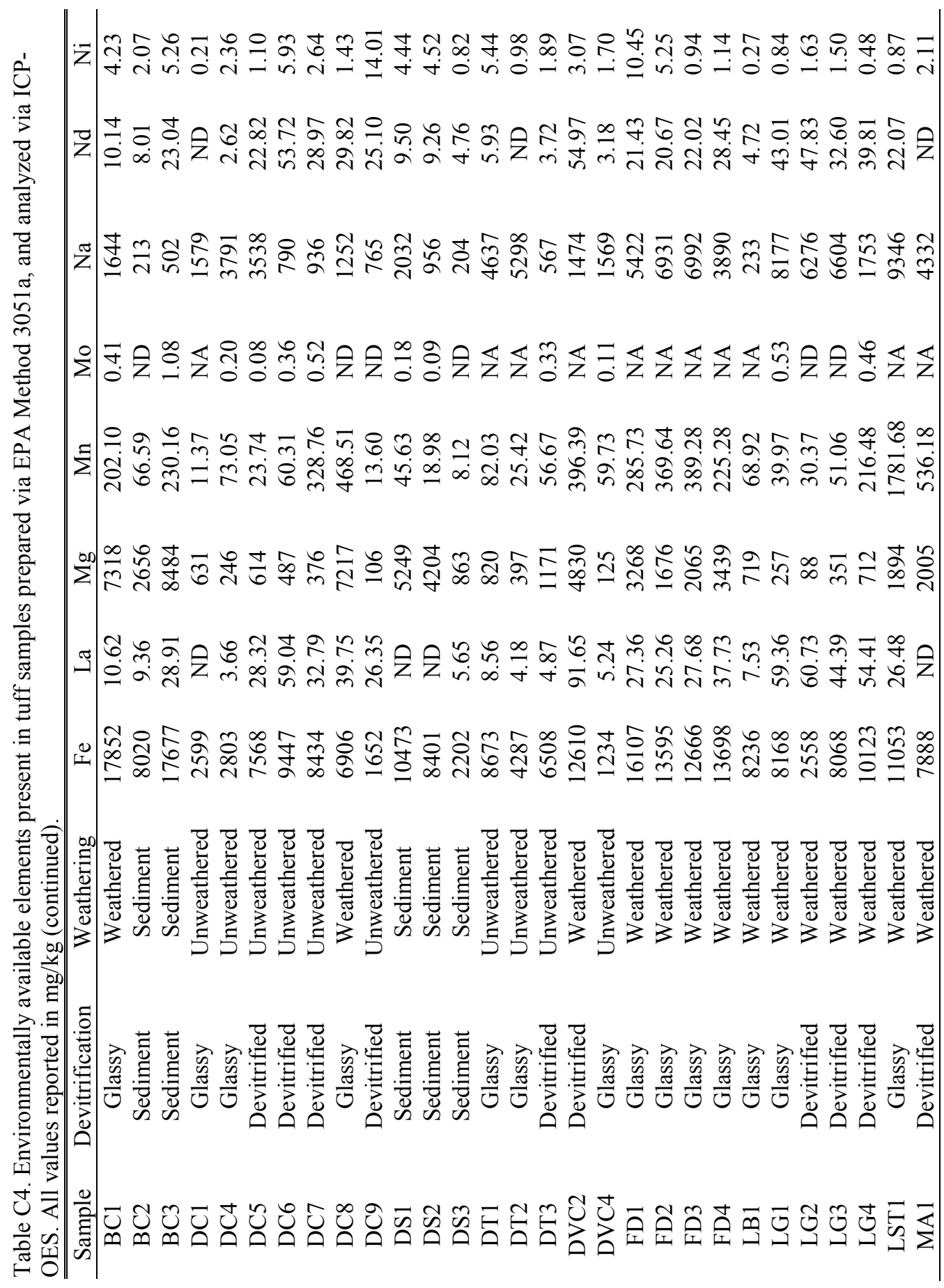

131 


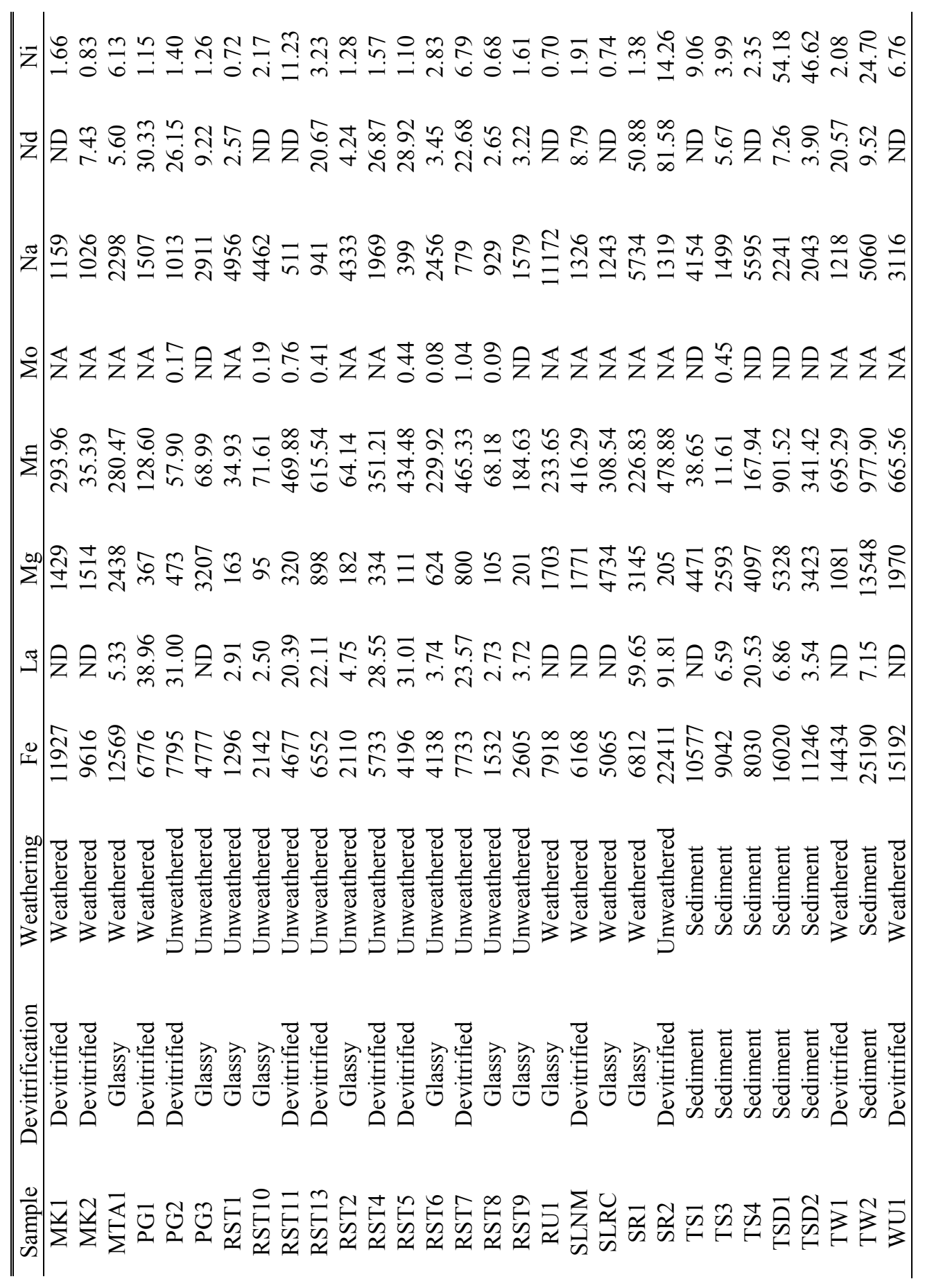

132 


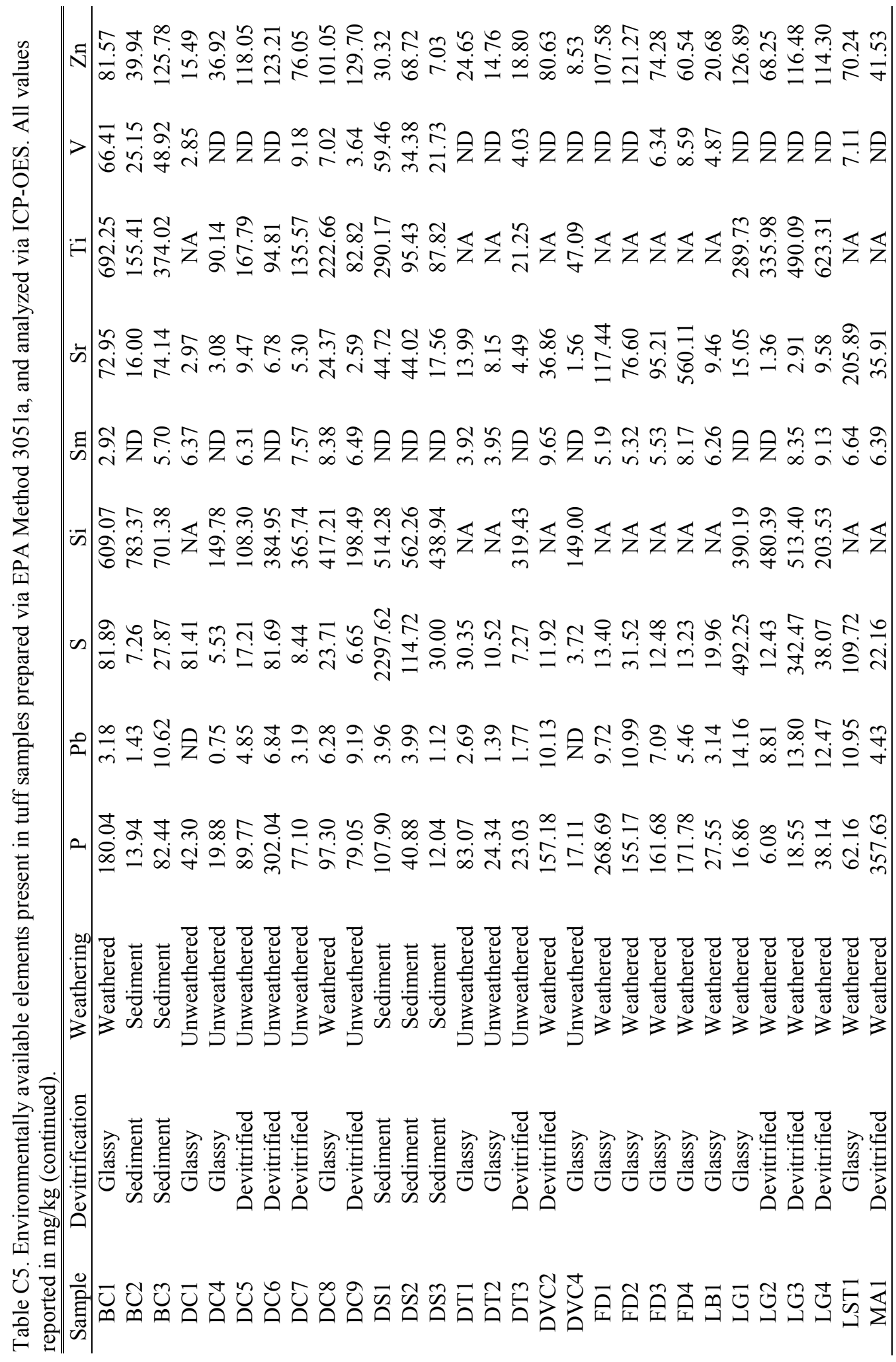

133 


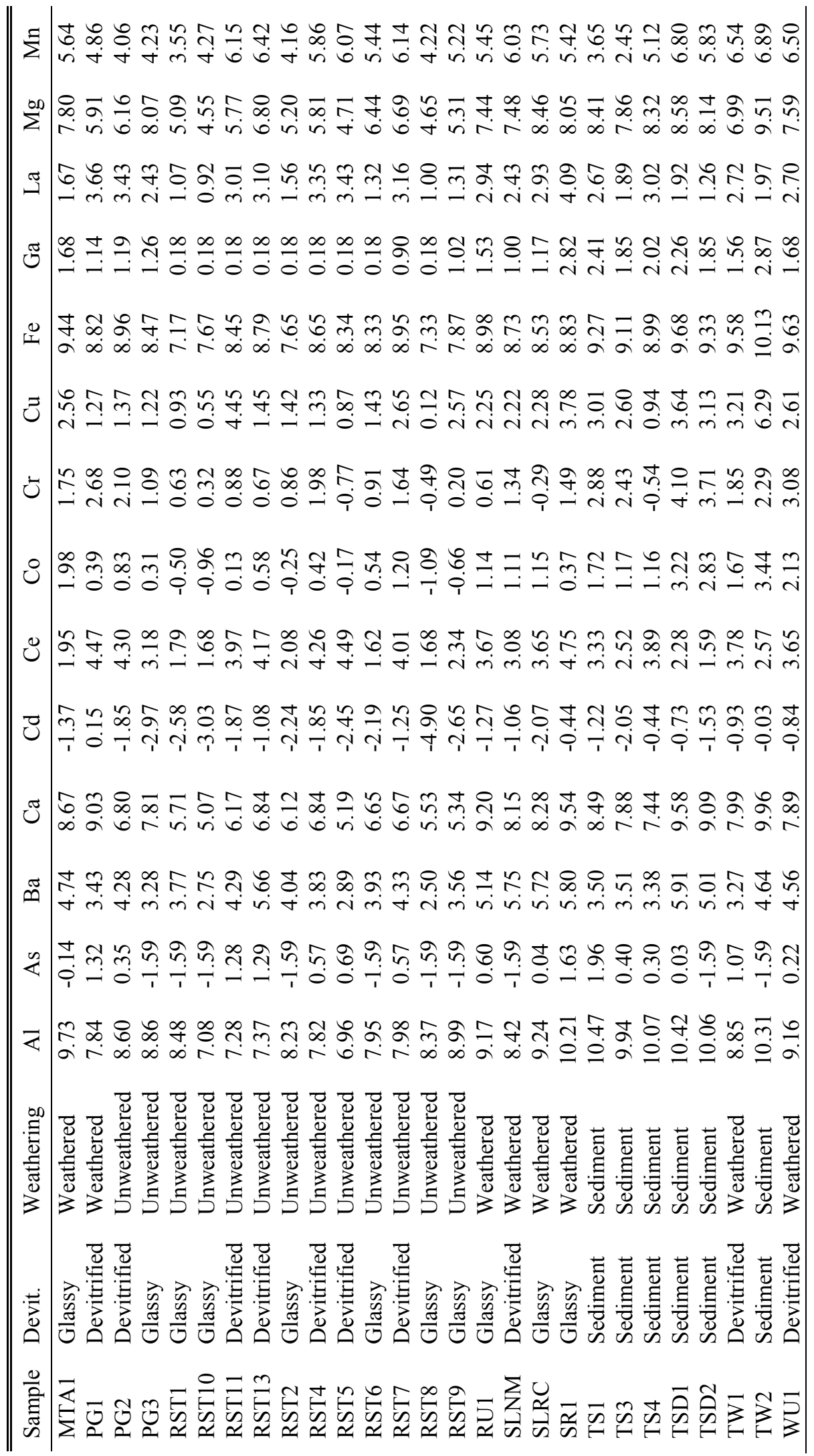




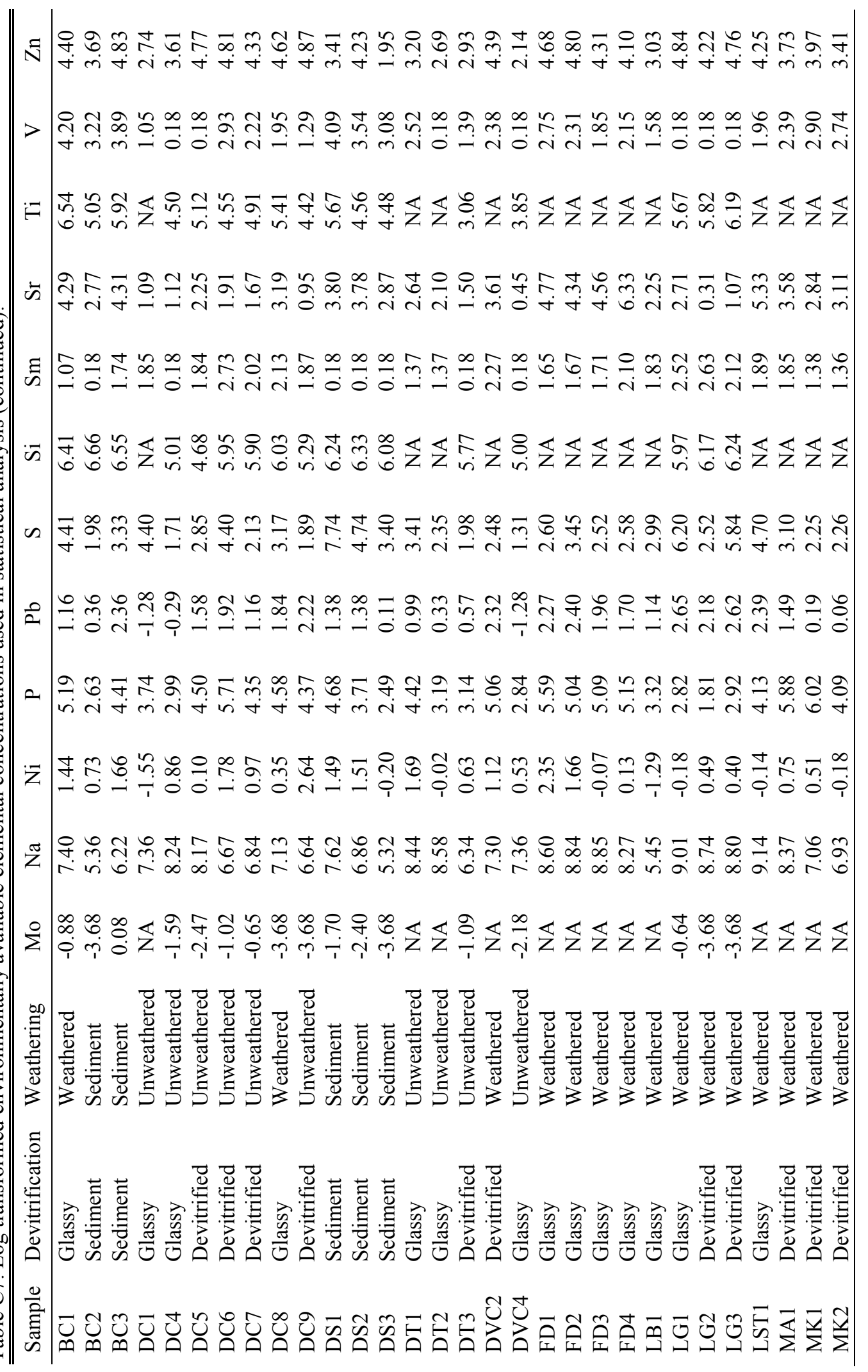




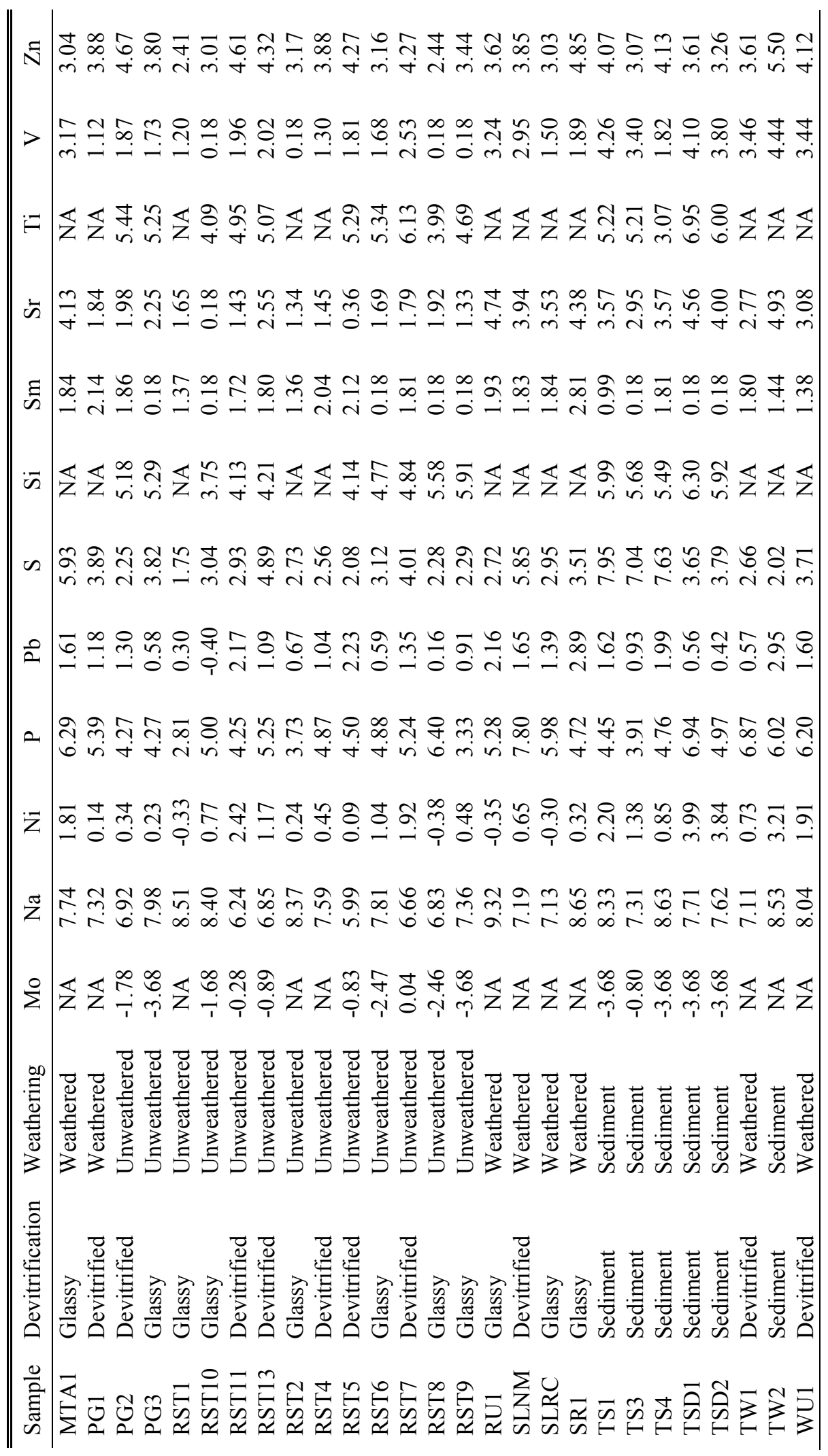




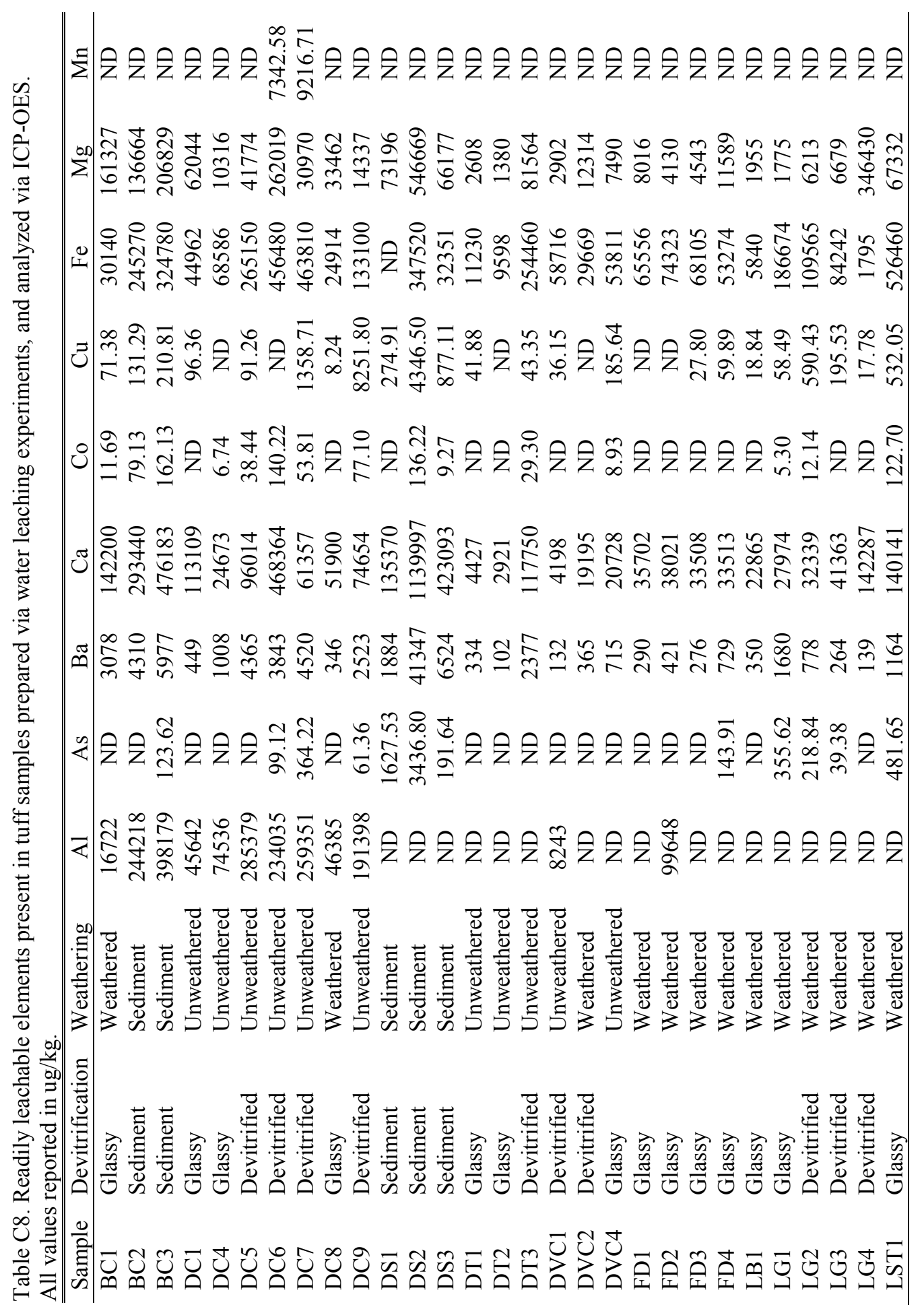




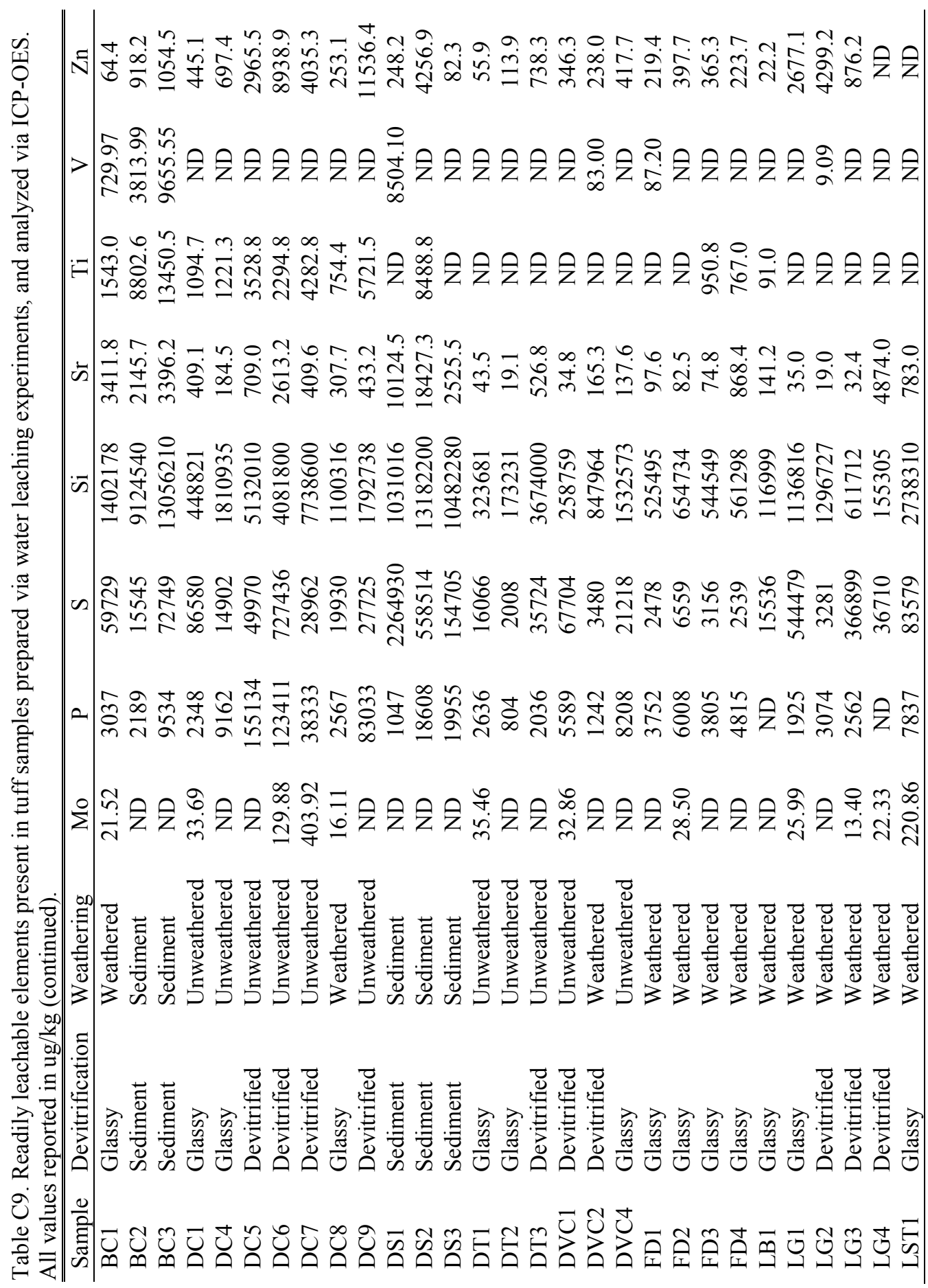


